\title{
Final Report: \\ Investigation and Demonstration of \\ Dry Carbon-Based Sorbent \\ Injection for Mercury Control
}

\author{
Prepared by
}

Jim Butz

ADA Technologies, Inc.

8100 Shaffer Parkway, Suite 130

Littleton, CO 80127

and

Terry Hunt

Public Service Company of Colorado $55015^{\text {th }}$ Street, Suite 800

Denver, Colorado 80202

\section{Contract DE-AC22-95PC95256}

$10 / 1 / 1995$ to $9 / 30 / 2000$

Draft Final: November 1, 2000

Approved Final: November 1, 2005 


\section{Disclaimer}

This report was prepared as an account of work sponsored by an agency of the United States Government. Neither the United States Government nor any agency thereof, nor any of their employees, makes any warranty, express or implied, or assumes any legal liability or responsibility for the accuracy, completeness, or usefulness of any information, apparatus, product, or process disclosed, or represents that its use would not infringe privately owned rights. Reference herein to any specific commercial product, process, or service by trade name, trademark, manufacturer, or otherwise does not necessarily constitute or imply its endorsement, recommendation, or favoring by the United States Government or any agency thereof. The views and opinions of authors expressed herein do not necessarily state or reflect those of the United States Government or any agency thereof. 


\begin{abstract}
Public Service Company of Colorado and ADA Technologies, Inc. have performed a study of the injection of activated carbon for the removal of vapor-phase mercury from coal-fired flue gas streams. The project was completed under contract to the US Department of Energy's National Energy Technology Laboratory, with contributions from EPRI and Public Service Company. The prime contractor for the project was Public Service Company, with ADA Technologies as the major subcontractor providing technical support to all aspects of the project.
\end{abstract}

The research and development effort was conducted in two phases. In Phase I a pilot facility was fabricated and tests were performed using dry carbon-based sorbent injection for mercury control on a coal-fired flue gas slipstream extracted from an operating power plant. Phase II was designed to move carbon injection technology towards commercial application on coal-fired power plants by addressing key reliability and operability concerns. Phase II field work included further development work with the Phase I pilot and mercury measurements on several of PSCo's coal-fired generating units. In addition, tests were run on collected sorbent plus fly ash to evaluate the impact of the activated carbon sorbent on the disposal of fly ash. An economic analysis was performed where pilot plant test data was used to develop a model to predict estimated costs of mercury removal from plants burning western coals.

Testing in the pilot plant was undertaken to quantify the effects of plant configuration, flue gas temperature, and activated carbon injection rate on mercury removal. All three variables were found to significantly impact the mercury removal efficiency in the pilot. The trends were clear: mercury removal rates increased with decreasing flue gas temperature and with increasing carbon injection rates. Mercury removal was much more efficient with reverse-gas and pulse-jet baghouse configurations than with an ESP as the particulate control device. The native fly ash of the host unit provided significant mercury removal capacity, so that the activated carbon sorbent served as an incremental mercury removal mechanism.

Tests run to characterize the waste product, a combination of fly ash and activated carbon on which mercury was present, showed that mercury and other RCRA metals of interest were all below Toxic Characteristic Leaching Procedure (TCLP) regulatory limits in the leachate. The presence of activated carbon in the fly ash was shown to have an effect on the use of fly ash as an additive in the manufacture of concrete, which could limit the salability of fly ash from a plant where activated carbon was used for mercury control. 


\section{Table of Contents}

1.Introduction.............................................................................................................................................

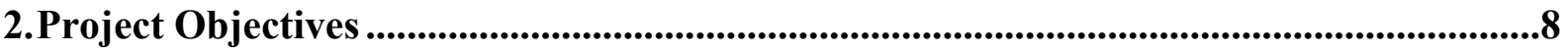

3.Facility Description ..............................................................................................................................11

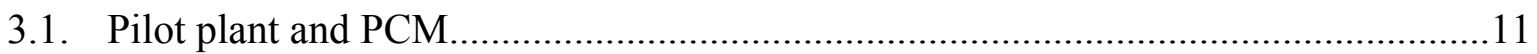

3.2. Mercury measurement techniques ............................................................19

4. Results and Discussion....................................................................................................................23

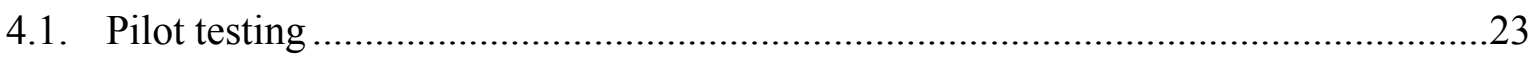

4.2. Full-scale m mercury removal al PSCo generating plants............................................

4.3. Waste dharacterization .........................................................................................62

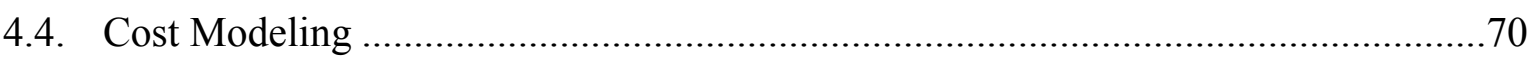

5.Conclusions..............................................................................................................................84

6.References...............................................................................................................................91

6.1. $\quad$ Report Ifferences ...............................................................................................91

6.2. List of Project Publications.................................................................................92

7.Acknowledgments ............................................................................................................................93

8.|Appendix: Results Database ......................................................................................................94 


\section{Table of Figures}

Figure 3-1. Schematic of laboratory-scale test fixture......................................................... 12

Figure 3-2. Photo of Mercury Removal Pilot Plant Installed at Comanche Station .................... 13

Figure 3-3. Layout for the ESP Module of the Pilot PCM ................................................... 15

Figure 3-4. Pulse-Jet Baghouse Module for the Pilot PCM..................................................... 16

Figure 3-5. Reverse-gas Baghouse Configuration for the Pilot PCM ..................................... 17

Figure 4-1. Baseline Mercury Removal for Pilot in Reverse-Gas Baghouse Configuration........ 24

Figure 4-2. Effect of Carbon Injection Rate on Mercury Removal in Pilot with ESP ................. 26

Figure 4-3. Effect of Carbon Injection Rate on Mercury Removal in Pilot with Pulse-Jet Baghouse ................................................................................................. 27

Figure 4-4 Effect of Carbon Injection Rate on Mercury Removal in Pilot with Reverse-Gas Baghouse ........................................................................................... 29

Figure 4-5. Mercury removal in the TOXECON mode........................................................ 31

Figure 4-6. Long Term Carbon Injection Test Results ........................................................... 32

Figure 4-7. Long Term Carbon Injection, Repeated Test..................................................... 33

Figure 4-8. Mercury Removal during Long Term Carbon Injection...................................... 33

Figure 4-9. Baseline Operation, TOXECON Configuration. ............................................... 35

Figure 4-10. Injection of Recycled Norit .......................................................................... 36

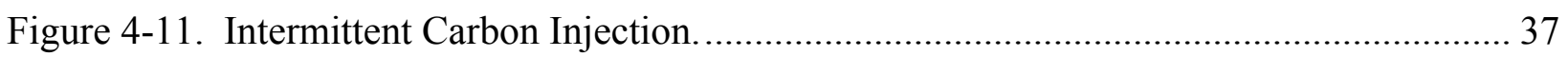

Figure 4-12. Mercury Removal Results from TOXECON with Spray Cooling............................ 38

Figure 4-13: Long-term Carbon Injection MERCEM Results,

Comanche Pilot - RG Configuration...

Figure 4-14. Long-term Carbon Injection IC Results, Comanche Pilot - RG Configuration....... 41

Figure 4-15. Mercury Concentration Data for Reinjection of Cherokee 3 Ash

in Comanche Pilot .................................................................................................. 42 
Figure 4-16. Comparison of MERCEM and IC Trap Mercury Measurements

for Cherokee 3 Ash ……............................................................................................ 43

Figure 4-17. Inlet and Outlet Hg Concentrations, Arapahoe Unit 1.................................... 49

Figure 4-18. Inlet and Outlet Mercury Concentrations, Arapahoe Unit 4 ............................. 51

Figure 4-19. Mercury Mass Balance Comparison, Arapahoe Unit 1 and Unit 4........................ 55

Figure 4-20. Inlet and Outlet Mercury Concentrations, Cherokee Unit 3..................................56

Figure 4-21. Mercury Mass Balance, Cherokee Unit 3....................................................... 57

Figure 4-22. Inlet and Outlet Mercury Concentrations, Comanche Unit 2. ............................. 59

Figure 4-23. Mercury Mass Balance, Comanche Unit 2................................................... 60

Figure 4-24. Particle Size Distribution of Cherokee 3 Ash................................................. 66 


\section{List of Tables}

Table 4-1. Summary of Mercury Removal Results for Reinjected Fly Ash

in the Comanche Pilot.

Table 4-2. Comparison of Measured Mercury Removal Rates for MERCEM and IC Traps..45

Table 4-3. Full-Scale Generating Unit Configurations .......................................................46

Table 4-4. Measurement Techniques for Full-Scale Survey..............................................4

Table 4-5. Mercury Removal Efficiencies, Percent............................................................ 51

Table 4-6. Mass Balances. ..............................................................................................

Table 4-7. Results of Hayden Full Scale Testing.............................................................62

Table 4-8. TCLP Results from Selected Fly Ash Samples...............................................66

Table 4-9. Carbon Mass Fractions for Separated Size Cuts................................................67

Table 4-10 Mercury and Carbon Distribution by Particle Size Fraction

(Sizes mixed from Bahco separation fractions).........................................................68

Table 4-11. Fractions from PMET Separations. ...................................................................69

Table 4-12. Stability of Mercury on Fly Ash ................................................................

Table 4-13. Multiple Linear Regression Analyses for Mercury Removal Tests ......................71

Table 4-14. Summary of Predicted Carbon Injection Rates for a PRB-fired Plant ..................73

Table 4-15. Factors Considered in the Cost Model and Their Basis ..................................... 75

Table 4-16. Comparative Specific Costs for Mercury Removal at 70\% Control Level ...........79

Table 4-17. Comparative Specific Costs for Mercury Removal at 90\% Control Level ...........80

Table 4-18. Incremental Specific Costs for Mercury Removal for Additional Mercury

Removed by Improving Removal from $70 \%$ to $90 \%$.................................................. 81

Table 4-19. Details of Cost Model Results for Mercury Removal at 975 MW(e) Plant ..........82

Table 4-20. Details of Cost Model Results for Mercury Removal at 100 MW(e) Plant ..........83 


\section{Executive Summary}

Public Service Company of Colorado (PSCo) and ADA Technologies, Inc. have completed a project to investigate the injection of activated carbon for the removal of mercury from the flue gas of coal-burning power plants. The project was conducted over a five-year period in two phases. In Phase I, a pilot plant was designed and built to extract a slipstream of flue gas from PSCo's Comanche station Unit 2 for mercury removal tests. Phase II was intended to move carbon injection technology towards commercial application on coal-fired power plants by addressing key reliability and operability concerns. Phase II field work included further developmental testing with the Phase I pilot, and mercury measurements on several of PSCo's coal-fired generating units. These tests at full-scale plants were added to the Phase II test plan when the Phase I pilot data indicated that the fly ash present in the Comanche flue gas showed an ability to sorb a significant fraction of the mercury present in the flue gas. In addition, tests were run on collected sorbent plus fly ash samples to evaluate the impact of the activated carbon sorbent on the disposal of fly ash. An economic analysis was performed where pilot plant test data were used to develop a model to predict estimated costs of mercury removal from plants burning western coals.

The pilot-scale testing addressed three parameters of interest in the mercury removal process: configuration of the particulate control equipment in the pilot, flue gas temperature, and the rate of activated carbon sorbent injection into the flue gas stream under treatment. There were three configurations of the pilot particulate control equipment included in the testing: an electrostatic precipitator (ESP), a reverse-gas baghouse, and a pulse-jet baghouse. The flue gas temperature was varied over a range of about $230^{\circ} \mathrm{F}$ to $330^{\circ} \mathrm{F}$. Typical flue gas temperatures in the host unit range from about $270^{\circ} \mathrm{F}$ to $300^{\circ} \mathrm{F}$, depending on the ambient temperature. The pilot was equipped with an in-duct heater to increase the temperature when required by the test matrix, and with a water fine mist injection system to decrease the temperature. The injection system for the activated carbon sorbent under test was fitted with a variable-speed motor so that the injection ratio could be carefully controlled. The activated carbon used for testing in Phase II was Norit Darco FGD ${ }^{\mathrm{TM}}$. Also tested as mercury sorbents in Phase II were several fly ashes collected from PSCo plants where full-scale mercury tests had shown high rates of mercury removal by the native fly ash.

Tests were run by establishing steady-state conditions of temperature and flow, and then initiating injection of carbon into the flue gas slipstream of the pilot. Mercury concentration was typically measured by extracting a small flow of flue gas through a sorbent trap sampling system 
simultaneously at the inlet and outlet of the pilot. The sorbent traps were packed with iodated carbon, with two traps installed in tandem. The first trap was analyzed for mercury content, and the total collected mercury value was used to calculate the vapor-phase mercury concentration of the sampled gas stream. A separate analysis was made of the particulate mercury captured in the filter installed upstream of the iodated carbon traps. The second trap was analyzed on selected runs to confirm that all of the mercury present was captured in the primary sorbent tube. Sampling time was nominally one hour at both the inlet and outlet locations. The sorbent traps were analyzed by an independent lab offsite, and turnaround was typically two to four weeks for results to be made available for analysis.

For a limited number of tests, a real-time mercury analyzer was used to collect mercury concentration data alternately from the inlet and outlet. This instrument was found to operate only when the flue gas slipstream was free of fly ash. A limited number of tests were run with the pilot in a configuration where the flue gas was extracted downstream of the reverse-gas baghouse used for particulate control on the host unit. A few sorbent trap measurements were made simultaneously with the operation of the real-time analyzer. Some discrepancy was noted; however, the real-time monitor was consistently biased low in comparison with the sorbent trap measurements, and the mercury removal rates measured with the real-time monitor were with a few percent of values found with the sorbent trap measurements.

Activated carbon injection tests were run for all three particulate control configurations of the pilot. The pulse-jet baghouse configuration demonstrated the most efficient mercury removal, followed closely by the reverse-gas baghouse configuration. Mercury removal at a fixed ratio of carbon injection was significantly lower for the ESP configuration in comparison with the baghouses. At a carbon injection ratio of 4 pounds per million actual cubic feet (lb/MMACF) of flue gas, the ESP configuration removed only about $65 \%$ of the mercury in the flue gas, compared to over $90 \%$ removal for both the reverse-gas and pulse-jet baghouse configurations.

The tests also showed a definite trend where mercury removal increased as the temperature of the flue gas decreased. In the ESP configuration, the average mercury removal increased from $48 \%$ to over $60 \%$ when the flue gas was cooled from $295^{\circ} \mathrm{F}$ down to $230^{\circ} \mathrm{F}$. The trend was more pronounced when baseline tests were run without carbon injection for the reverse-gas baghouse configuration. The native fly ash was found to remove about $10 \%$ of the flue gas mercury at a temperature of $330^{\circ} \mathrm{F}$; when the flue gas was cooled to $230^{\circ} \mathrm{F}$, the fly ash removed about $75 \%$ of the mercury. Another test of the impact of flue gas cooling was run with 
the pilot in the TOXECON configuration, where a pulse-jet baghouse is run as a polishing unit at a high air-to-cloth ratio filtering flue gas extracted from downstream of the existing Comanche reverse-gas baghouse. When the flue gas was cooled to $230^{\circ} \mathrm{F}$, the mercury removal rate was measured to be $49 \%$ at an activated carbon injection ratio of $0.18 \mathrm{lb} / \mathrm{MMACF}$. The activated carbon injection ratio was raised to one $\mathrm{lb} / \mathrm{MMACF}$, and the mercury removal rate rose to $96 \%$. Since there was no fly ash present in this gas stream, the baseline mercury removal rate was zero for this TOXECON test.

Increasing the injection ratio of activated carbon resulted in increases in the level of mercury removal for all particulate control configurations, but not in direct proportion to the injection ratio. The ESP configuration showed an increase from about 50\% mercury removal at a carbon injection ratio of one $\mathrm{lb}$ per million actual cubic feet to about $65 \%$ at $4 \mathrm{lb} / \mathrm{MMACF}$. Increases in the injection ratio of activated carbon were less effective in the reverse-gas and pulse-jet configurations, in part because the removal rates at the lower injection ratios were already quite high. In both cases, the typical removal rate at a carbon injection ratio of 1 $\mathrm{lb} / \mathrm{MMACF}$ was over $80 \%$, and was seen to increase to over $90 \%$ when the injection ratio was increased to $4 \mathrm{lb} / \mathrm{MMACF}$.

A long-term test was performed in the reverse-gas configuration to investigate the effect of dust cake buildup on the mercury removal efficiency. Several activated carbon injection ratios were set over the 10-day duration of the test. Mercury removal was consistently over $80 \%$, and reached over $95 \%$ for an injection ratio of $5 \mathrm{lb} / \mathrm{MMACF}$. Mercury measurements were obtained over a range of tubesheet differential pressures, where an increase in dust cake thickness can be correlated with the increase in tubesheet differential pressure. A small trend was seen in the data, where an increased dust cake thickness showed an increase in mercury removal rate of a few percent over the time from immediately after a cleaning cycle to immediately before the next cycle.

A test was run with the pilot in the TOXECON configuration where the clean flue gas supplied to the pilot was doped with vapor-phase elemental mercury. The TOXECON configuration was very effective in removing the mercury from the flue gas stream at very low injection ratios of activated carbon. Mercury removal rates of over $80 \%$ were measured at carbon injection ratios of 0.5 to $1 \mathrm{lb} / \mathrm{MMACF}$.

Baseline test results in the pilot indicated that the fly ash present in the Comanche Unit 2 flue gas had an affinity for mercury. To investigate the extent of this phenomenon, 
measurements were made on a total of five generating units in the PSCo system. The units represented a range of sizes, particulate control configurations, and source coals. There was one unit equipped with an ESP, three with reverse-gas baghouses, and one with a combination spray dryer absorber and reverse-gas baghouse. Three of the units burned Powder River Basin coals, and the other two a Colorado bituminous coal. Results were interesting and thought to be significant.

The unit equipped with an ESP burned PRB coal, and was measured to have a mercury removal rate of under $30 \%$. Another unit at the same plant also burned PRB coal, and showed mercury removal rates of $60 \%$ to $90 \%$ through a reverse-gas baghouse. This unit had a significant fraction of unburned carbon in the fly ash (LOI) of over $12 \%$, which may have contributed to the mercury sorbent capacity of the native fly ash. Another unit burning Colorado bituminous coal had a measured LOI of about $7.5 \%$, and replicate sampling found that $98 \%$ of the mercury present was removed across the baghouse. This result was surprising, and was duplicated when a second test series was run five months later. The same coal was burned in another PSCo unit equipped with a spray dryer absorber and reverse-gas baghouse, and a mercury removal rate of about 95\% was measured. Finally, Comanche Unit 2 (host to the pilot plant) was included in the survey. The host site was found to experience mercury removal of about $60 \%$ across the reverse-gas baghouse. Comanche Unit 2 burns PRB coal, and has a typical LOI of about $0.6 \%$. This provided some evidence that the mercury removal was not due in total to the presence of unburned carbon in the fly ash upon which the mercury is collected.

When project test results indicated that some fly ash materials removed significant fractions of mercury from flue gas in the pilot tests and in full-scale plants, plans were made to evaluate in the pilot the injection of fly ash from selected PSCo plants as mercury sorbents. The pilot was configured as a reverse-gas baghouse, drawing flue gas downstream from the existing Unit 2 full-scale baghouse. Since the mercury level in the clean flue gas extracted downstream of the Unit 2 baghouse was low, vapor-phase elemental mercury was doped into the flue gas. Fly ash samples were collected from the host Comanche Unit 2, Cherokee Unit 3, and Arapahoe Unit 4 sites for testing in the pilot. The Comanche fly ash was not effective as a mercury sorbent, removing only $13 \%$ and $22 \%$ of the vapor-phase mercury when injected "as-collected" and after a hot gas purge to remove mercury previously collected. The Cherokee Unit 3 fly ash performed better as a sorbent, removing $75 \%$ of the vapor-phase mercury at an injection ratio of about 1/3 grain per actual cubic foot of flue gas. The Arapahoe Unit 4 fly ash was found to perform the best of the reinjected fly ashes, removing $80 \%$ of the vapor-phase mercury at an injection ratio of 0.13 grains per actual cubic foot, or about five times the injection rate needed to 
obtain an $80 \%$ mercury removal when using activated carbon at a comparable flue gas temperature. These results showed that there may be a potential to use selected fly ash materials as mercury sorbents in plants firing western coals, where a majority of the mercury in the flue gas is present in the elemental state.

A series of tests were run on the Cherokee 3 fly ash to help understand the mechanism for mercury removal by this material. A sample was subjected to a size separation, and the size fractions were analyzed to quantify the carbon and mercury content of each. Results showed that while the carbon tended to reside in the larger size fractions, the mercury in the fly ash was found in the smallest sizes. In fact, mercury in the particles smaller than 2.5 microns in diameter was seen to concentrate by a factor of greater than four with respect to the carbon. Thus, it appears that the ability of the fly ashes to sorb mercury was due to more than just the presence of carbon particles. There appears to be a size effect that contributed to the sorbent properties of this material which may be attributable to the greater surface area per unit mass of the smaller particles. This is topic recommended for further investigation.

Samples of fly ash collected from the project pilot plant, from the host unit, and from Cherokee Unit 3 were subjected to Toxic Characteristic Leaching Procedure (TCLP) to determine if the mercury deposited on the fly ash and activated carbon sorbent could be dissolved into the leachate. All samples were found to pass the EPA standard easily; in fact, the mreacury levels in the leachate were below limits of detection in all the samples taken.

One other series of tests was performed to determine if mercury sorbed by activated carbon and fly ash samples remained present on the material after an extended period of time. Four samples were analyzed for mercury content, then stored for eight months, at which time they were analyzed again. The data indicated that once captured, the mercury remained on the particles at essentially the same concentrations.

Finally, a cost model was prepared to generate information on the cost of removal of mercury from plants burning western coals. The project model used as its basis a model originally developed by EPA and used to generate cost data for the EPA Mercury Study Report to Congress (1997). The EPA model was modified using a standard costing approach to account for changes in activated carbon injection ratios, and the use of spray cooling to adjust the temperature of the flue gas. Mercury removal costs were predicted for two sizes of coal-fired plants, $100 \mathrm{MW}(\mathrm{e})$ and $975 \mathrm{MW}(\mathrm{e})$. Two target mercury removal levels were included in the cost study: $70 \%$ and $90 \%$, based on the total mercury present in the flue gas as particulate-bound 
and gas-phase.

The activated carbon injection rates were calculated from prediction equations developed from data gather during the pilot. A multivariable regression analysis was used to generate the prediction equations, using flue gas temperature, carbon injection ratio, and mercury concentration in the flue gas as the independent variables. Separate equations were developed for the three particulate control configurations: ESP, reverse-gas baghouse, and pulse-jet baghouse.

A total of six cases were defined for the economic study, and the model was applied to each. The cases were run for the two sizes of plants, and two levels of mercury control for a total of 24 model data points. Results of the model were calculated as levelized costs assuming a 7\% interest rate over a twenty-year amortization period. The model was programmed as a Microsoft Excel spreadsheet, with results expressed in terms of dollars per pound of mercury removed from the flue gas.

Model results showed the ESP to be the most expensive configuration for mercury removal from coal-fired power plants. Costs for the various ESP cases of plant size, mercury control level, and flue gas temperature ranged between $\$ 12,500$ and $\$ 27,200$ per pound of mercury removed.

The pulse-jet baghouse was estimated to be the cheapest particulate control configuration for removal of mercury with injection of activated carbon. This was in large part due to the fact that the pulse-jet showed very high baseline (no-injection) mercury removal rates in the pilot study. The predicted pulse-jet costs ranged from $\$ 200$ to $\$ 4,900$ per pound of mercury removed.

The reverse-gas baghouse configuration estimates fell between the ESP and pulse-jet predictions. Estimated costs for mercury removal ranged between $\$ 5,800$ and $\$ 9,100$ per pound of mercury removed from the flue gas. Finally, the incremental costs to increase the mercury removal efficiency from $70 \%$ to $90 \%$ were calculated from the model predictions. These costs were seen to range from as low as $\$ 4,500$ to as much as $\$ 47,600$ per pound of mercury removed. The highest values were associated with the ESP configuration, and the loweset with the reversegas baghouse. The economic modeling showed that the removal of mercury from plants fired with western coals will be expensive, and that the incremental costs to increase the removal efficiencies from $70 \%$ to $90 \%$ may be quite significant. 


\section{Introduction}

The Clean Air Act of 1990 mandated that the EPA investigate the costs and benefits of controlling mercury emissions from sources in the US, including coal-fired power plants. EPA has collected data from a variety of sources, among them the coal supplied to power plants across the country, as well as from a series of stack measurements that the agency has required from selected power plants. These data are being compiled to support a position paper now in preparation that will make a recommendation regarding regulation of mercury emissions from coal-fired power plants. This recommendation is due for release in December, 2000.

In anticipation of possible emissions control regulation, the Department of Energy's National Energy Technology Laboratory established a program to develop technology alternatives for mercury control at coal-fired power plants. A Program Research and Development Announcement (PRDA) was issued in 1995, requesting proposals for projects develop technology for the economic removal of mercury from coal-fired flu gas streams. The team of Public Service Company of Colorado (PSCo), EPRI, and ADA proposed an effort to explore the injection of activated carbon for mercury removal from flue gas streams. Injection of activated carbon for mercury control has been implemented in other applications where the mercury concentration is considerably higher than in coal-fire flue gas; it thus represented a prime candidate for use in power plants, should the EPA require reduction of mercury emissions from coal-fired power plants in their December ruling.

The proposed approach to the project was to build a pilot-scale test facility that would evaluate sorbent performance on a slipstream of actual flue gas from an operating coal-fired power plant in the PSCo system. Testing was to be conducted over a range of flue gas temperatures and sorbent injection rates. The pilot test facility was to be versatile, designed for quick conversion to three different particulate control configurations so the impact of plant emissions control equipment could also be determined. Testing was to be performed by measuring mercury content of the flue gas upstream of sorbent injection and downstream of the particulate control device, and calculating the mercury removal efficiency for the specific test conditions.

The team assembled for this effort brought to the project a complementary set of skills and perspectives. Public Service of Colorado provided the host utility site and a user's engineering expertise that kept the test plan and analysis of results on track to supply information that would be useful to the industry for which the technology was intended. EPRI brought 
technical expertise in the application of development efforts to real-world utility problems, specifically in the area of emissions controls from power plants. ADA Technologies, Inc. contributed several years of experience with industrial-scale particulate control innovation and pilot plant operation. In addition, ADA was developing a national reputation in the treatment of mercury emissions from gaseous, liquid, and solid waste streams. Projects in mercury control and measurement at ADA have been funded by several branches of the US Department of Energy, the National Institutes of Health, and the Environmental Protection Agency. Other mercury control projects at ADA were completed under the sponsorship of companies with mercury contamination and emissions issues that needed solution.

The PSCo/ADA/EPRI project for investigation of the use of activated carbon for mercury control in coal-fire flue gas streams was funded in 1995 . The effort was intended to be carried out in two phases, where Phase I addressed design, fabrication, and installation of a pilot test facility and initial tests of the use of activated carbon as a mercury sorbent. Phase I was conducted over a two-year period, followed by the preparation of a proposal for Phase II activities. In Phase II, an extended test program was completed to gather performance data for carbon injection over a wide range of flue gas conditions and pilot particulate control configurations. Additional tasks were included to provide support data for the scaling of pilot results to designs of mercury control systems for operating plants. Among these tasks were a survey of mercury removal levels at five operating PSCo generating units, evaluation of the impact of activated carbon on the disposal of fly ash, and preparation of an economics model for the prediction of mercury removal costs based on pilot test results.

\section{Project Objectives}

The overall objective of the PSCo two-phase program was to investigate the use of activated carbon sorbents to control mercury emissions from the flue gas of coal-fired utility boilers. This information is of great interest to the utility industry in anticipation of potential regulations by EPA regarding mercury emissions from these sources. During Phase I of the program, a 600 cubic foot per minute (cfm) pilot-scale test facility was engineered, constructed, and integrated into Public Service Company of Colorado (PSCo)'s Comanche Station in Pueblo, Colorado to evaluate the performance of various carbon sorbents injected for mercury removal under different operating conditions and configurations. The pilot treated a slipstream of flue gas drawn from the Unit 2 boiler at the plant. The pilot test facility was designed with flexibility to study mercury removal with the particulate control module (PCM) configured as an electrostatic precipitator (ESP), a pulse-jet baghouse (PJ), or a reverse-gas baghouse (RG). 
Carbon-based sorbents were injected upstream of the PCM and mercury concentration measurements were made to determine the mercury removal efficiency for each sorbent and test configuration. Details of the Phase I program were presented in the final report, which included a full description of the equipment and analytical procedures used as well as the data and conclusions from the tests.

Phase II was designed to move carbon injection technology towards commercial application on coal-fired power plants by addressing key reliability and operability concerns. The objectives of Phase II were to demonstrate repeatable results over a range of operating conditions in the pilot unit, and to obtain sufficient information to confidently scale up the technology. The pilot test facility with its easily-reconfigured PCM was used in Phase II for further mercury control evaluations. In this phase, selected sorbents were tested with the PCM configured as an electrostatic precipitator, a pulse-jet baghouse, TOXECON, and a reverse-gas baghouse. TOXECON is a patented EPRI technology where a pulse-jet baghouse is installed downstream of an existing particulate control device, and upstream of a sorbent injection system to control gas-phase pollutants of interest. The TOXECON pulse-jet is operated at a high air to cloth ratio to minimize its size and cost; it removes the sorbent material and residual fly ash from the gas stream.

The pilot-scale test facility was designed to permit significant control over the operating conditions during sorbent evaluation tests. In addition to changing the particulate control configurations, operating parameters such as flue gas flow rate, duct temperature, flue gas moisture content, in-duct sorbent residence time, and flue gas mercury concentration were controlled and varied over ranges of interest. For example, in Phase II sorbent effectiveness was evaluated at temperatures ranging from $230^{\circ} \mathrm{F}$ to $350^{\circ} \mathrm{F}$. This broad temperature window was targeted because of the dependence observed in Phase I of sorption characteristics on temperature of the flue gas, and the need to better understand this relationship due to its effect on process economics. Sorbents were introduced to the system through ports located in the injection section, situated to afford residence times in the ductwork of 0.5 to 1.5 seconds, to evaluate the impact of duct residence time on sorbent effectiveness.

The PCM is designed with interchangeable particle collection hardware modules to allow configuration as an ESP, conventional pulse-jet baghouse, reverse-gas baghouse, or TOXECON. Tests to quantify mercury removal by injected activated carbon with each of these PCMs were performed in Phase II.

Several other tasks were included in the Phase II project to support the commercialization effort. These were directed at understanding the factors that influence scale-up of the technology 
to implementation on operating power plants. One was to perform a survey of several full-scale generating units of Public Service Company to quantify mercury emissions from operating coalfired generators. Another was to explore the properties of the activated carbon on which mercury had been deposited to determine if there were potential disposal problems for the sorbent. And an economic analysis of the use of activated carbon for mercury removal was completed in order to generate information that would be useful in the EPA rulemaking process and for use by utilities in developing contingency plans for mercury control from coal-fire power plants.

In addition to activated carbon, several fly ash sorbents were evaluated in Phase II testing. Baseline tests in the pilot facility and full-scale plant survey results provided strong evidence that some western coal fly ashes provided significant mercury removal, especially in plants equipped with baghouses for particulate collection. Because of this observed fly ash affinity for mercury, tests were added to the planned activated carbon matrix to evaluate the use of fly ashes as mercury sorbents. 


\section{Facility Description}

\subsection{Pilot plant and PCM}

The pilot-scale test facility for evaluation of activated carbon sorbents for mercury control was installed at the Comanche Generating Station of Public Service Company of Colorado. Ductwork supplied a slipstream of flue gas from the plant's 350 MW Unit 2 which burns Powder River Basin coal from the Belle Ayre mine in Wyoming. The total mercury concentration in the flue gas was typically around $7 \mu \mathrm{g} / \mathrm{Nm}^{3}$ at the test location. The $\mathrm{SO}_{2}$ concentration (@3\% $\mathrm{O}_{2}$, dry) was 275 to 325 ppm and the $\mathrm{NO}_{\mathrm{x}}\left(@ 3 \% \mathrm{O}_{2}\right.$, dry) concentration was 180 to $250 \mathrm{ppm}$. The pilot facility was designed and fabricated to permit significant control over the operating conditions during mercury removal testing. It consisted of several sections: a supply duct, injection duct, particulate control module (PCM), and return duct. An operations trailer was located on-site to provide a controlled environment for the data acquisition system and some of the instrumentation. The pilot was built and installed in Phase I of the project.

The most significant operating feature of the pilot was the particulate control module, an element that was designed to allow quick and simple change-out of the particulate control technology used in the pilot. The PCM could be quickly opened and the internal components changed to allow operation as an electrostatic precipitator (ESP), a reverse-gas baghouse, or a pulse-jet baghouse.

The pilot test facility was designed for year-round, outdoor use, so all ducting was sealed and insulated. Gate valves were installed so that the pilot test facility could be isolated from the plant flow to make modifications and to allow operation of the pilot on a normal work week schedule. Operating parameters such as duct temperature, flue gas moisture content, in-duct sorbent residence time, and flue gas mercury concentration could be controlled over ranges of interest. Sorbent effectiveness was evaluated for flue gas temperatures from $200^{\circ} \mathrm{F}$ to $350^{\circ} \mathrm{F}$. Flue gas cooling was achieved by injecting a fine water mist that evaporated in the flue gas slipstream to decrease its temperature. The test flue gas stream could also be heated with an electric element inserted into the flow. The sorbent injection ports were situated to allow in-duct sorbent residence times of 0.5 to 1.5 seconds to evaluate the effect of residence time on sorbent 
effectiveness. An overall schematic of the test fixture is shown in Figure 3-1.

Figure 3-1. Schematic of laboratory-scale test fixture.

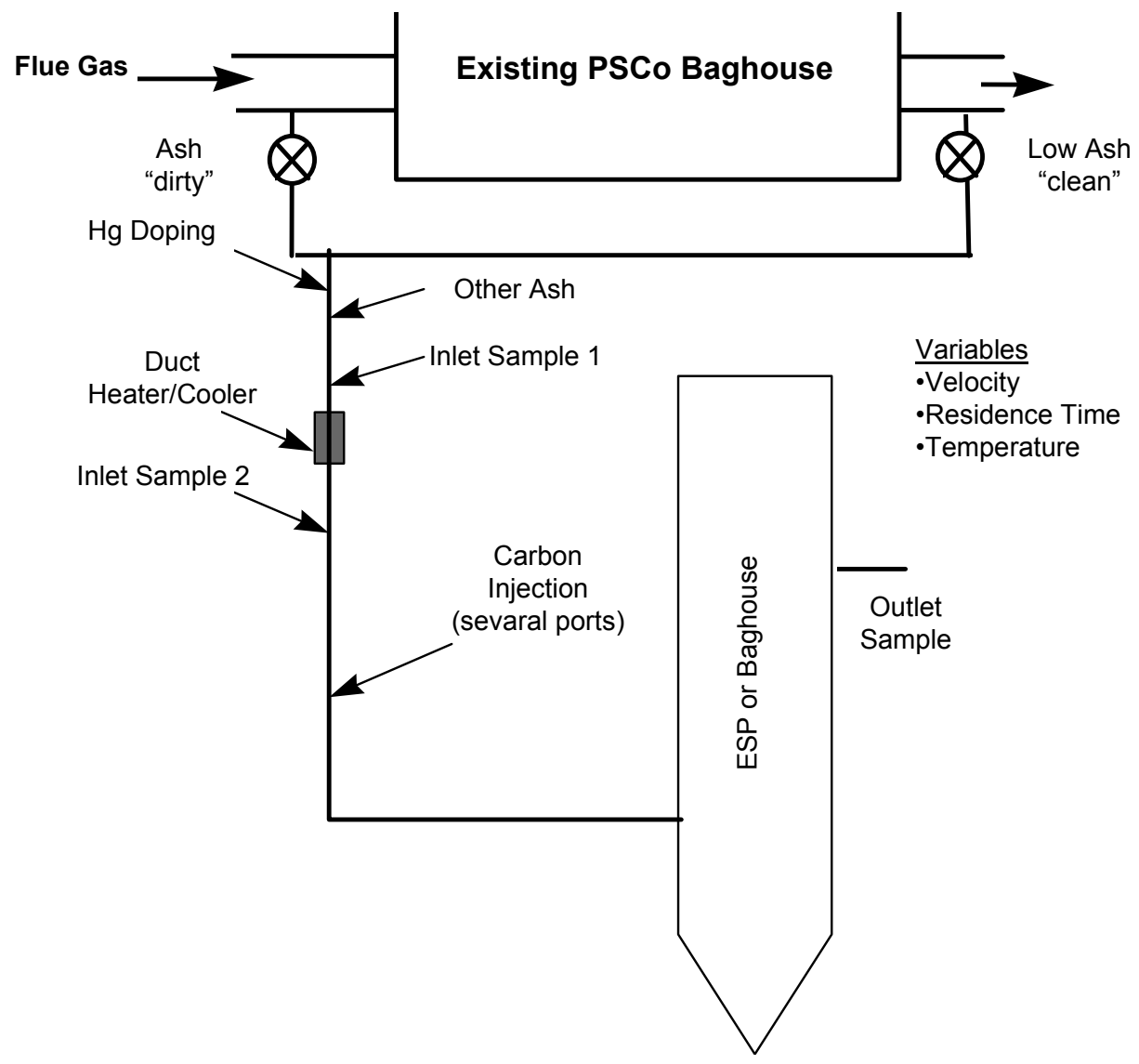

The 30 foot high particulate control module was incorporated into the 8 -foot by 10 -foot framework shown in the photo in Figure 3-2. The injection section and collection section were built within the framework and were accessible from platforms. A mast was installed on the tower to allow configuration changes in the PCM without the assistance of a crane. At most, two people were required for major configuration changes in the PCM, such as conversion from the electrostatic precipitator to the pulse-jet baghouse. 
Figure 3-2. Photo of Mercury Removal Pilot Plant Installed at Comanche Station



\section{Control System}

The control system was designed to allow manual or automatic operation of the pilot. The primary control elements for the pilot consisted of a Programmable Logic Controller (PLC) and an intelligent data-logger. Pneumatic actuators on the inlet, outlet, bypass, flow control, purge, and hopper discharge valves permitted automatic flow control, off-line cleaning, and isolation of the pilot for shut-down. The control system was programmed to bring the pilot offline, clean the bags or rap the plates, and purge the system for alarm trip conditions. Trip conditions included low boiler load and low duct temperature for all configurations and high duct temperature and high tubesheet pressure drop during the fabric filter tests. The bag cleaning or plate rapping sequence could be initiated automatically or controlled manually at the control panel. Monitored and recorded parameters included: gas temperatures, flowrate, pressures, host boiler load, secondary voltage and current (ESP), cleaning/rapping frequency, and pulse pressure or reverse gas flow (fabric filters). Data were stored in time-stamped arrays for transfer to other 
software for analysis and graphical presentation.

\section{Electrostatic Precipitator Configuration}

The pilot-scale electrostatic precipitator was a wire-tube type unit. It is more practical to use a tube-type precipitator design for ESP pilots treating flow below approximately 1000 acfm primarily because gas "sneakage" around the active section and changes in the electric field at the edges of the plates become dominating factors in flat plate designs at low flow rates. Sneakage in a wire/plate ESP becomes a major concern in pilots treating flue gas in this flow rate range because the spacing required between the high voltage components and ground to avoid electrical arcs is the same in the pilot-scale as in a full-scale. Although the distance required between high voltage and ground is a small fraction of the overall ESP box height in a full scale ESP where plates are 20 to 40 feet tall, it becomes a significant percentage of the box height for a pilot ESP, where plate height may be only a few feet. In a wire-tube ESP, all the gas flows through the active section, the constant electric field formed between the corona wire and grounded tube.

It is important to maintain the same wire-to-collector spacing in a pilot ESP as in the fullscale design being simulated, as this spacing defines the electrical field strength. A typical wireto-plate spacing in an older full-scale ESP is 5 inches. The collector tube diameter in the pilot ESP is 10 inches to provide a wire-to-tube wall spacing of 5 inches.

The ESP was a wire-tube type unit designed to treat $620 \mathrm{acfm}$. This flowrate resulted in a velocity of $5 \mathrm{ft} / \mathrm{sec}$ through the 20 foot long ESP collection section. The specific collection area (SCA), a standard measure of collection area to total gas flow, at these operating conditions was $327 \mathrm{ft}^{2} / \mathrm{Kacfm}$. This SCA was selected because it was representative of many ESPs installed at utilities in the United States.

Four 10-inch diameter collection tubes, the gas passages for the ESP, were hung from a tubesheet at the top of the 28-inch diameter collection vessel housing. Four high-voltage electrodes, one situated on the centerline of each gas passage, were attached to a rigid frame and

powered from a single transformer-rectifier $(T / R)$ set. The lower frame was weighted to keep the wires straight and a pneumatic vibrator was attached for cleaning ash from the electrodes. The top frame was attached to the high voltage bus at the feedthrough insulators. The T/R set was controlled by an automatic voltage controller (AVC) and was set to simulate conditions in a full- 
scale wire-plate ESP. For these tests, the T/R set was operated in the $40 \mathrm{KV}, 15 \mathrm{~mA}$ range (at 15 $\mathrm{mA}$, the current density is $80 \mathrm{nA} / \mathrm{cm}^{2}$ ). Comanche Station burns a Powder River Basin coal, which typically causes problems with back corona on full-scale ESPs because of the high resistivity flyash it produces. The ESP T/R controls were set for intermittent energization, which successfully quenched the back corona in the pilot. Figure 3-3 presents a schematic of the configuration for the ESP module.


Figure 3-3. Layout for the ESP Module of the Pilot PCM

\section{Pulse-Jet Baghouse Configuration}

The pulse-jet module was designed to filter 628 acfm flue gas at an air-to-cloth ratio of 4 $\mathrm{ft} / \mathrm{min}$. To achieve this ratio, six 20-foot long (full-scale) bags were hung from the pulse-jet tubesheet. Full-scale bags were specified for the pilot to better simulate the filtering and cleaning characteristics experienced in a full-scale unit. The bags were sealed to the tubesheet by means of a metal snap band and a double-beaded gasket sewn into the top of the bag. A rigid steel wire cage was inserted into each bag. Flue gas entered the bag compartment at the bottom and passed through the bags from outside to inside, depositing the particulate matter on the outside of the bags. The flue gas then flowed out of the compartment through the outlet plenum 
on the clean side of the tubesheet. Flue gas in the outlet duct flowed past an annutube flow sensor, the flow control damper, then through a section of duct located beneath the ash hopper. Ash from the hopper was fed into this duct section by a rotary valve. The particulate-laden gas then returned to the host duct. The bags were cleaned by pulses of compressed air delivered from pulse pipes located above each row of three bags. Figure 3-4 shows the layout for the pulse-jet bags in the pilot PCM.

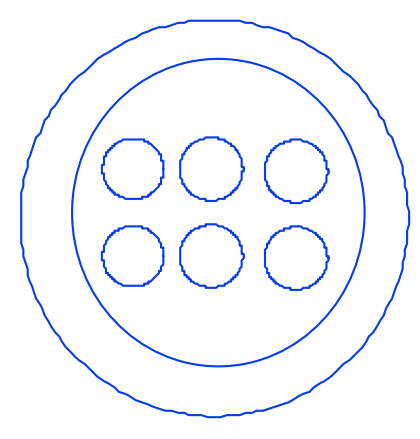

Figure 3-4. Pulse-Jet Baghouse Module for the Pilot PCM

\section{Reverse-Gas Baghouse Configuration}

The PCM was configured as a reverse gas baghouse by installing a cell plate with seven 8-inch diameter holes near the bottom of the PCM housing. Each bag was attached to the cell plate by a metal snap band and a fiberglass double-beaded gasket sewn into the bottom of the bag. The 21-foot long, 8" diameter full-scale fiberglass bags were sealed at the top by a metal bag cap. The caps were attached to tensioning springs at the top of the PCM and the bags were pre-tensioned to a load of approximately $35 \mathrm{lbs}$. Flue gas entered the bag compartment from the bottom and passed through the cell plate into the interior of the bags. The gas then flowed from inside to outside of the bags, deposited the ash on the inside of the bags, and exited the 
compartment via the outlet plenum. The bags were cleaned by reversing gas flow across the bags from outlet to inlet causing the bags to gently collapse, thus breaking off the dust cake collected on the inside of the bags. The ash fell into the ash hopper at the bottom of the compartment. The PCM system used Comanche's hot, clean, dry preheat air for reverse-gas. During a clean, automatic valves were actuated to close the outlet duct of the PCM and open the reverse gas line. This allowed reverse gas to enter the compartment through the outlet plenum. Cleans were initiated when pressure drop across the bags exceeded a threshold level. In the Phase II of the project, a problem was encountered with cleaning of the bags in the reverse-gas configuration. This was solved with the installation of a sonic horn to apply additional energy in the form of sound waves to the bags during cleaning. Figure 3-5 presents the layout for the reverse-gas baghouse PCM configuration.
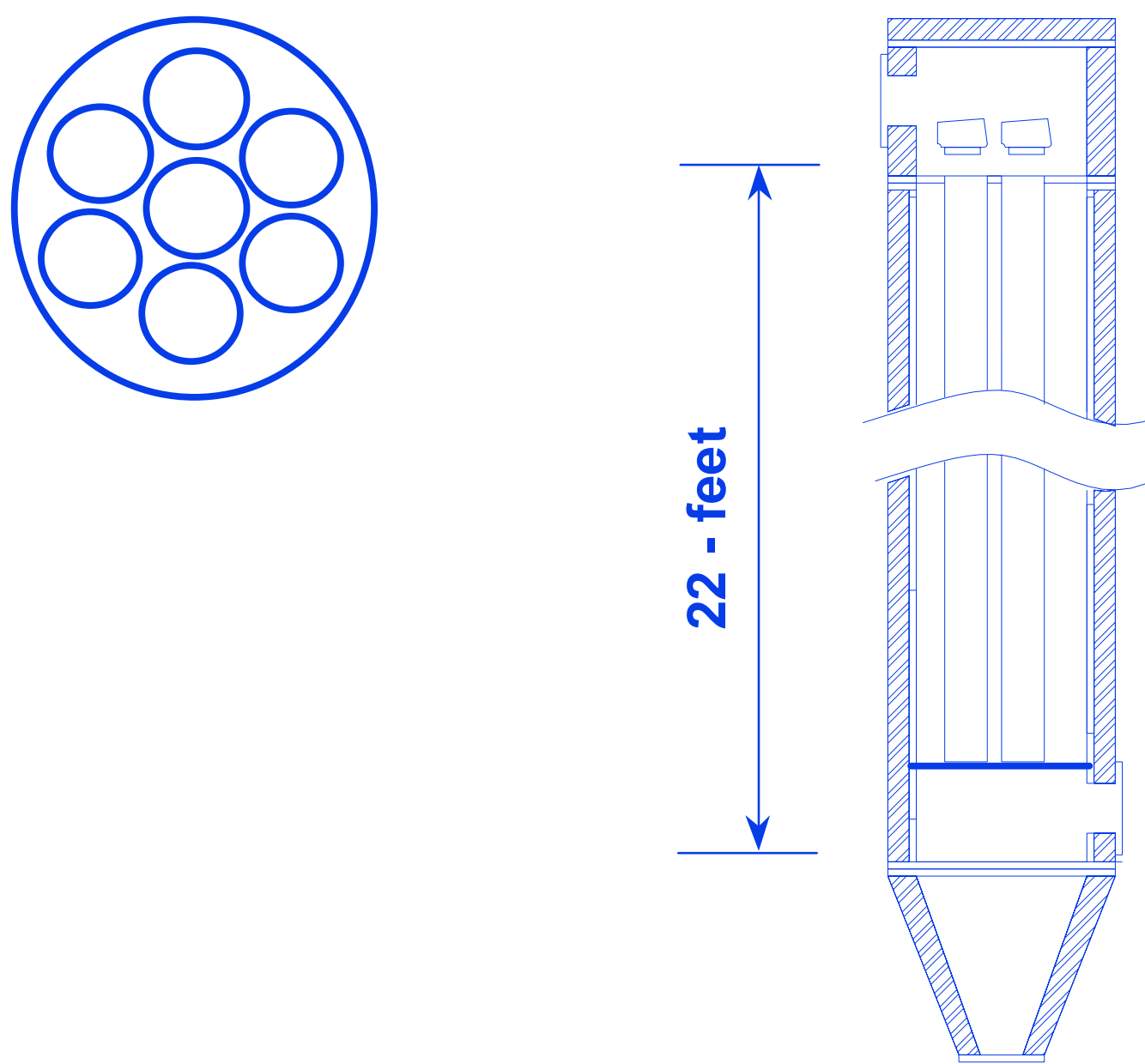

Figure 3-5. Reverse-gas Baghouse Configuration for the Pilot PCM 


\section{TOXECON Configuration}

TOXECON is a pulse-jet baghouse with sorbent injection for air toxics removal operating at a high $\mathrm{A} / \mathrm{C}$ ratio downstream of a primary particulate collector. EPRI has patented the TOXECON process. This configuration for the PCM was designed to filter $633 \mathrm{acfm}$ of flue gas at an air-to-cloth ratio of $16 \mathrm{ft} / \mathrm{min}$. The target operating air-to-cloth ratio for these tests was 12 $\mathrm{ft} / \mathrm{min}$, which meant that the flow was somewhat below the design value. To achieve this ratio, two 15-foot long bags were hung from the TOXECON tubesheet and the PCM filtered $470 \mathrm{acfm}$ of flue gas. An annulus was installed in the PCM in this configuration to increase the can velocity (upward gas velocity in the vessel on the dirty-side of the tubesheet) to approximately $900 \mathrm{ft} / \mathrm{min}$ at an $\mathrm{A} / \mathrm{C}$ ratio of $12 \mathrm{ft} / \mathrm{min}$ to better simulate the flows in a full-scale unit. The injected sorbent was collected on the exterior of the felted bags, as in a full-scale unit. Because TOXECON is designed for installation downstream of a primary particulate collector, the pilot facility was configured to draw flue gas downstream of the existing Comanche baghouse. The operation of TOXECON is similar to a conventional pulse-jet baghouse except that cleaning is initiated by a timer and the bags are cleaned off-line.

\section{Mercury Doping System}

A mercury doping system was designed to increase the elemental mercury vapor concentration in the duct that supplied flue gas to the pilot facility. The design of this doping system was based on similar systems designed for other ADA mercury control projects. Nitrogen was passed at a constant rate over liquid elemental mercury in a temperature controlled container. The mercury concentration in the gas exiting the vessel was regulated by the temperature of the vessel and the nitrogen flow rate. This system was used on some pulse-jet, reverse-gas and TOXECON tests when there was little fly ash present in the inlet gas stream and the inlet mercury concentration was expected to be below $2 \mu \mathrm{g} / \mathrm{m}^{3}$.

\section{Sorbent Injection}

Sorbent was injected into the duct via a screw feeder with an electronic speed control for feed rate to allow the operator to change the injection rate independent of gas flow. The screw feeder delivered sorbent to an eductor, where a carrier air stream fluidized the sorbent and transported it to the test duct. A feed hopper was used to store and supply sorbent to the feeder. Sorbents were introduced into an injection section upstream of the pilot's PCM. The injection section was a 12-inch diameter pipe with 4-inch ports at five locations along its 16-foot length. These port locations were spaced to allow in-duct sorbent residence times from 0.5 to 1.5 
seconds at typical operating conditions. Flue gas flowed into the test fixture through a heater assembly at the top of the unit, into the injection section and then into the lower portion of the main collection section.

\subsection{Mercury measurement techniques}

When sampling particulate-laden gas in all configurations an isokinetic sampling system was used to collect a representative sample of ash along with the gas. The sampling system consisted of a standard particulate filter, used in EPA Methods 5 and 29, with the addition of a glass cyclone upstream of the sampling filter to collect the fly ash. The cyclone removed a large fraction of the fly ash, thus minimizing the contact of the flue gas with the fly ash on the filter. The vapor mercury measurements were made with a modified Mercury Speciation Adsorption (MESA) method, where particulate-free gas (downstream of the isokinetic ash sampling) was passed through tandem iodated carbon (IC) traps. The modified MESA train consisted of the last two traps (primary and backup) of the full MESA train. These two traps adsorbed all forms of mercury at the temperatures tested. Following sampling, the traps were analyzed for mercury content using cold vapor atomic fluorescence spectroscopy (CVAFS) (Prestbo and Bloom, 1995). The mercury concentrations measured with the traps were reported as total vapor-phase mercury.

Use of a particulate filter for sampling is not an ideal arrangement to quantify the fractions of mercury on the fly ash and in vapor phase because Comanche fly ash has deomonstrated the capacity to sorb mercury. It was likely that forcing the flue gas through a fixed bed of this fly ash (i.e. EPA method 29 or similar sampling filter) probably increased the amount of mercury collected on the ash and lowered the vapor phase values found from the iodated carbon traps. Therefore, mercury measurements in this document are reported as total mercury, the sum of the mercury captured on the fly ash plus the mercury captured in the iodated carbon traps. Samples collected during sorbent injection were compared to baseline (no sorbent injection) to assess a sorbent's effectiveness as an incremental removal of mercury from the flue gas stream. For some test conditions, significant removal of mercury by native Comanche coal fly ash was observed.

A series of tests was conducted with the standard MESA configuration (all four sorbent traps in the train) with the two sets of sorbent traps reversed. Based upon laboratory data, there was concern that some mercury would exit the iodated carbon traps as $\mathrm{Hg}^{++}$. When placed downstream of the iodated carbon traps, a KCl-impregnated soda lime trap should capture any 
remaining oxidized mercury species. Test results indicated that no mercury was captured in the downstream traps, so the modified MESA (two-trap) configuration was used for most of the pilot plant tests.

\section{Sampling System Evolution}

Results from ESP testing with the modified Mercury Speciation Adsorption (MESA) method showed high mercury levels on the quartz wool particulate filter. Although the MESA is sampled non-isokinetically, a large fraction of mercury on the particulate under some conditions indicates significant mercury adsorption onto the flyash. The fly ash entering the MESA train and collecting on the glass wool particulate filter may not be representative of the flue gas fly ash concentration as it is not sampled isokinetically and is dependent on parameters such as fly ash size distribution and gas velocities in the probe relative to the flue gas velocity in the supply duct.

In addition to the mercury measurement concerns related to isokinetic sampling, other changes in the test configuration (such as changes in bulk flue gas temperature) further complicated data analysis. During testing in the pilot, the flue gas slipstream is often cooled or heated to a target temperature to satisfy a particular test condition. If the temperature of the fly ash was modified, it was likely that the ash was adsorbing or desorbing mercury; thus the vapor mercury concentration downstream of heating or cooling was likely to be different than upstream of heating or cooling. The inlet mercury sampling location was only a short distance downstream of the gas temperature control elements so that ash may not have been in equilibrium with the flue gas with respect to mercury partitioning between vapor and deposition phases. Carbon sorbents were injected just downstream of the inlet sampling port. If mercury continued to adsorb onto the fly ash beyond the inlet sampling location, vapor mercury removal occurred that should not be attributed to the sorbent. Since the temperature of the flue gas in Comanche's duct changes with normal plant operation, different amounts of heating or cooling are required to maintain the pilot at a fixed temperature. It is likely that the fraction of mercury vapor adsorbed/desorbed was affected by the variations in heating/cooling. Thus, although baseline flyash mercury removal measurements were made, significant uncertainty remains when assessing contribution of the flyash to overall mercury removal during sorbent injection for this dynamic system. If a representative total mercury measurement can be obtained, erroneous conclusions concerning the affinity of a sorbent for mercury drawn from non-isokinetic flue gas sampling could be minimized. 
Comanche fly ash has been shown to sorb mercury and it was likely that forcing the flue gas through a fixed bed of flyash (i.e. EPA method 29 or similar sampling filter) increased the amount of mercury collected on the ash, resulting in a bias for the vapor-phase mercury measurements. Sorbents, such as activated carbon, are evaluated for their ability to remove mercury from the vapor phase and unrepresentative low inlet vapor measurements could introduce difficulties in assessing the effectiveness of the sorbent under test. Rigorous sample system development and testing was outside the scope of this project; therefore, the selected device was similar to existing devices that have proven effective for mercury measurement. For initial tests, the front-end of a Method 29 sampling train was used with the addition of glass cyclones upstream of the particulate filter. The cyclones were inserted to remove a large fraction of the flyash, thus minimizing the contact of the flue gas and flyash.

\section{MERCEM analyzer}

To obtain data on mercury concentrations in near real-time, an analytical instrument for mercury was leased from Perkin Elmer for use in the Phase II testing. The MERCEM analyzer has been in use in Europe for a number of years to monitor mercury emissions from waste incinerators. This analyzer has functioned well in tests at the University of North Dakota's Energy and Environmental Research Center (UNDEERC), with results within 25\% of impingerbased methods. The analyzer measures total gaseous mercury in a sampled gas stream. The sample probe includes a heated filter box outside the stack that contains two sintered metals filters in series. These two filters remove the majority of the particulate before the gas is extracted through a heated $\left(360^{\circ} \mathrm{F}\right)$ sample line to the analyzer. In the analyzer a $\mathrm{SnCl}_{2}$ solution is used to reduce any oxidized mercury present in the gas sample to elemental mercury. After drying, the gas sample is sent through a gold trap for amalgamation. Periodically, the trap is heated to desorb the mercury, which is then analyzed by cold vapor atomic absorbence spectroscopy (CVAAS) (Laudal, et al 1996). The approximate cycle time for the instrument is about one minute per sample. Data from the MERCEM analyzer (both inlet and outlet) was compared with analyses from manual samples (iodated carbon traps coupled with isokinetic ash collection at the inlet) to determine the resolution and accuracy of analyzer data for use in test definition and scheduling.

The MERCEM analyzer was installed in the pilot facility operations trailer, since it required a controlled environment for proper operation. Heated sample lines were routed to the analyzer to allow the extraction of gas samples from both the inlet and outlet mercury sampling locations. The output of the MERCEM was connected to a data logger to facilitate electronic 
acquisition and storage of results. The sampling system was configured to alternately acquire samples from the inlet and outlet.

Initial tests with the MERCEM instrument showed poor agreement with iodated carbon trap samples. The instrument was checked per the user's manual, but performance did not improve. In an effort to move the instrument to operational status, ADA contracted with PerkinElmer to send a factory-trained technician to the site. Several days were spent in maintenance and a series of checkout and performance tests. Upon departure, the instrument appeared to be in working order, however, data errors quickly returned. This pattern was repeated once more, at which time it became obvious that the MERCEM unit could not provide the needed resolution for gas samples containing fly ash; that is, samples extracted from the inlet sampling location upstream of the pilot particulate control module. It was discovered that the MERCEM provided reasonable data when making measurements on a clean gas stream, either at the outlet of the pilot (downstream of the particulate control module) or when the pilot was operated on flue gas extracted downstream of the Comanche Unit 2 baghouse. The MERCEM was thus available only for a limited amount of testing in Phase II. 


\section{Results and Discussion}

There were several activities performed in this project, each of which supported different objectives. Extensive testing was performed in the mercury removal pilot plant, where activated carbon and fly ash sorbents were tested in an extensive series of cases reflecting different hardware configurations and flue gas conditions. Measurements of mercury removal were made at five PSCo full-scale generating units to characterize the performance of existing particulate control systems in capturing mercury from coal-fired flue gas. Laboratory tests were undertaken to understand the impact on disposal options of the addition of activated carbon to collected fly ash. And finally, an economic model was developed to predict the cost of mercury removal from coal-fired power plants using data acquired in the pilot plant testing. Results of each of these activities are discussed in detail in the following sections of this report.

\subsection{Pilot testing}

Testing was performed in the pilot facility at Comanche station from April of 1998 through June of 1999. Approximately 170 individual test cases were evaluated, comprising four different hardware configurations, a range of flue gas temperatures, and the injection of activated carbon as well as fly ash sorbents at different injection ratios. For each hardware configuration, a series of baseline tests were run to determine the mercury removal by the native fly ash before the start of testing to evaluate the use of activated carbon as a mercury sorbent. Results are summarized below for each of the hardware configurations in addition to the baseline testing.

\section{Mercury Removal by Native Fly Ash ("Baseline" Tests)}

Mercury removal across the pilot without any carbon injection was tested to obtain a baseline for mercury removal by the native (resident) fly ash at several different temperatures for three particulate control module configurations. There was no baseline data taken for the TOXECON configuration, because flue gas for the TOXECON tests was extracted downstream of the Unit 2 reverse-gas baghouse, and contained virtually no particulate matter. Baseline test results for the reverse-gas baghouse pilot are reported in Figure 4-1. There is a definite trend with temperature (i.e., higher removal rates at lower temperatures), although some variability is seen in the data. This trend was common to all the PCM configurations. For example, at $230^{\circ} \mathrm{F}$ (all tests at this temperature included spray cooling), the ESP configuration showed 53\% to $61 \%$ mercury removal, while the reverse-gas baghouse showed $72-79 \%$ removal. At $280^{\circ} \mathrm{F}$, the ESP showed 10-39\% (average 26\%) control, while the baghouses showed 34-78\% (average 66\%) control at this temperature. Higher temperature tests fall within broader ranges. At $330-350^{\circ} \mathrm{F}$ 
mercury removal is generally below $20 \%$, with the exception of a few pulse-jet tests that showed higher removal rates.



Flue Gas Temperature $\left({ }^{\circ} \mathrm{F}\right)$

\section{Figure 4-1. Baseline Mercury Removal for Pilot in Reverse-Gas Baghouse Configuration}

\section{Mercury Removal with Carbon Injection}

Norit Darco FGD ${ }^{\mathrm{TM}}$ was the activated carbon used for all carbon injection tests. This material has proven to be an effective mercury sorbent in the laboratory and in prior field tests in flue gas applications. Tests were run to evaluate sorbent performance over a range of flue gas temperatures, activated carbon injection rates, and PCM configurations. Mercury removal efficiency results are plotted as a function of carbon concentration in the flue gas. The mercury removal efficiency at a specific carbon concentration is relatively insensitive to inlet mercury concentration over the range of four to thirteen $\mu \mathrm{g} / \mathrm{Nm}^{3} @ 3 \% \mathrm{O}_{2}$ measured in the Comanche flue gas extracted for these tests. The activated carbon injection rate is expressed as carbon concentration in the flue gas, in pounds per million actual cubic feet of flue gas (lb/MMacf).

Mercury capture by an injected sorbent depends on the adsorption equilibria (sorbent capacity) and mass transfer to the sorbent surface. The carbon capacity and reactivity are strongly dependent on temperature and mercury concentration. Thus, when the temperature is too high or the mercury concentrations are too low, overall removal will be governed by the sorbent's limited capacity. Mass-transfer-limited conditions normally apply when the carbon has 
sufficient capacity and reactivity. Under mass-transfer-limited conditions, the vapor-phase mercury removal efficiency is dependent on the distance between carbon particles (i.e., the carbon concentration) and contact time rather than the mercury concentration. Either case may hold for coal-fired flue gas depending on the flue gas temperature. Typically, at lower temperature mass transfer limits the removal rate, while at higher temperatures the lack of sorbent capacity dominates.

\section{ESP Configuration}

Carbon injection testing in the ESP configuration took place across the same target temperature range as baseline tests. Figure 4-2 presents a summary graph of the results of all carbon injection ESP tests. The activated carbon was injected at a location to allow 0.5 or 1.0 second contact time before entering the ESP particle collector, with the majority of tests conducted at 1.0 second contact time. Inlet flue gas mercury concentrations for the ESP tests ranged from 4 to $13 \mu \mathrm{g} / \mathrm{Nm}^{3} @ 3 \% \mathrm{O}_{2}$.

The ESP particulate control configuration offered the poorest performance of the configurations tested in the pilot facility; even at the highest carbon injection rates, mercury removal did not rise above $70 \%$. At $228^{\circ} \mathrm{F}$ with spray cooling, the injection of activated carbon sorbent results in no additional removal of mercury in comparison with baseline data. This is likely due to the fact that the baseline removal by the native fly ash was significant at the cool flue gas temperature. At higher temperatures, however, carbon injection does increase the mercury removal, and the removal increases with injection rate. For example, at typical flue gas temperatures from $280-312^{\circ} \mathrm{F}$, increasing the carbon concentration from $0.5 \mathrm{lb} / \mathrm{MMacf}$ to 4.5 $\mathrm{lb} / \mathrm{MMacf}$ resulted in a rise in the mercury removal rate from around $30 \%$ to over $60 \%$.

Sorbent contact time with the gas stream was reduced from 1.0 second to 0.5 second under two conditions; one at existing flue gas temperature, and a second for a heated flue gas stream. No significant effect of contact time was seen in triplicate tests for these two conditions. The highest temperature tests $\left(340-350^{\circ} \mathrm{F}\right.$, in the ESP) showed slightly lower mercury removals than the lower temperatures, for the same carbon-injection concentration. This is seen in comparing mercury removal of $53 \%$ at $340-350^{\circ} \mathrm{F}$ with over $60 \%$ removal for all tests at lower temperatures and similar carbon concentrations.

It must be noted that the ESP configuration employed in the pilot facility was a wire and tube design, which is more appropriate for this size. However, operational problems were 
encountered with fly ash from the Powder River Basin coal burned at Comanche Station. An ESP does not collect this fly ash efficiently, which is the primary reason that the plant's fullscale generating units use reverse-gas baghouses for particulate control. Average particle collection efficiency for the ESP was only $92 \%$, and it was difficult to maintain stable operating conditions during mercury removal testing.

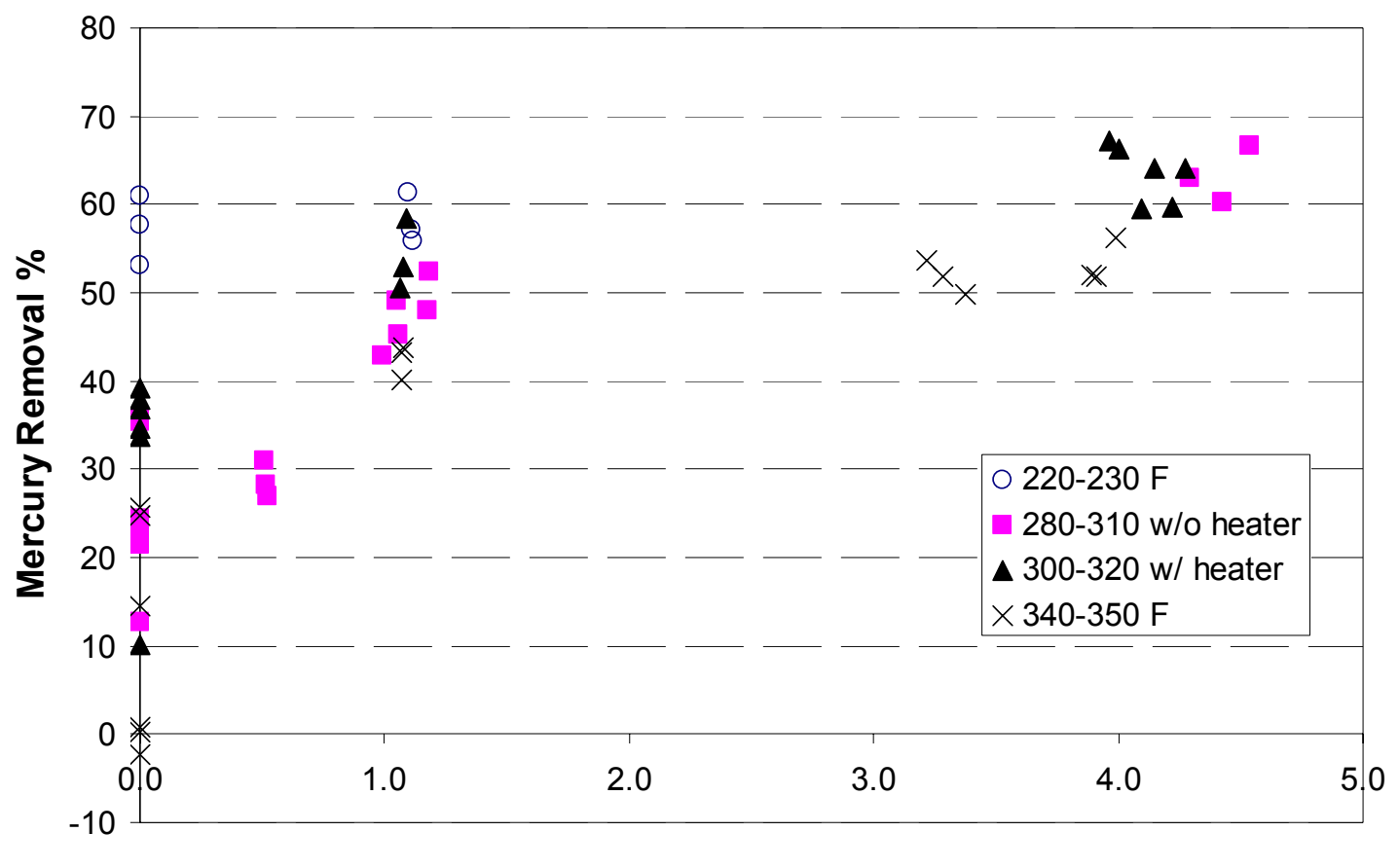

Carbon Concentration, Ib/MMacf

Figure 4-2. Effect of Carbon Injection Rate on Mercury Removal in Pilot with ESP

\section{Pulse-Jet Configuration}

Tests of carbon injection for mercury removal in the pulse-jet baghouse configuration for the pilot were run at nine different test conditions, with multiple mercury samples taken at most conditions. Inlet mercury concentration in the slipstream flue gas ranged from 6.5 to 10.9 $\mu \mathrm{g} / \mathrm{Nm}^{3}$. The mercury removal results are presented in Figure 4-3 as a function of the carbon sorbent concentration in the flue gas stream. One factor to note immediately is the higher baseline (no carbon injection) mercury removal provided by the native fly ash in the pulse-jet baghouse configuration of the pilot facility. Phase I testing had indicated that mercury removal rates higher than the ESP configuration were expected in the pulse-jet tests, so no tests with spray cooling were run in this series. Instead, two levels of heating were evaluated to explore the decrease in sorbent performance as a function of increasing temperature. 


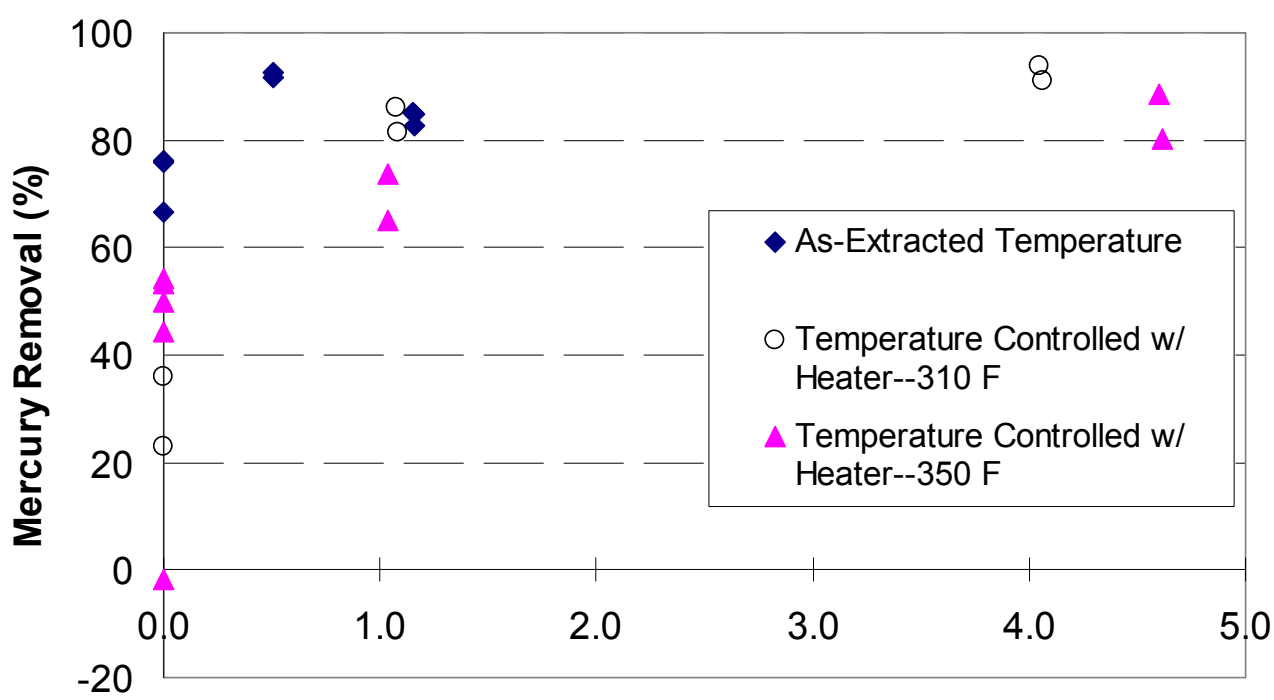

Carbon Concentration (Ib/MMacf)

Figure 4-3. Effect of Carbon Injection Rate on Mercury Removal in Pilot with Pulse-Jet Baghouse

Trends in the pulse-jet tests followed those observed in the ESP testing - increased carbon injection rates resulted in improved mercury removal, and the efficiency of mercury removal by carbon injection decreased with increasing flue gas temperature. However, the pulse-jet is seen to provide much higher mercury removal rates at fixed injection ratios of activated carbon in comparison with the ESP results. Normal duct temperature tests were conducted at flue gas temperatures between $280^{\circ}$ and $285^{\circ} \mathrm{F}$ (as-extracted from the plant duct). Carbon concentrations of 0.5 and $1.1 \mathrm{lb} / \mathrm{MMacf}$ were tested in this temperature range. Both of these carbon concentrations resulted in an increase in the removal of mercury from the flue gas, as compared with baseline tests. The $0.5 \mathrm{lb} /$ MMacf rate actually demonstrated higher removal than the $1.1 \mathrm{lb} / \mathrm{MMacf}$ rate, although both were well above $80 \%$. In fact, the high removal rates at $0.5 \mathrm{lb} /$ MMacf can be explained upon closer examination of the test data. For these two test cases, the mercury present in the flue gas was partitioned very heavily to the particulate phase, deposited on the fly ash. The vapor-phase component of the inlet mercury was only about 10$20 \%$ of the total. The fly ash is almost completely removed in the pulse-jet baghouse, and only the vapor-phase component is measured at the downstream location. This partitioning guarantees that the removal rates measured for these tests will be very high.

The higher-temperature data reflected the common trend of reduced mercury removal with increased temperature. The data also show that increasing the carbon concentration in the flue gas stream increases the rate of mercury removal. For carbon concentrations greater than 4 
$\mathrm{lb} /$ MMacf, a mercury removal rate greater than $80 \%$ was achieved for both the $310^{\circ}$ and $350^{\circ} \mathrm{F}$ flue gas temperatures. For an $80 \%$ mercury removal target, a mercury removal system could be operated by injecting $\sim 4 \mathrm{lb} /$ MMacf activated carbon or by cooling the flue gas to below $310^{\circ} \mathrm{F}$ and injecting $\sim 1 \mathrm{lb} / \mathrm{MMacf}$ carbon.

\section{Reverse-Gas Configuration}

In the reverse-gas baghouse configuration, the tested flue gas temperatures were asextracted $\left(270^{\circ}-280^{\circ} \mathrm{F}\right)$, heated $\left(330^{\circ}-340^{\circ} \mathrm{F}\right)$, and spray-cooled $\left(220^{\circ}-232^{\circ} \mathrm{F}\right)$. The conditions for the spray-cooling tests differed somewhat from those seen during the ESP spray-cooling tests. During ESP testing, the as-extracted inlet gas temperatures were high, $\sim 320^{\circ} \mathrm{F}$ and required injection of fine water mist at approximately 0.2 gallons per minute (gpm) to reach the target temperature of $230^{\circ} \mathrm{F}$. For the reverse gas testing, inlet temperatures during spray cooling were well below $270^{\circ} \mathrm{F}$, and required water mist injection of only $0.06 \mathrm{gpm}$. This difference in the flue gas temperature is a function of ambient air temperature; the two tests were conducted in summer and winter, respectively. Flue gas temperatures for the cooled gas streams in both configurations were comparable, however moisture content of the cooled flue gas was not. Limited research on the effect of moisture on mercury sorption by activated carbon sorbents has indicated that increased moisture reduces the efficiency of mercury removal in laboratory experiments (Liu, et. al., 2000). High moisture content is well known to be detrimental to carbon capacity in applications involving the capture of organic compounds. The possibly lower mercury removal rate at $230^{\circ} \mathrm{F}$ compared to the as-extracted $270^{\circ}-280^{\circ} \mathrm{F}$ rate may indicate that the moisture effect offset the anticipated gains from dropping the gas temperature.

In the reverse-gas configuration for the pilot, nine different test conditions were run with multiple samples taken for each test condition. Activated carbon injection rates varied from 0.6 to $4.3 \mathrm{lb} /$ MMacf. Measured inlet mercury concentrations in the slipstream flue gas ranged from 4.6 to $10.6 \mu \mathrm{g} / \mathrm{dNm}^{3}$. Test results are graphed on Figure $4-4$ as a function of the carbon sorbent concentration in the flue gas stream.

Trends in the reverse-gas configuration followed those of other configurations with respect to flue gas temperature. Spray-cooling of the flue gas resulted in mercury removal by the native fly ash (without activated carbon) comparable to carbon injection of about one lb/MMacf at the typical flue gas temperature $(70-80 \%$ removal). These spray cool results were similar to those seen with the ESP configuration. Mercury removal rates at the heated flue gas condition $\left(\sim 330^{\circ} \mathrm{F}\right)$ were found to be slightly below values measured at natural temperatures, $78 \%$ mercury 
removal for the heated gas condition vs. 91\% removal for the natural flue gas temperature at a carbon injection ratio of around $4 \mathrm{lb} / \mathrm{MMacf}$. Activated carbon injection at a low ratio (1 $\mathrm{lb} / \mathrm{MMacf}$ or less) resulted in fairly high mercury removal efficiencies in this pilot configuration, from $\sim 74 \%$ removal at $330^{\circ} \mathrm{F}$ to $\sim 85 \%$ at $275^{\circ} \mathrm{F}$. In general, the baghouses demonstrated more efficient mercury removal with activated carbon injection than did the ESP configuration of the pilot. This improved performance is attributed to the intimate contact with the activated carbon that occurs as the flue gas passes through the filter cake on the bag surfaces, in which the activated carbon has been captured from the flue gas.



\section{Figure 4-4 Effect of Carbon Injection Rate on Mercury Removal in Pilot with Reverse-Gas Baghouse}

\section{TOXECON Configuration}

The particulate control module of the pilot was refitted to the TOXECON configuration, where a pulse jet baghouse is operated at a high air to cloth ratio to remove injected sorbent from a flue gas stream. The unit ran well when operated on clean gas with intermittent carbon injection (injection for $\sim 1$ hour, followed by a 1-hour period of no injection), but did not perform well during a test with long term carbon injection (injection for $\sim 1$ week). After the long-term operating problems were encountered, the air to cloth $(\mathrm{A} / \mathrm{C})$ ratio at which the pulse-jet baghouse 
was operated was reduced to $12 \mathrm{ft} /$ minute by decreasing the flue gas flow through the pilot to $471 \mathrm{acfm}$. The long-term carbon injection test was repeated after the operating parameters were changed.

Testing was delayed on two separate occasions due to problems with the mercury doper. Process upsets in the mercury doper caused injection of high levels of mercury into the pilot ducting system $\left(>100 \mu \mathrm{g} / \mathrm{nm}^{3}\right)$ as recorded by the MERCEM analyzer. The problem was traced to a cold spot which caused mercury to condense within the injection system. After sufficient build up, the condensed liquid-phase mercury was blown into the pilot ducting and onto the duct surfaces where it would slowly evaporate, yielding high levels of mercury vapor in the flue gas. Once isolated and identified, this problem was easily corrected.

\section{Carbon Injection in TOXECON.}

Activated carbon (AC) injection testing was conducted with the pilot operating in "clean gas" mode and doped with elemental mercury, as the standard operating condition for TOXECON is downstream of a primary particulate control device. Figure 4-5 presents the TOXECON mercury removal results. Since baseline data was collected without ash or sorbent, the expected mercury removal efficiency would be $0 \%$. The test at $330^{\circ} \mathrm{F}$ with low $\mathrm{AC}$ injection rate $(0.15 \mathrm{lbs} / \mathrm{MMacf})$ had only one data point due to an error in the duplicate test. This rate was chosen as the lowest stable setting for the material feeder, and was included because previous testing at $0.50 \mathrm{lbs} / \mathrm{MMacf}$ produced very high removals in the TOXECON mode. High vaporphase mercury removal rates $(\sim 77-95 \%)$ were seen again at an $\mathrm{AC}$ injection rate of 0.50 $\mathrm{lbs} /$ MMacf with a flue gas temperature of $\sim 280^{\circ} \mathrm{F}$. With the flue gas temperature increased to $\sim 330^{\circ} \mathrm{F}$, a carbon injection rate of approximately $1.0 \mathrm{lb} / \mathrm{MMacf}$ was needed to achieve mercury removal rates comparable to that for a flue gas temperature of $280^{\circ} \mathrm{F}$, in the range of $75-95 \%$. 


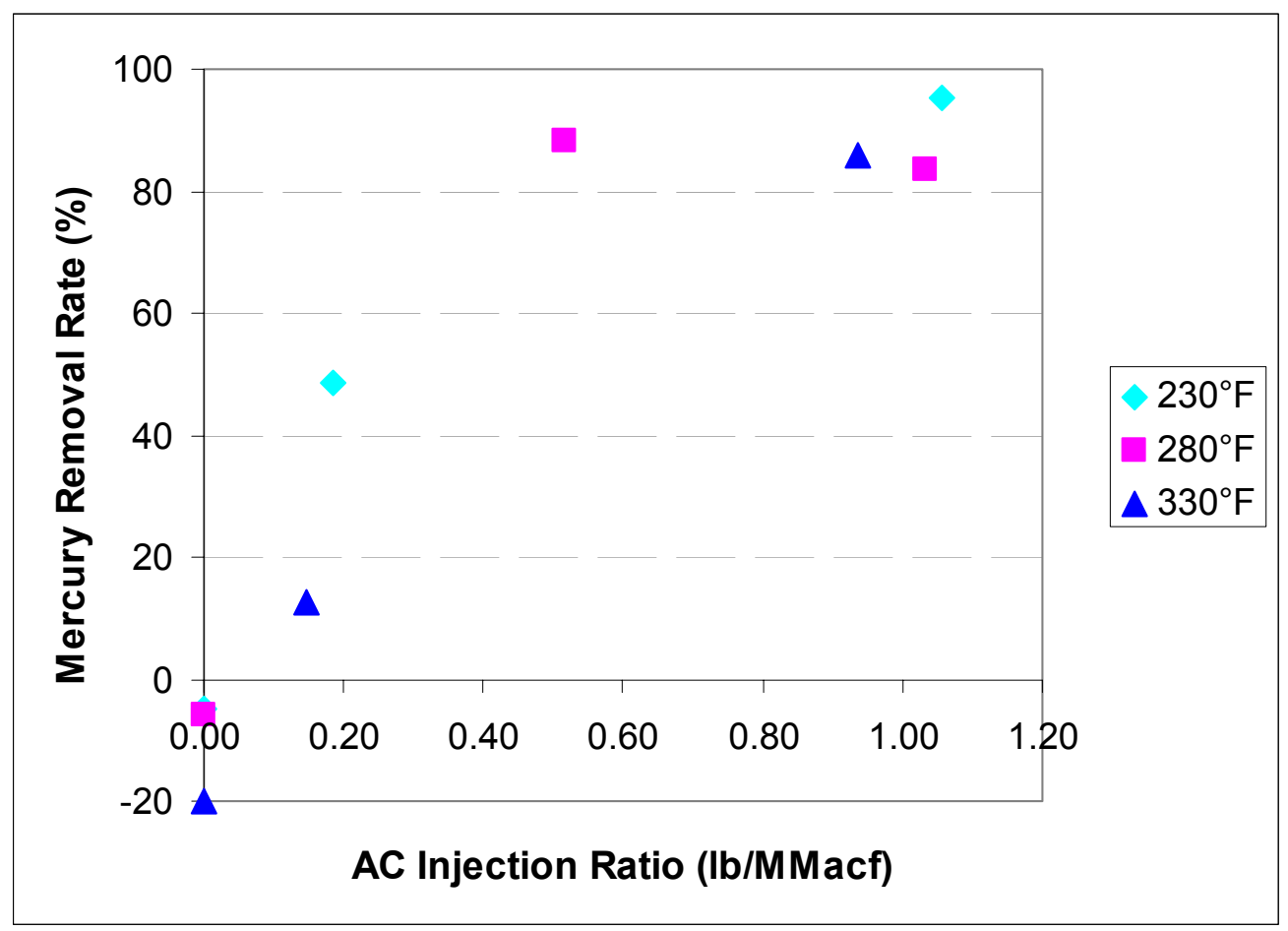

Figure 4-5. Mercury removal in the TOXECON mode.

\section{Long Term Carbon Injection.}

In order to determine the operational impact of carbon injection on the TOXECON baghouse and to assess mercury removal over a longer injection period, an extended test of activated carbon injection was performed. The test protocol called for carbon to be injected into the system for 5 days at a ratio of $1 \mathrm{lb} / \mathrm{MMacf}$ with the baghouse set to clean when the tubesheet differential pressure exceeded 5" $\mathrm{H}_{2} \mathrm{O}$. After completion of the long-term test, all injected carbon was recovered for later testing of reinjection to evaluate the ability of recycled activated carbon to adsorb additional mercury.

The first long-term carbon injection test experienced bag-blinding problems. After three days of carbon injection, the unit was in a nearly-constant clean cycle as illustrated by Figure 46. The high $\mathrm{A} / \mathrm{C}$ ratio $(16 \mathrm{ft} / \mathrm{min}$ ) and associated face velocity at which this test was run appeared to have embedded the carbon into the fiber matrix of the fabric. Further evidence of this is the increase in "post-clean" differential pressure as test time accumulated. The post-clean differential was seen as the low point in the oscillating pressure drop trace in Figure 4-6, which started at about 2.5 inches and increased to 4 inches by the time that the baghouse was in a state of continuous clean. Cleaning frequency is seen in the figure as the rate of saw-tooth oscillation 
in the differential pressure trace. The clean trigger condition was increased to 7" $\mathrm{H}_{2} \mathrm{O}$ for a day and a half, although this did little to improve the performance of the unit. The $\mathrm{A} / \mathrm{C}$ was lowered to $10 \mathrm{ft} / \mathrm{min}$ for the final day of the test, which also had little positive effect. The operational changes were made in attempts to promote more effective cleaning of the bags. The original bags did not respond to repeated off-line cleaning cycles due to severe blinding and therefore were replaced with new bags. The new bags were pre-coated with Neutralite before testing resumed. This precoat treatment is common industry practice to reduce the potential for blinding of filter bags.



Figure 4-6. Long Term Carbon Injection Test Results

The long-term injection test was repeated at a later date. The $\mathrm{A} / \mathrm{C}$ ratio for the retest was set at $12 \mathrm{ft} / \mathrm{min}$ based on work conducted during Phase 1 of the project. The clean-initiate differential pressure was set to 7" $\mathrm{H}_{2} \mathrm{O}$. Figure 4-7 presents performance data for the repeated long-term carbon injection test. With the new bags, cleaning was consistent throughout the course of testing. During the final day, cleans took place on a 2 hour-40 min interval, and cleaned down to 2.5 " tubesheet differential. A post-clean differential of less than 3 " $\mathrm{H}_{2} \mathrm{O}$ is generally considered to indicate adequate removal of collected particulate matter from the bags. Baseline operation was maintained for more than a week after the long term test and showed that without carbon injection, the tubesheet differential increased by only $1 / 2$ " in eight days. This indicated that the bags were not blinded as in the initial long-term test. 




Figure 4-7. Long Term Carbon Injection, Repeated Test.

During the second long-term carbon injection test, continuous mercury measurements were made with the MERCEM instrument switched between inlet and outlet, with results as shown in Figure 4-8. For this test the average mercury removal rate during the final two days was 70\%. IC trap samples were not taken during either of the long-term carbon injection tests. This mercury removal rate compares to $83 \%$ removal under similar flue gas conditions (as measured with IC traps) during earlier carbon injection testing in the TOXECON configuration (see Figure 4-5).

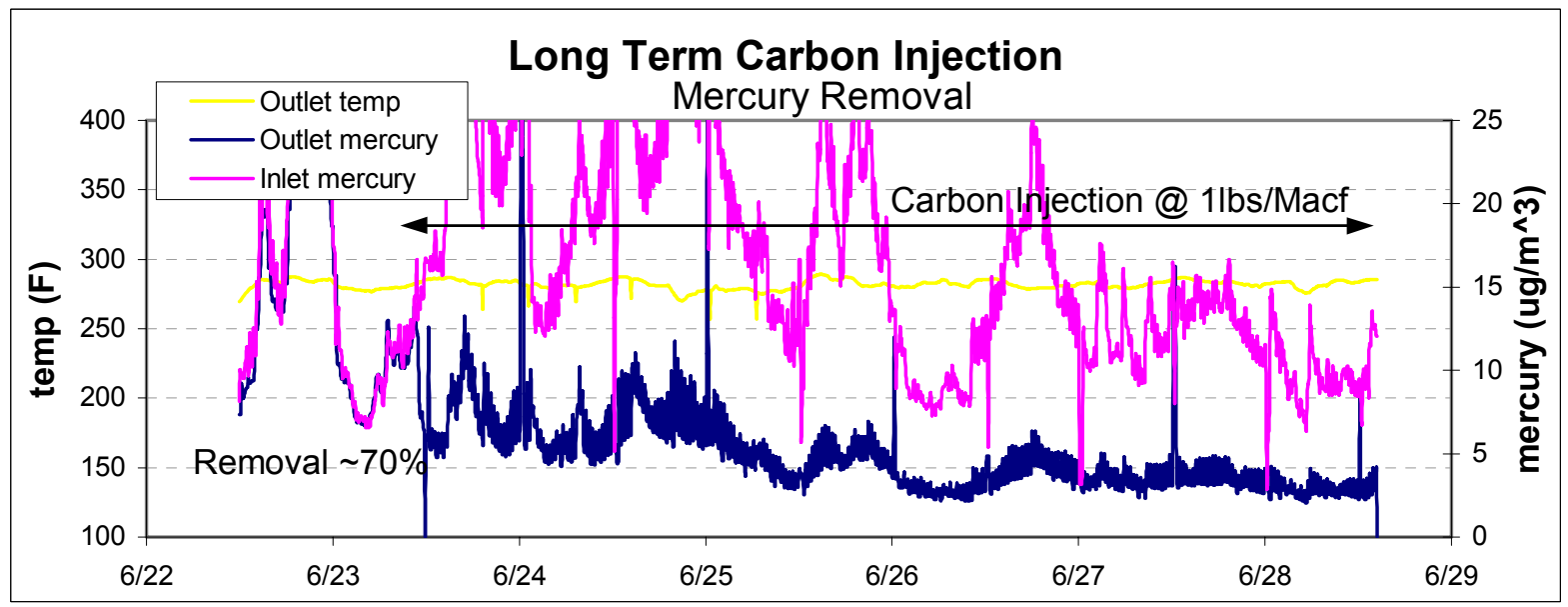

Figure 4-8. Mercury Removal during Long Term Carbon Injection. 


\section{Sorbent Recycling.}

Many sorbent injection systems re-inject a portion of recovered sorbent back into the system to increase utilization rates. To evaluate this technique for use with carbon, sorbent from the original long-term injection test was accumulated by retaining in the baghouse hopper the carbon released from the bags during cleaning, rather than returning it to the host duct. The collected material should have consisted primarily of the activated carbon injected during the test, since the TOXECON pilot draws flue gas from downstream of the host reverse gas baghouse (i.e. flue gas without the presence of fly ash). Visual inspection determined that the collected material seemed to be mostly fly ash. It was originally thought that the ash in the sample must have fallen off ductwork, or come from some other sources in the pilot, but subsequent attempts to collect a more representative high-carbon sample met with little success. A quick calculation shows that if the Unit 2 reverse-gas baghouse operates with a 99.5\% collection efficiency, the ash loading in the gas to the TOXECON pilot would be about equal to the carbon loading at $1 \mathrm{lb} /$ MMacf. This indicates that the relative amounts of fly ash and carbon are dependent on the capture efficiency of the plant baghouse. Another possible mechanism that could impact the amount of fly ash collected in the TOXECON unit is that a layer of activated carbon, which is comprised of small, light particles, may increase the filtering efficiency of the TOXECON bags. Method 17 testing (for particulate loading) was not performed on the pilot unit while in the TOXECON mode, thus a value for particle loading is not available. Figure 4-9 shows pilot performance over several days of operation without sorbent injection. In eight days, the pressure drop across the baghouse increased a mere $1 / 2 " \mathrm{H}_{2} \mathrm{O}$ due to the minimal ash content of the flue gas downstream of the Unit 2 baghouse. This suggested that the particulate found in the flue gas is the extremely small-size particulate matter that penetrated the host RG baghouse and was collected by the TOXECON pilot only when a layer of carbon already coated the bags. The periodic downward spikes in the flow trace were artifacts generated during blowback of the flow measurement venturi taps to keep them free of particulate matter. 


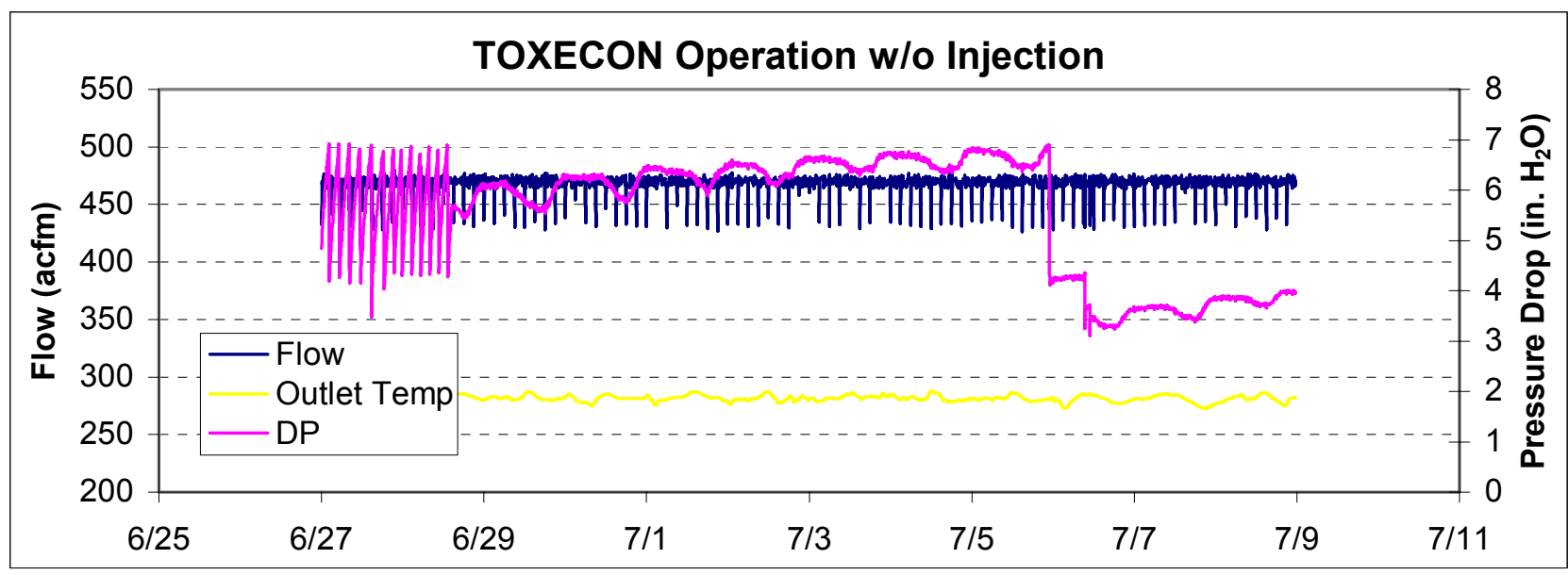

Figure 4-9. Baseline Operation, TOXECON Configuration.

As noted previously, visual inspection of the material collected from the first long-term carbon injection test suggested that it consisted mostly of fly ash. This was confirmed when ADA performed an LOI analysis of a sample which yielded a value of only $8 \%$ for the material. Three more attempts were made to collect a "mostly carbon" sample from the pilot hoppers. The unit was operated as mentioned previously. The pilot was allowed to operate over a 3-5 day period with carbon being injected into the system at a rate of $\sim 1 \mathrm{lb} / \mathrm{MMacf}$. At the end of the operational period, the baghouse was manually cleaned several times. However, after attempts to gather a high carbon sample, it was observed (and later confirmed by ADA LOI analysis) that the material was mostly ash. The highest LOI material from the four samples collected was chosen for reinjection. The material used for reinjection had an LOI of 11\%. Samples of activated carbon have been analyzed in the past with typical LOI values of $68.5 \%$. This suggested that nominally $16 \%$ of the reinjected material was activated carbon, the balance being collected ash.

Figure 4-10 shows results from a test of the reinjection of recycled sorbent (approximately 16\% activated carbon / 84\% Comanche ash). No appreciable removal of mercury was detected, possibly due to the low concentration of activated carbon in the sample. Earlier tests had shown that reinjected Comanche fly ash only yielded $\sim 13 \%$ mercury removal efficiency. The purpose of recycling the collected material from the long-term injection test was to evaluate the ability of recovered carbon to remove additional mercury under field operating conditions. Unfortunately, due to the difficulty in collecting a high-carbon concentrated material from the TOXECON baghouse hoppers, this test was inconclusive. 


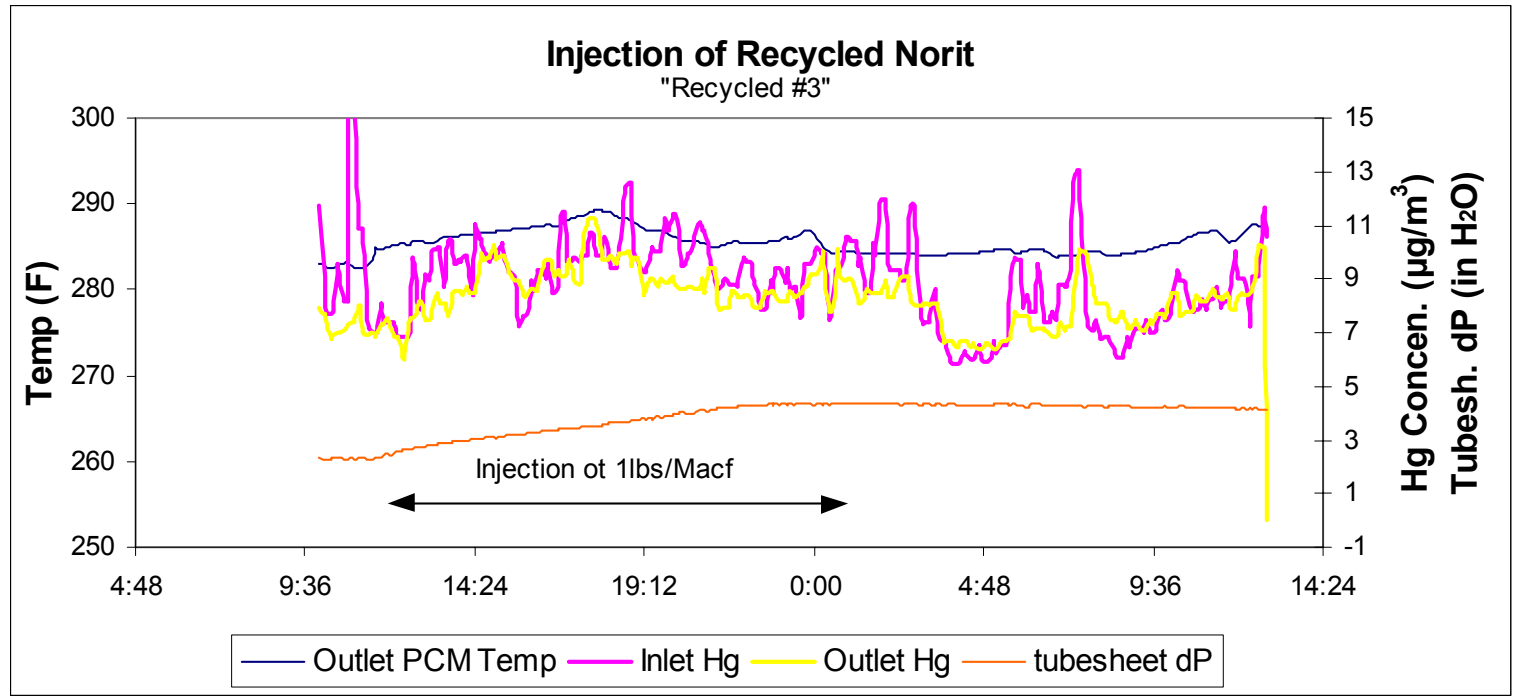

Figure 4-10. Injection of Recycled Norit.

\section{Intermittent Carbon Injection.}

A test was performed to gauge the effectiveness of intermittent carbon injection for mercury removal in the TOXECON configuration. This test was conducted to measure the residual removal due to carbon left on the bags after injection was stopped. By exploiting this effect, sorbent consumption would be reduced. Carbon was injected at $0.5 \mathrm{lbs} / \mathrm{MMacf}$ for one hour. During injection, mercury removal efficiency reached a high of $30 \%$. After the carbon injection stopped, the pilot was allowed to continue to operate with mercury removal efficiencies being recorded by the MERCEM analyzer. As shown on Figure 4-11, within one hour after the carbon injection was halted, outlet mercury levels had climbed back to inlet levels, signaling the saturation and/or inactivation of the sorbent. 


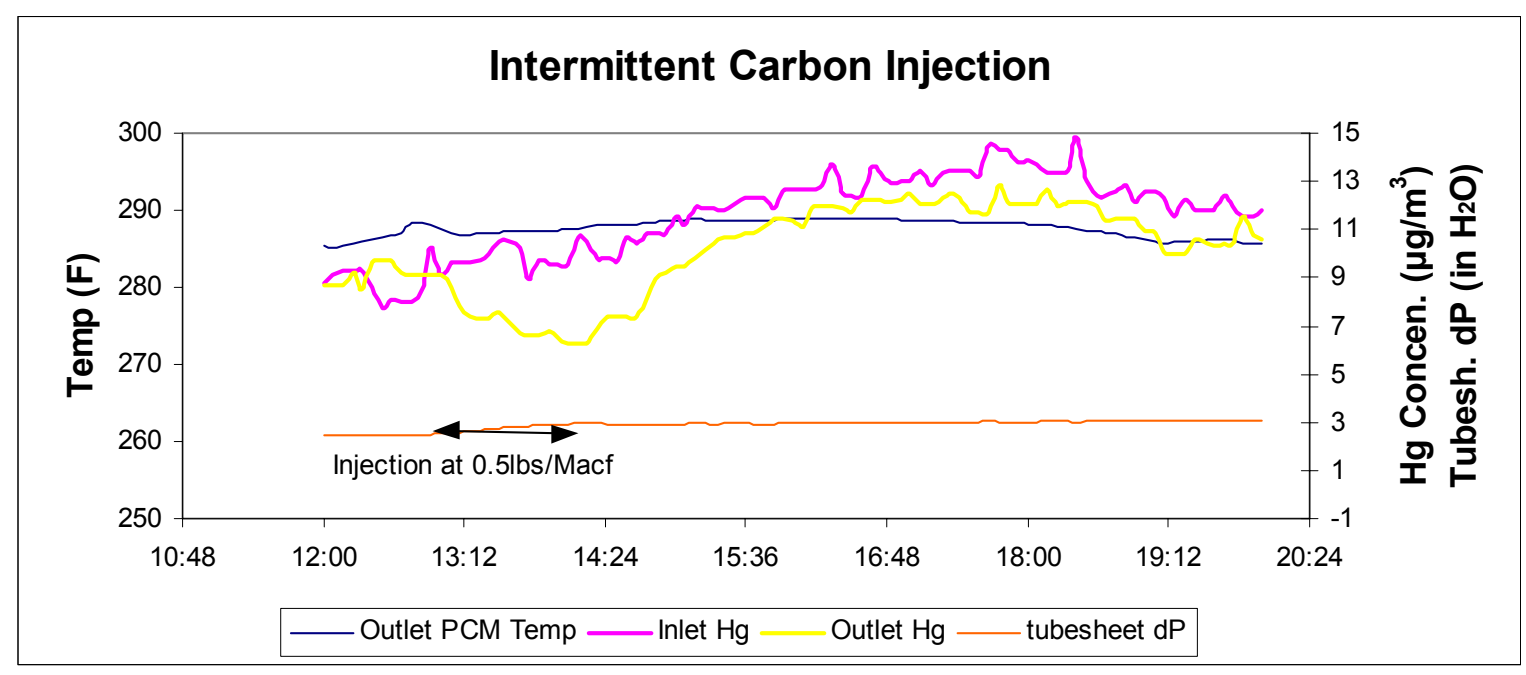

Figure 4-11. Intermittent Carbon Injection.

\section{Spray Cooling in TOXECON.}

Carbon injection in the TOXECON configuration was conducted with spray cooling to determine mercury removal rates at low flue gas temperatures. The target gas temperature was $230^{\circ} \mathrm{F}$. Due to warm ambient temperatures and high unit load, the required water injection rate to maintain a flue gas temperature of $230^{\circ} \mathrm{F}$ was higher during TOXECON testing than during reverse-gas testing. TOXECON cooling to the target temperature required 0.36 gallons per minute and resulted in a flue gas moisture content of $15.2 \%$. Reverse-gas cooling required only $0.07 \mathrm{gpm}$ and resulted in a flue gas moisture of $11.4 \%$. The average flue gas moisture for the fifteen tests prior to reverse gas spray cooling was $10.7 \%$. Research has shown that increased moisture content of flue gas has a negative impact on sorption efficiency of activated carbons.

Spray cooling testing completed earlier in both reverse-gas and ESP configurations resulted in high mercury removal at baseline conditions (with no $\mathrm{AC}$ injection). At $230^{\circ} \mathrm{F}$, baseline ESP removals were 53-61\%, while baseline reverse-gas removals were 72-79\%. Results for TOXECON did not follow this trend. The difference in removal can be attributed to the absence of ash in the gas stream, as the TOXECON draws from downstream of the host baghouse. Figure 4-12 shows the MERCHEM and Iodated Carbon trap (IC) mercury concentration measurement results for the spray cooling tests. The plotted lines present MERCEM data taken continuously, while the shorter labeled horizontal lines indicate the sample time and analyzed mercury concentrations for the IC trap samples. As seen in the topmost graph, baseline mercury removal is essentially zero. Measured mercury removal with IC traps during 
carbon injection at $0.18 \mathrm{lbs} / \mathrm{MMacf}$ was $49 \%$. This was the lowest stable injection rate that could be achieved with current material feeding equipment. At an activated carbon injection rate of 1 lbs/MMacf, the indicated IC trap measured mercury removal was 96\%. For comparison, the reverse-gas mode mercury removal rate when the flue gas was cooled to $230^{\circ} \mathrm{F}$ was only $76 \%$ with $\mathrm{AC}$ injection at $1 \mathrm{lbs}$./MMacf.
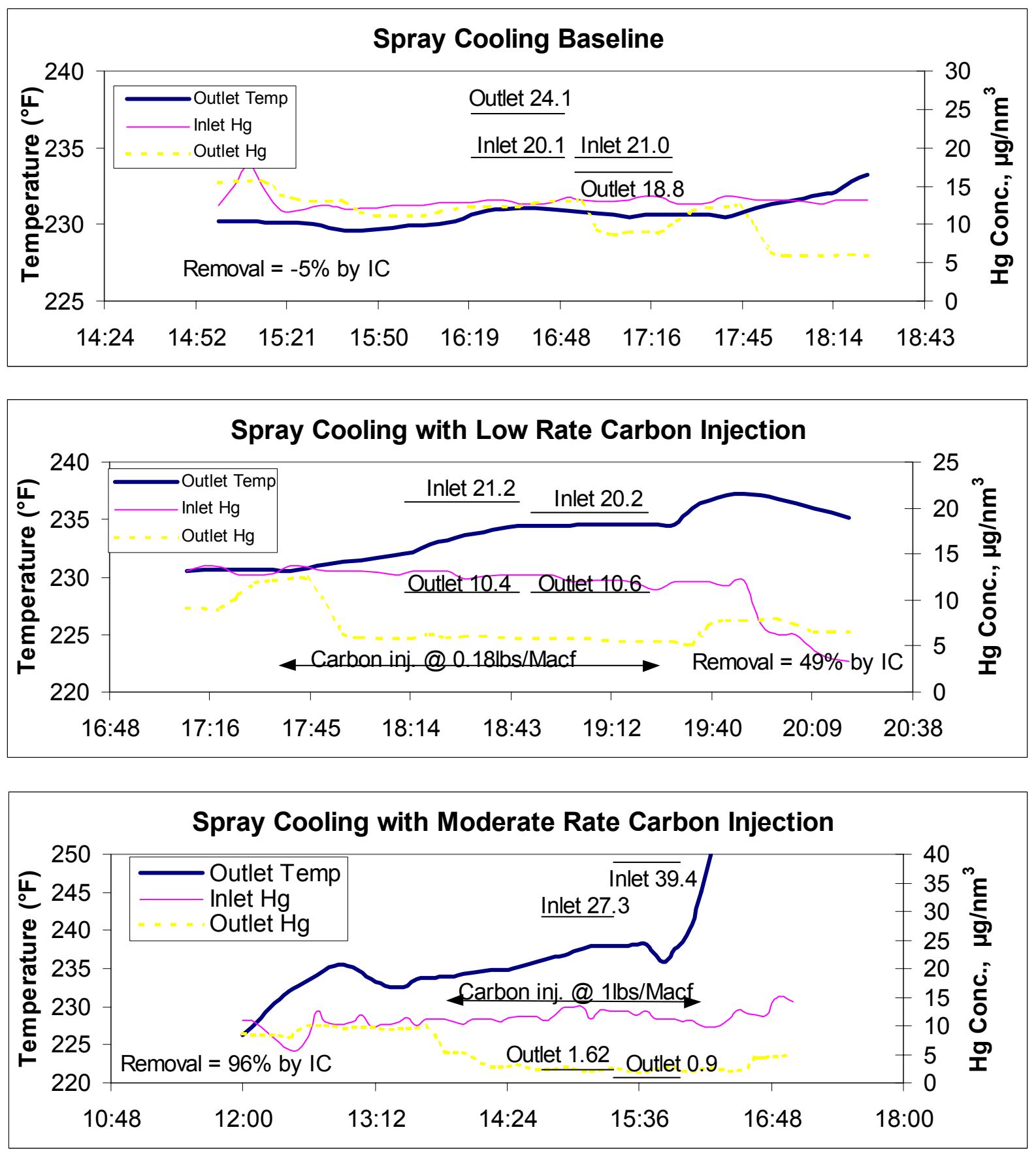

Figure 4-12. Mercury Removal Results from TOXECON with Spray Cooling 


\section{Long-Term Carbon Injection}

From December 30, 1998 to January 8, 1999 ADA performed long-term carbon injection testing. Tests were run with the pilot in the reverse-gas baghouse configuration. In all previous mercury control tests, sampling to measure mercury concentration was begun after $\sim 10$-minutes of carbon injection. These longer-term tests were designed to determine how a layer of carbon on the bags affected mercury removal. Sampling tests for mercury removal efficiency were performed when the reverse-gas baghouse exhibited 3" and 5" $\mathrm{H}_{2} \mathrm{O}$ differential pressures across the bags, after both one and five days of injection. These test conditions were intended to be representative of a case midway between cleaning cycles $\left(3\right.$ " $\left.\mathrm{H}_{2} \mathrm{O}\right)$ and just prior to initiation of a clean cycle $\left(5 " \mathrm{H}_{2} \mathrm{O}\right)$. MERCEM data plotted on Figure 4-13 indicate that a layer of carbon on the bags does not affect removal efficiency. The graph features two vertical axes: the left axis indicates the tubesheet pressure drop across the reverse-gas baghouse, and the right axis plots mercury concentration in the gas stream as measured with the MERCEM analyzer. Additionally, Figure 4-13 illustrates that the long term carbon injection did not affect the performance of the baghouse, as pressure drop operation remained consistent. As the differential pressure across the baghouse tubesheet rises from 3" to $5 " \mathrm{H}_{2} \mathrm{O}$ DP, the mercury removal due to carbon injection remains reasonably constant. There are two likely interpretations of these data: One is that sorption of mercury is mostly an in-duct phenomenon; the other is that the removal rates for these tests were so high that any effect of dustcake thickness was obscured by the typical variations seen among the test cases throughout the pilot testing. Significant quantities of the activated carbon and fly ash collected in the pilot during the longer-term test were removed from the hopper and stored. The high-carbon fraction from such a process could be reused as a sorbent, with or without treatment to remove mercury adsorbed during first-time injection.

Figure 4-14 shows the results of isokinetic flue gas sampling in the pilot using iodated carbon (IC) traps. As seen in Figure 4-14, the average mercury removal percentages for shortterm tests (10-minutes after start of injection) at a carbon injection rate of $0.5 \mathrm{lbs}$./MMacf and $4.0 \mathrm{lbs} . / \mathrm{MMacf}$ are $74 \%$ and $78 \%$ respectively. The mercury removal across the bags increases to $93 \%$ after 0.5 days with carbon injection at $5 \mathrm{lbs}$./MMacf, and to $98 \%$ after 1 day with carbon injection at $5 \mathrm{lbs}$./MMacf. Per the IC sampling results, the mercury removal efficiency increases approximately $20 \%$ when comparing measurements from 10 minutes after carbon injection is initiated to measurements taken one day after the start of continuous injection. Further analysis of each injection rate as a function of pressure drop shows that the average mercury removal efficiency remains nearly the same throughout the time between cleans of the baghouse. For an injection rate of $5 \mathrm{lbs} / \mathrm{MMacf}$ with 1 day operation, the mercury removal percentage was $\sim 98 \%$ with operation of the pilot at 3" $\mathrm{H}_{2} \mathrm{O}$ and $5 " \mathrm{H}_{2} \mathrm{O}$. For all injection points in which a data point 
was taken at both 3" and 5" DP, the mercury removal percentage remained reasonably constant. Therefore the MERCEM data appears to corroborate the IC trap data in that over the long term, mercury removal rate remains constant, and is not a function of tubesheet differential pressure, at least for the high removal rates found in the pilot testing. This indicates that sorption of mercury is either mostly an in-duct phenomenon or that the residual layer of carbon present on the bags after cleaning remains adequate for mercury removal.

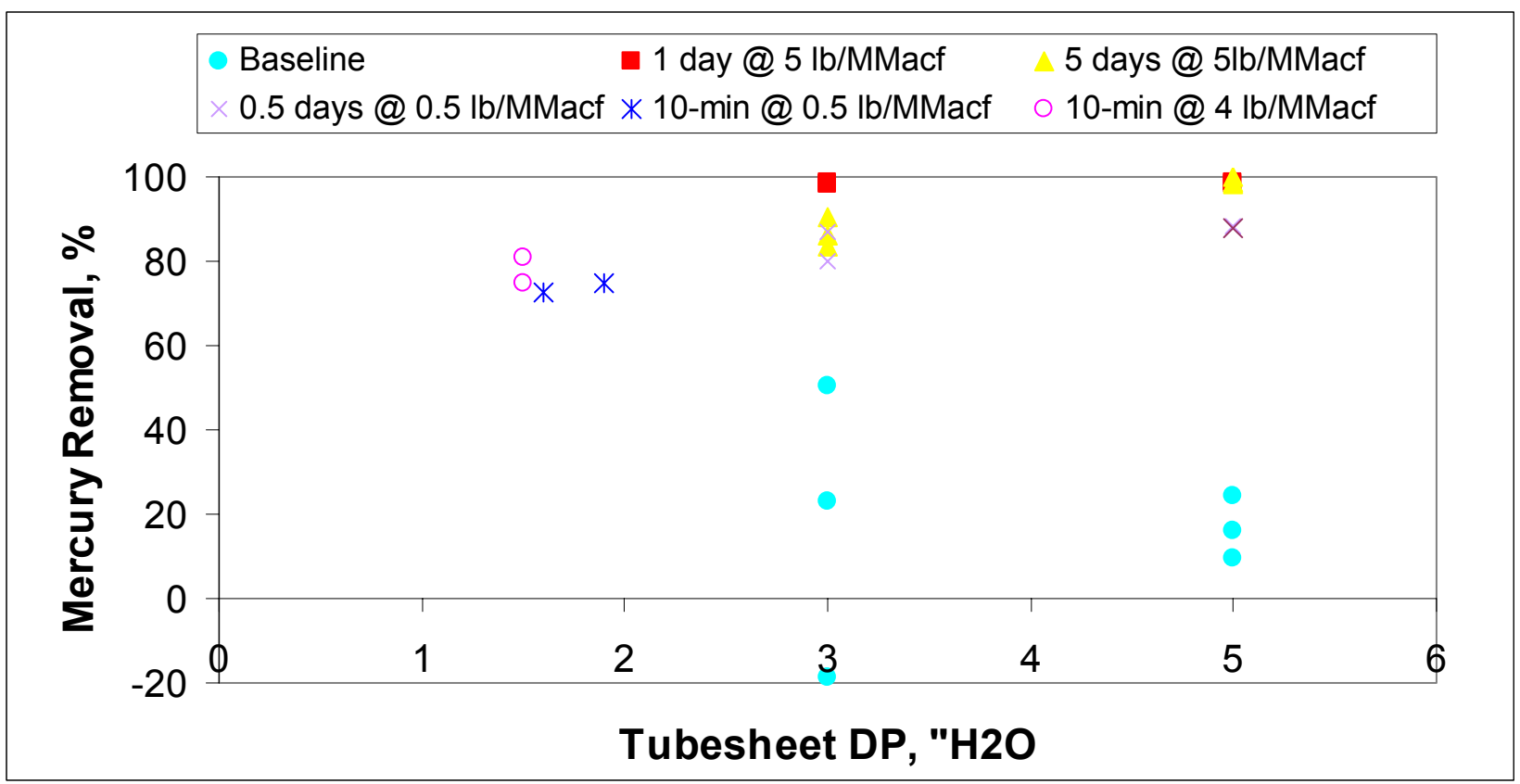

Figure 4-13: Long-term Carbon Injection MERCEM Results, Comanche Pilot - RG Configuration. 


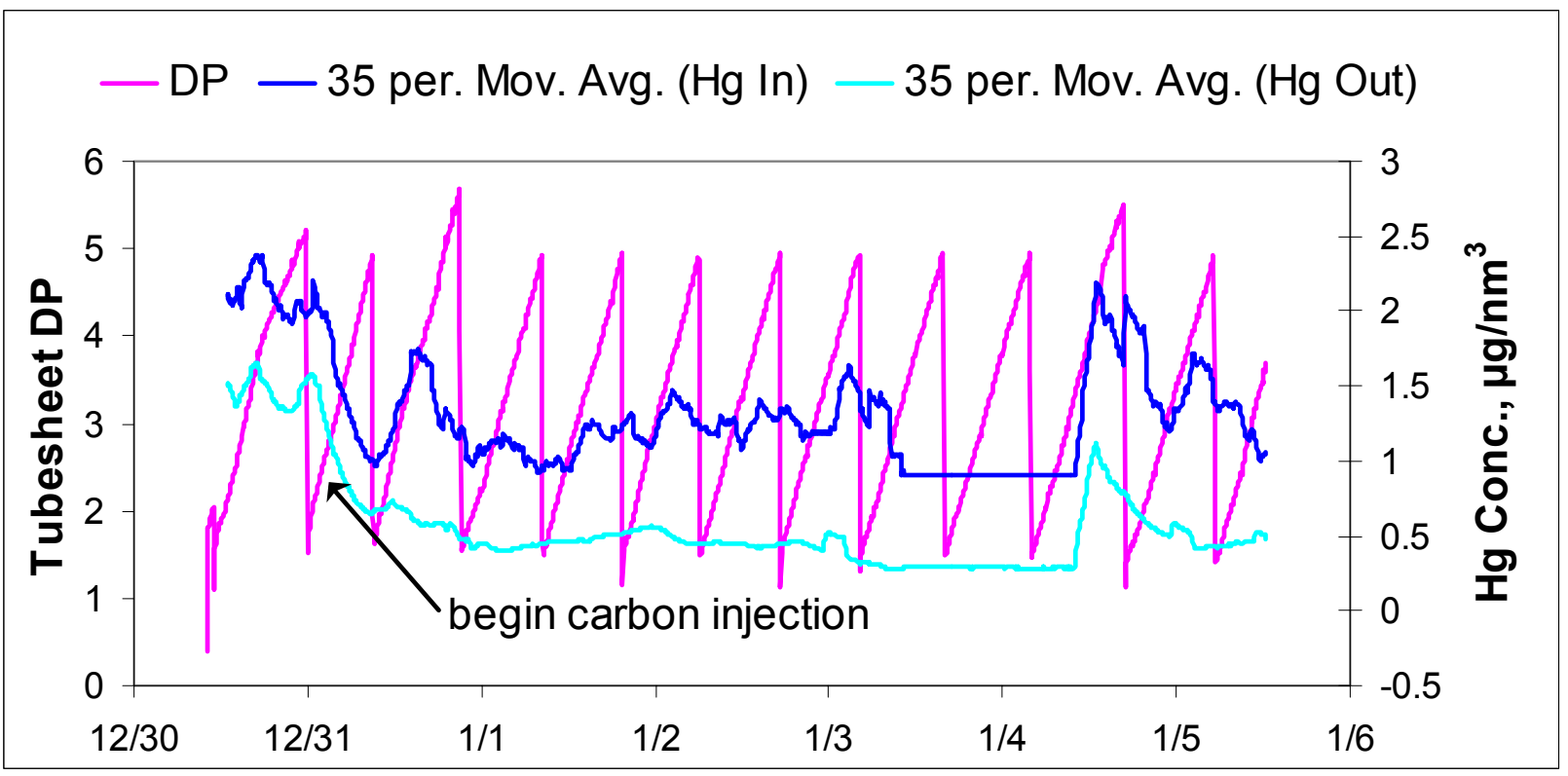

Figure 4-14. Long-term Carbon Injection IC Results, Comanche Pilot - RG Configuration.

\section{Reinjection of Fly Ash for Mercury Removal}

A decision was made to perform a series of tests where fly ash obtained from the fullscale particulate control equipment at the several generating units would be injected into the mercury removal pilot at Comanche station. The candidate ash samples were not treated in any way to enhance their mercury-sorbing properties. These materials had already been exposed to flue gas with mercury vapor, and had been shown to remove most of the mercury from the gas. So one issue under investigation was to determine if there was additional capacity in the candidate fly ashes for mercury beyond what had already been sorbed from their source flue gas streams. For one test with fly ash from the pilot host unit, Comanche 2, the fly ash was treated with a hot nitrogen purge in an attempt to desorb any mercury on the ash particles. Candidate fly ash materials were injected over a range of mass ratios. The largest was representative of the typical grain loading for fly ash in the Comanche pilot when operated on flue gas extracted upstream of the reverse-gas baghouse. Lower rates were tested in order to evaluate the potential for mercury removal at rates where the added load from the injected fly ash would not materially impact the performance of the existing particulate control equipment; these lower rates were as little as $10 \%$ of the typical particulate inlet grain loading to the full-scale baghouse.

Mercury measurement data for a typical run is shown in Figure 4-15. This graph plots the continuous mercury concentrations as measured by the MERCEM instrument at inlet and 
outlet of the pilot for an ash injection period of about one hour, starting shortly after noon. The dramatic drop in outlet mercury concentration almost immediately upon the start fly ash injection is quickly seen. Also of considerable interest is the residual effect, where mercury continued to be sorbed from the flue gas stream well after injection of fly ash is halted shortly after 1 PM. This is believed to be due to the mercury sorption capacity of the fly ash which was deposited on the bags in the reverse-gas module of the pilot. Further evidence of this is that after cleaning, the outlet mercury concentration rises rapidly back to the inlet level.

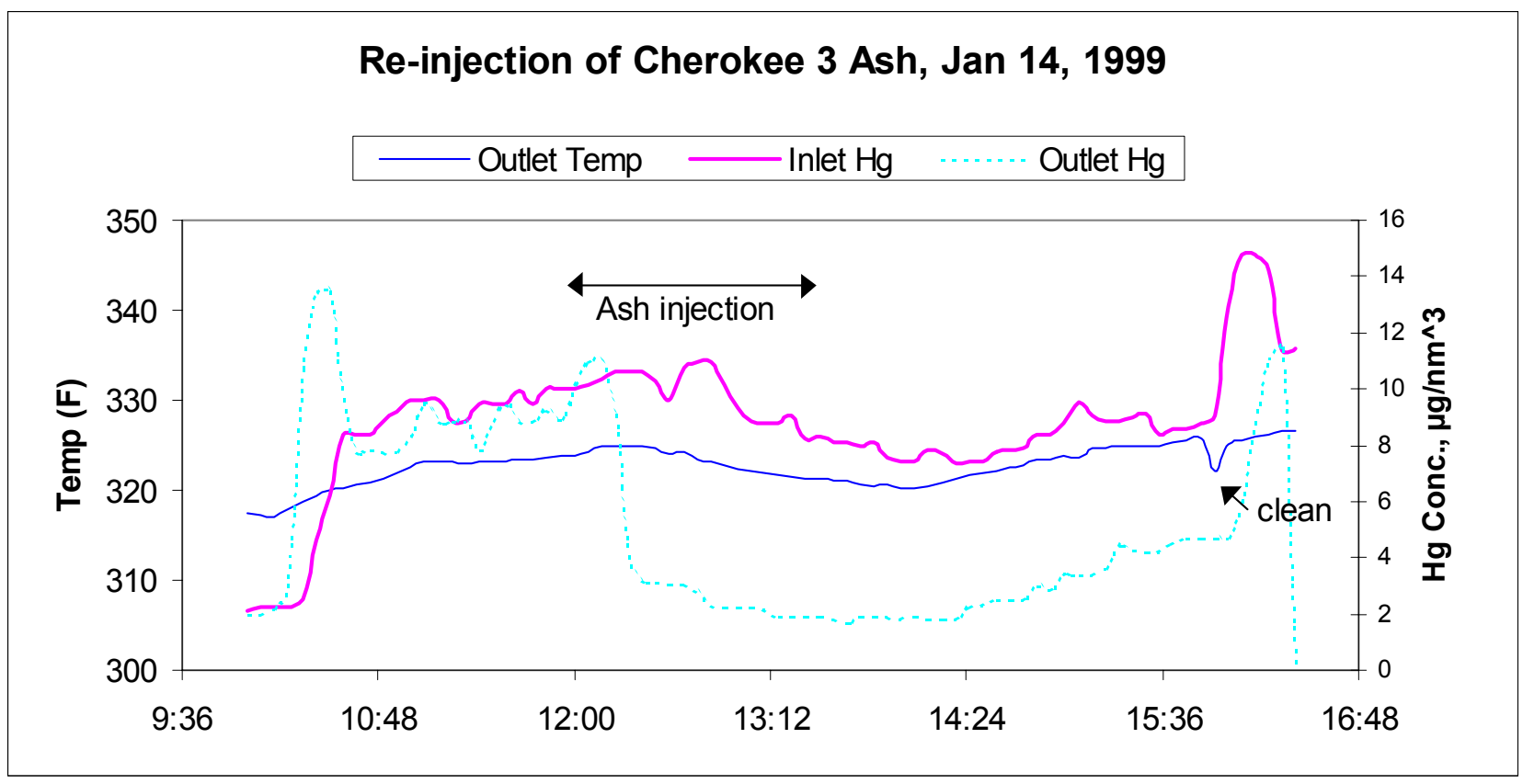

\section{Figure 4-15. Mercury Concentration Data for Reinjection of Cherokee 3 Ash in Comanche Pilot}

For some of the reinjection tests, iodated carbon (IC) trap samples were taken simultaneous to measurements with the MERCEM instrument. This was done to compare MERCEM and IC trap results in order to validate the large quantity of data acquired with the MERCEM unit. Typical results are presented in Figure 4-16. This plot shows MERCEM results for a reinjection test, with results from IC trap samples inserted for comparison. The IC trap data is plotted at the appropriate times as recorded in the test log, and at mercury concentrations as reported by the commercial lab that completed analyses of the traps. The figure shows that the IC trap measurements track the MERCEM data closely, both at the inlet and outlet of the pilot. 


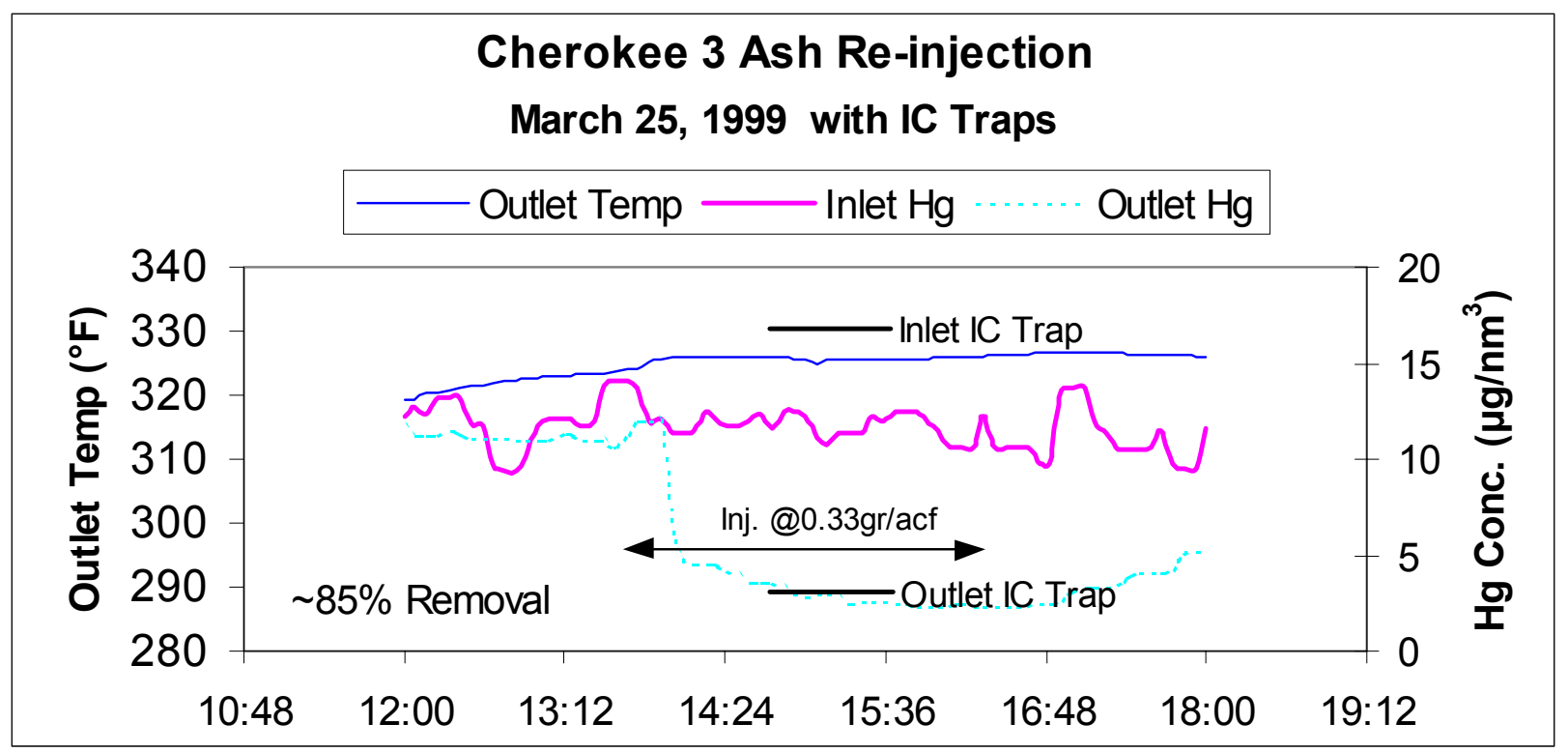

Figure 4-16. Comparison of MERCEM and IC Trap Mercury Measurements for Cherokee 3 Ash

Results from the MERCEM instrument for the fly ash reinjection tests are summarized in Table 4-1. Comanche 2 ash demonstrated a moderate affinity for vapor phase mercury. The ash has enough capacity to remove most of the mercury in the Comanche flue gas, but seems to be nearly saturated (or no longer reactive) when collected by the baghouse. Re-injection showed only $13 \%$ removal, although removal increased to $22 \%$ when the the ash was thermally treated to desorb mercury before reinjection. Ash was injected at a rate of about one grain/acf, loading that is typical for the pilot when operating on a slipstream extracted upstream of the Comanche baghouse. Comanche 2 LOI (Loss On Ignition) is typically $0.6 \%$, a low value which makes the ash salable for PSCo; the samples tested in the reinjection showed an even lower carbon content $(0.3$ to $0.4 \%)$.

Fly ash from Cherokee 3 showed good capacity for mercury adsorption. In full-scale measurements on the Cherokee 3 unit, mercury removal across the baghouse was found to be very high, $\sim 98 \%$. LOI for this fly ash is $\sim 9 \%$. Re-injection testing at the pilot demonstrated near complete removal $(86 \%)$ at an ash injection rate of 0.33 grains/acf. This injection rate is about a quarter of the typical flue gas ash content at Comanche, and would definitely impact the performance of most particle collectors. 
Table 4-1. Summary of Mercury Removal Results for Reinjected Fly Ash in the Comanche Pilot.

\begin{tabular}{|c|c|c|c|c|}
\hline Ash & $\begin{array}{c}\text { Temperature } \\
\left({ }^{\circ} \mathbf{F}\right)\end{array}$ & $\begin{array}{c}\text { Inj. Rate } \\
\text { (grains/acf) }\end{array}$ & $\begin{array}{c}\text { Carbon } \\
\text { Content (\%) }\end{array}$ & $\begin{array}{c}\text { Hg Removal } \\
\text { (\%) }\end{array}$ \\
\hline Comanche 2 & 280 & 1.13 & 0.42 & 13 \\
\hline $\begin{array}{c}\text { Comanche 2 } \\
\text { (desorbed) }\end{array}$ & 280 & 1.21 & 0.26 & 22 \\
\hline Cherokee 3 & 320 & 0.33 & 7.6 & 75 \\
\hline Arapahoe 4 & 320 & 0.13 & 14.4 & 80 \\
\hline $\begin{array}{c}\text { Activated } \\
\text { Carbon }\end{array}$ & 320 & 0.028 & $(100)$ & 82 \\
\hline Spray cooling & $260 \rightarrow 230$ & $*$ & 0.42 & $45 \rightarrow 75$ \\
\hline
\end{tabular}

${ }^{*}$ Native ash concentration about $1 \mathrm{gr} / \mathrm{acf}$, no additional sorbent injected.

Arapahoe 4 ash had very strong affinity for mercury under pilot conditions, although measured removal across the full-scale Arapahoe 4 baghouse was less than that seen at Cherokee $3(82 \%$ vs. $98 \%)$. Re-injection at the pilot yielded a very high removal rate $(80 \%)$ at an injection ratio of 0.13 grains/acf. This lower injection rate would still increase particulate loading to the current baghouse by $\sim 10 \%$ at the Comanche station. LOI for this ash is $\sim 14 \%$. The observed trend is for high carbon ashes to adsorb more mercury. Separated ash carbon has been shown by other investigators to adsorb mercury under low temperature, high mercury vapor concentration bench scale conditions (DeVito and Rosenhoover, 1999).

In the ADA pilot tests as well as others, temperature has been shown to affect the sorption of mercury onto ashes and activated carbon, with lower temperatures favoring high mercury removal. For comparison, typical results from testing in the pilot for a case of spray cooling is included in the table. ADA has performed several tests using spray cooling to enhance the sorptive activity of fly ash already present in the flue gas stream. In a test using flue gas from upstream of the Comanche 2 baghouse at $260^{\circ} \mathrm{F}$, mercury removal due to collection on resident fly ash was $45 \%$. When the flue gas temperature was lowered to $230^{\circ} \mathrm{F}$ by spray cooling, removal of mercury across the particle collector increased to $75 \%$. Lower flue gas temperatures facilitated greater mercury removal across particle collectors for the Comanche fly ash. 
For several of the fly ash reinjection tests, IC trap samples were obtained simultaneous to operation of the MERCEM instrument. These tests allow a direct comparison of the mercury measurements from the two techniques. While the absolute values of the measurements do not correlate well, the mercury removal rate as calculated from inlet and outlet measurements show good agreement. Results for several of the fly ash reinjection tests are included in Table 4-2. Two facts at noteworthy in this data: first, the MERCEM and IC trap removal rates agree quite well, and second, both Cherokee 3 and Arapahoe 4 fly ashes showed high mercury removal rates are relatively low injection ratios. At 0.13 grains per actual cubic foot, the additional loading to the particulate control collector presented by the fly ash mercury sorbent becomes less than $10 \%$ of the typical loading, and should be manageable with existing systems.

\section{Table 4-2. Comparison of Measured Mercury Removal Rates for MERCEM and IC Traps}

\begin{tabular}{|l|c|c|c|}
\hline \multicolumn{1}{|c|}{ Ash ID } & $\begin{array}{c}\text { Injection Rate } \\
\text { (gr/acf) }\end{array}$ & $\begin{array}{c}\text { IC Trap Hg } \\
\text { Removal Rate (\%) }\end{array}$ & $\begin{array}{c}\text { MERCEM Hg } \\
\text { Removal Rate (\%) }\end{array}$ \\
\hline Cherokee 3 & 0.33 & 75 & 75 \\
\hline Cherokee 3 & 0.33 & 82 & 78 \\
\hline Arapahoe 4 & 0.13 & 82 & 77 \\
\hline Arapahoe 4 & 0.13 & 85 & 82 \\
\hline
\end{tabular}

\subsection{Full-scale mercury removal at PSCo generating plants}

Five PSCo full-scale generating units were surveyed to measure mercury removal across the current particulate control equipment. The units represented a variety of boiler types, particulate control equipment styles, and coals. This activity became of much greater interest as the baseline testing in the pilot facility at Comanche station revealed that the native fly ash demonstrated a significant affinity for mercury, resulting in mercury removal rates as high as $80 \%$ without injection of activated carbon. Three if the five units were in the Denver metropolitan area, at the Arapahoe and Cherokee stations. The fourth unit was the host for the pilot facility, at PSCo's Comanche station in Pueblo, Colorado, and the fifth was located at the Hayden station near Steamboat Springs, Colorado. Arapahoe Unit 1 is equipped with an ESP for particulate control. Arapahoe Unit 4, Cherokee Unit 3, Hayden Unit 1, and Comanche Unit 2 all have reverse gas baghouses. In addition, the Hayden unit was recently retrofitted with a spray 
dryer scrubber for control of $\mathrm{SO}_{2}$ emissions. The unit descriptions are summarized in Table 4-3.

Table 4-3. Full-Scale Generating Unit Configurations

\begin{tabular}{|l|c|l|l|l|}
\hline \multicolumn{1}{|c|}{ Plant ID } & $\begin{array}{c}\text { Output } \\
\text { (MW) }\end{array}$ & \multicolumn{1}{|c|}{ Boiler } & \multicolumn{1}{|c|}{ Coal } & \multicolumn{1}{|c|}{$\begin{array}{c}\text { Environmental } \\
\text { Controls }\end{array}$} \\
\hline Arapahoe 1 & 45 & B\&W vertically fired & PRB Antelope & ESP @SCA=279 \\
\hline Arapahoe 4 & 110 & $\begin{array}{l}\text { B\&W w/OFA and low- } \\
\text { NOx burner retrofit }\end{array}$ & PRB Antelope & $\begin{array}{l}\text { Reverse-gas } \\
\text { fabric filter }\end{array}$ \\
\hline Cherokee 3 & 150 & $\begin{array}{l}\text { B\&W front wall with } \\
\text { low-NOx burner retro. }\end{array}$ & $\begin{array}{l}\text { Colo. bituminous } \\
\text { Twenty Mile }\end{array}$ & $\begin{array}{l}\text { Reverse-gas } \\
\text { fabric filter }\end{array}$ \\
\hline Comanche 2 & 375 & $\begin{array}{l}\text { B\&W opposed wall with } \\
\text { OFA }\end{array}$ & $\begin{array}{l}\text { PRB Belle Ayr } \\
\text { Reverse-gas }\end{array}$ & $\begin{array}{l}\text { Rebric filter } \\
\text { fabriter }\end{array}$ \\
\hline Hayden 1 & 200 & $\begin{array}{l}\text { Riley Stoker with low- } \\
\text { NOx burner retrofit }\end{array}$ & $\begin{array}{l}\text { Colo. bituminous } \\
\text { Twenty Mile }\end{array}$ & $\begin{array}{l}\text { Reverse-gas } \\
\text { fabric filter }\end{array}$ \\
\hline
\end{tabular}

SCA: Specific collection area $\left(\right.$ acfm/ESP plate area in $\left.\mathrm{ft}^{2}\right)$.

OFA: Overfire air for NOx control.

PRB: Powder River Basin coal, (name of supply mine).

\section{Test Methodology}

In-situ flue gas measurements were made upstream and downstream of the particulate control device with an EPA Method 5/Method 29 type sampling probe and mass flow train, often referred to as a rack box. The probes were heated to stack temperature, and the iodated carbon traps used to sorb mercury from the sample gas stream were housed in the section of the probe inserted into the duct. The measurement techniques used on each PSCo unit during the testing program for flue gas sampling are summarized in Table 4-4. The first three units were tested using an iodated carbon sorbent trap for mercury collection, while Comanche Unit 2 was tested using the Ontario-Hydro $(\mathrm{OH})$ method. All inlet sampling was done isokinetically through a nozzle, with the collected sample kept at stack temperature through the probe and filter assembly. Downstream of the filter assembly either sorbent traps (iodated carbon trap method) or impingers (OH method) captured vapor-phase mercury. Separate particulate-mercury and vapor-phase mercury values were obtained for each inlet sample run. In general, outlet samples were not collected isokinetically (exceptions are noted in the results discussion below). At the outlet, only vapor-phase mercury was measured in most cases, because the plant particulate control equipment collected virtually all the fly ash from the flue gas. Mercury removal rates 
thus include mercury deposited on the fly ash upstream of the inlet measurement and mercury that is in the vapor phase at the inlet location, and is subsequently removed from the gas stream by the fly ash through the particulate control device. In addition to the flue gas samples, coal and ash samples were collected at each individual unit during testing. All of these samples were analyzed for mercury concentration and the results are discussed below.

Table 4-4. Measurement Techniques for Full-Scale Survey.

\begin{tabular}{|c|l|l|l|}
\hline Msmt. & \multicolumn{1}{|c|}{ Unit ID } & \multicolumn{1}{|c|}{ Inlet } & \multicolumn{1}{c|}{ Outlet } \\
\hline Total Hg & $\begin{array}{l}\text { Summer: Arap. 1\&4, } \\
\text { Cher. 3 } \\
\text { Winter: Cherokee 3, } \\
\text { Hayden 1 }\end{array}$ & $\begin{array}{l}\text { Isokinetic sample and in-situ IC trap } \\
\text { with heated probe and particulate } \\
\text { capture assembly. }\end{array}$ & $\begin{array}{l}\text { In-situ IC trap with heated } \\
\text { probe (non-isokinetic } \\
\text { sample). }\end{array}$ \\
\hline Total Hg & Winter: Arapahoe 1 & $\begin{array}{l}\text { Isokinetic sample and in-situ IC trap } \\
\text { with heated probe and particulate } \\
\text { capture assembly. }\end{array}$ & $\begin{array}{l}\text { Isokinetic sample and in- } \\
\text { situ IC trap with heated } \\
\text { probe and particulate } \\
\text { capture assembly. }\end{array}$ \\
\hline $\begin{array}{l}\text { Speciated } \\
\text { Mercury }\end{array}$ & Winter: Arapahoe 4 & $\begin{array}{l}\text { Isokinetic sample and in-situ MESA } \\
\text { trap with heated probe and } \\
\text { particulate capture assembly. }\end{array}$ & $\begin{array}{l}\text { Isokinetic sample and in- } \\
\text { situ MESA trap with } \\
\text { heated probe. }\end{array}$ \\
\hline $\begin{array}{l}\text { Speciated } \\
\text { Mercury }\end{array}$ & $\begin{array}{l}\text { Summer: Comanche } \\
\text { 2 }\end{array}$ & $\begin{array}{l}\text { EPA Method 29 and EPA Ontario- } \\
\text { Hydro with cyclone particulate } \\
\text { capture assembly. }\end{array}$ & $\begin{array}{l}\text { EPA Method 29 and EPA } \\
\text { Ontario-Hydro with } \\
\text { cyclone particulate capture } \\
\text { assembly. }\end{array}$ \\
\hline
\end{tabular}

${ }^{a}$ An in-situ IC sample was used to speciate mercury. This method is expected to provide accurate total mercury measurements.

${ }^{\mathrm{b}}$ Standard Ontario-Hydro sampling was performed to accurately measure speciated $\mathrm{Hg}$.

For ease of comparison, all mercury data are expressed as $\mu \mathrm{g} / \mathrm{Nm}^{3}$ corrected to $3 \% \mathrm{O}_{2}$. Mercury concentrations in coal and ash were converted to equivalent flue-gas concentrations via combustion calculations based on the coal ultimate analysis data. Additionally, all scatter in the data is presented as $\% \mathrm{RSD}$, the standard deviation divided by the mean. The reported \%RSD is a combination of both the variability in the sampling / measurement method and the variability in the flue gas mercury due to natural fluctuations in coal mercury and combustion conditions. A high \%RSD indicates a source of uncertainty in the data set. This reporting methodology is consistent throughout this report. 


\section{Mercury Measurement}

Flue gas measurements were made with two independent techniques. Comanche Unit 2 flue gas mercury was sampled and analyzed by the Ontario-Hydro $(\mathrm{OH})$ method, performed by CONSOL, Inc. (Pittsburgh, PA). Mercury sampling at the other four units utilized the modified MESA method that employs iodated carbon trap sorbent tubes, developed by Frontier GeoSciences of Seattle, Washington (FGS). IC traps through which flue gas samples had been drawn were sent to FGS for analysis by cold vapor atomic fluorescence (CVAF). The IC trap sampling at the five sites surveyed was performed by an ADA sampling crew. This method has been described previously and has compared very well for total mercury with both EPA Method 29 and the OH Method (Nott, 1995; Laudal, et. al., 1996; Prestbo and Tokos, 1997). In previous reporting, side-by-side testing at the Comanche Unit of the MESA method and the $\mathrm{OH}$ method gave MESA mercury concentrations results within $4-20 \%$ of the $\mathrm{OH}$ results (Bullock, et. al., 1997). Modifications to the MESA method for this series of tests were developed by FGS and ADA jointly during the test program at the Comanche pilot and in the full-scale survey sampling. Specifically, FGS developed an isokinetic, in-situ filter assembly containing a nozzle, filter holder and IC trap. All samples were therefore collected at stack temperature. However, both the $\mathrm{OH}$ and IC method may not accurately represent the partitioning between particulate and vapor-phase mercury. This is because the flue gas first passed through a filter assembly, which removed the ash from the flue gas sample stream during sample collection. As illustrated in the results below, this "collected ash filter cake" may have continued sorb vapor-phase mercury from the sample flue gas stream in some instances.

\section{Arapahoe Unit 1 Flue Gas Testing and Results}

Testing procedures followed the test methodology described earlier and summarized in Table 4-4. While the summer outlet flue gas samples were collected non-isokinetically, quantifying only vapor-phase mercury, winter testing was conducted using isokinetic sampling at both the inlet and outlet of the particulate control equipment (note that this applies only to the Arapahoe Unit 1, which is also the only ESP tested). This modification was a response to the poor data consistency of the summer test results, which showed a large variability in mercury removal results among the triplicate tests. The variability could have been due to the inexperience in mercury testing at full-scale facilities, as Arapahoe Unit 1 was the first generating unit tested in the survey task.

The second (winter) series of triplicate tests did exhibit improved repeatability of $\mathrm{Hg}$ removal efficiencies in comparison with the first (summer) series. However this is probably not 
attributable to the change in outlet measurement procedures to isokinetic sampling. The outlet particulate mercury was quite low, as illustrated in Figure 4-17. Less than 11\% of the total outlet mercury was measured in the sample train ash, indicating that the lack of a representative particulate sample in the summer testing was likely not significant. The mercury removal calculation for the winter series resulted in 24 to $32 \%$ removal, with $14 \% \mathrm{RSD}$, significantly better than the first series.

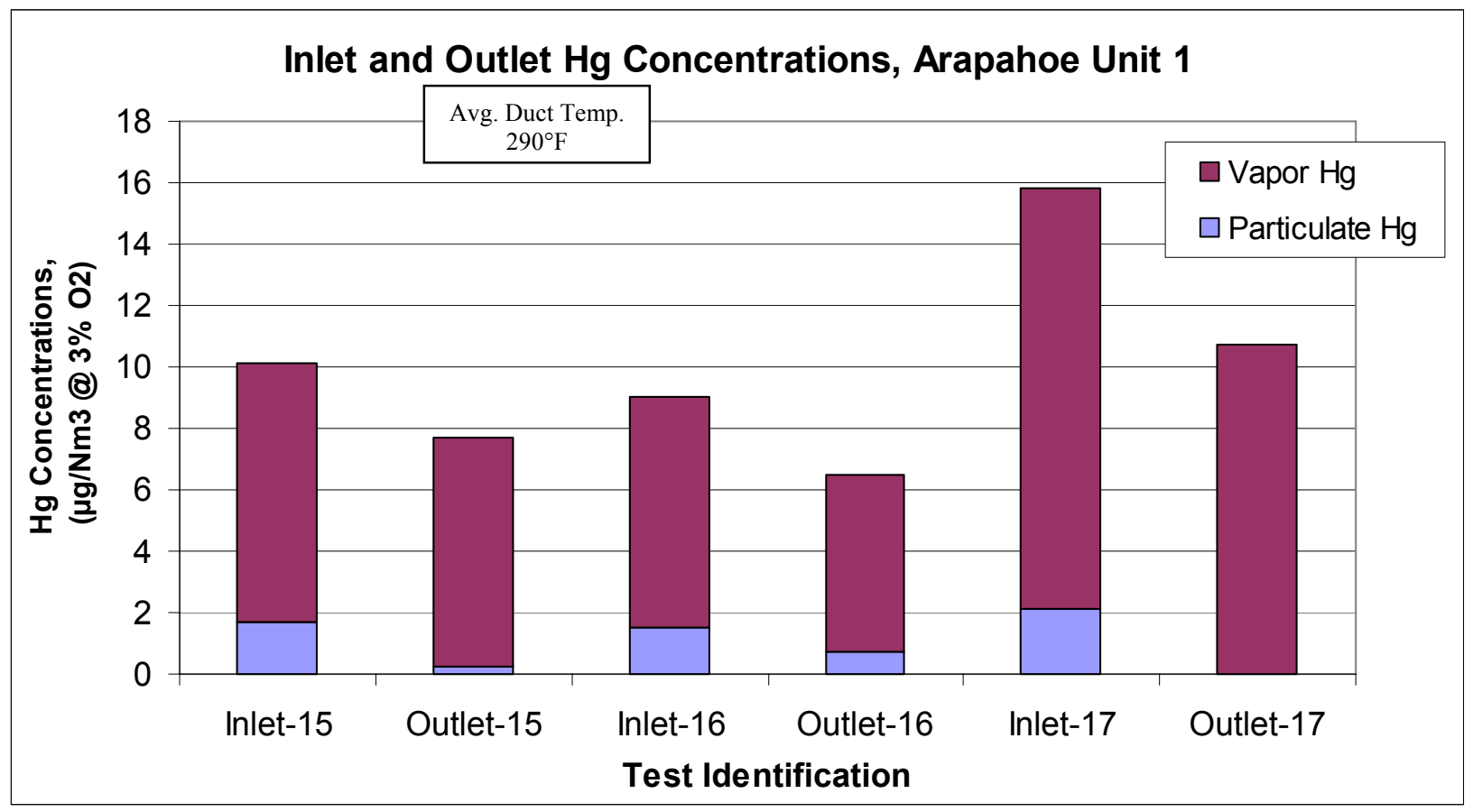

Figure 4-17. Inlet and Outlet Hg Concentrations, Arapahoe Unit 1.

The fraction of mercury in the particulate phase at the inlet is not high enough to account for all of the mercury removed across Arapahoe Unit 1's ESP. Therefore, some vapor-phase removal is occurring in the duct between the inlet and outlet sample locations. This can only be asserted for winter test results, since the summer results are too inconsistent to draw conclusions on the removal. If $28 \%$ removal is truly representative, then the drop in mercury at the outlet must be explained by deposition on surfaces. These surfaces could either be the flyash or the unit ductwork itself. It is logical to assume that the unit ductwork would become saturated for the given temperature conditions over time, and would not continue to remove mercury. Thus, flyash capture seems the most likely mechanism for mercury removal in the ESP during testing. 


\section{Arapahoe Unit 1 Coal and Ash Analysis}

Coal and flyash samples submitted for mercury concentration analysis were composites of several samples taken during the triplicate flue gas tests. Replicate samples were sent to the laboratory for analysis to determine the repeatability of the analysis. During the winter testing, three composite coal samples were sent for analysis with the coal mercury value ranging from $55-62 \mathrm{ng} / \mathrm{g}$ which results in an average equivalent mercury concentration of $9.9 \mu \mathrm{g} / \mathrm{Nm}^{3} @ 3 \%$ $\mathrm{O}_{2}$ (6\%RSD). Triplicate composite ash samples were sent for analysis with the ash mercury value ranging from $280-320 \mathrm{ng} / \mathrm{g}$ which results in an average equivalent mercury concentration of $3.1 \mu \mathrm{g} / \mathrm{Nm}^{3} @ 3 \% \mathrm{O}_{2}(7 \% \mathrm{RSD})$. The nominal carbon in the ash (LOI) was less than 1\%.

\section{Arapahoe Unit 4 Flue Gas Testing and Results}

Sampling was done following the protocol noted earlier in this report. The inlet and outlet flue gas mercury concentration test results for Arapahoe Unit 4 are presented in Figure 418. The mercury removals as shown on Table 4-5 measured during the summer series were fairly consistent, with a mercury removal range of $69-90 \%$ (13.9\%RSD). The winter series results were even more uniform with a mercury removal range of $58-66 \%(6.6 \% \mathrm{RSD})$. While the duct temperatures remained virtually unchanged from the summer series of testing to the winter series of testing (ranging from 339 to $348^{\circ} \mathrm{F}$ ), the mercury removal percentage varied. The mercury removal was $82 \%$ in the summer and $63 \%$ in the winter.

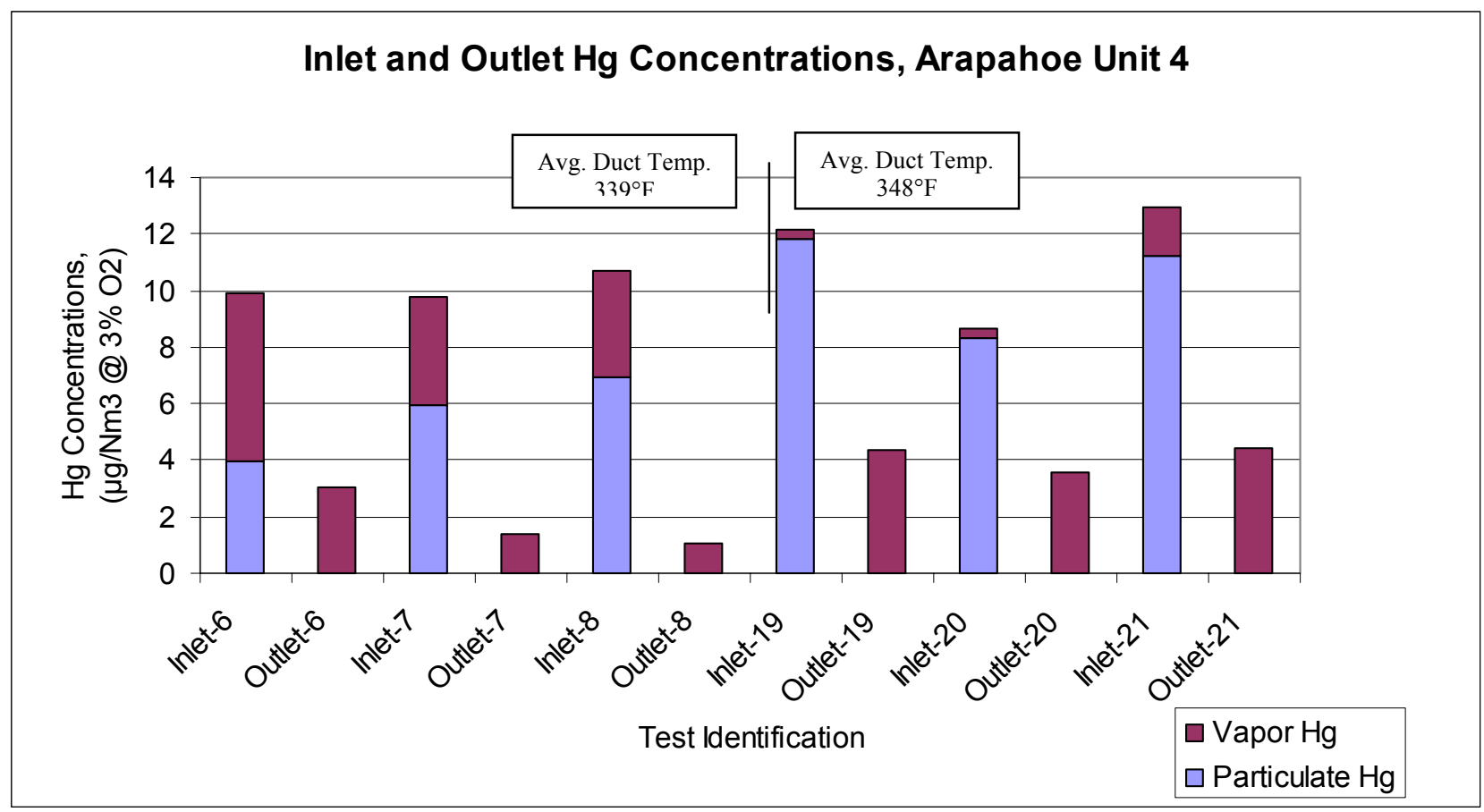


Figure 4-18. Inlet and Outlet Mercury Concentrations, Arapahoe Unit 4.

Table 4-5. Mercury Removal Efficiencies, Percent.

\begin{tabular}{|c|c|c|c|c|c|c|c|c|}
\hline \multirow[t]{2}{*}{ Replicate \# } & \multicolumn{3}{|c|}{ Summer Series } & \multicolumn{4}{|c|}{ Winter Series } & \multirow[b]{2}{*}{ Average* } \\
\hline & 1 & 2 & 3 & 4 & 5 & 6 & 7 & \\
\hline $\begin{array}{l}\text { Arapahoe } \\
\text { Unit } 1\end{array}$ & N/A & N/A & N/A & 24 & 28 & 32 & N/A & $28^{*}$ \\
\hline $\begin{array}{l}\text { Arapahoe } \\
\text { Unit } 4\end{array}$ & 69 & 86 & 90 & 64 & 58 & 66 & N/A & 72 \\
\hline $\begin{array}{l}\text { Cherokee } \\
\text { Unit } 3\end{array}$ & 99 & 98 & 99 & 97 & 99 & 98 & 100 & 99 \\
\hline $\begin{array}{l}\text { Comanche } \\
\text { Unit } 2\end{array}$ & 71 & 57 & 68 & N/A & N/A & N/A & N/A & 65 \\
\hline
\end{tabular}

*Average of all listed tests except for Arapahoe Unit 1, where the first three tests were omitted due to poor repeatability.

The particulate mercury measured at Arapahoe Unit 4 was significantly higher than at Unit 1. Figures 4-16 and 4-17 show both units' inlet measurements. Clearly, significantly more of the mercury in the flue gas of Arapahoe 4 is in the particulate phase (56\% summer; $94 \%$ winter) compared to Arapahoe Unit $1(15 \%)$ for this particular testing methodology. This is in spite of the higher duct temperatures at Arapahoe Unit 4, which usually result in less mercury adsorption than at lower temperatures, and thus lower particulate-mercury levels. Test procedures used were the same for both units. The one major difference in the fly ashes between Units 1 and 4 is that Unit 4 is equipped with low-NOx burners, with an associated high fraction of unburned carbon in the fly ash.

The higher mercury removal level during summer testing could be due to the difference in process operations resulting in a higher particulate phase mercury and/or change in ash chemistry. In fact, the flue gas temperature for the winter tests was actually slightly higher than for the summer test series. It should also be noted that the summer tests were run at a part-load condition for the unit, resulting in a slight decrease in the air to cloth ratio of the baghouse. However, the winter Arapahoe Unit 4 test series inlet vapor-phase mercury measurements ranged from 0.3 to $1.7 \mu \mathrm{g} / \mathrm{Nm}^{3} @ 3 \% \mathrm{O}_{2}$, while outlet measurements ranged from 3.6 to $4.4 \mu \mathrm{g} / \mathrm{Nm}^{3} @$ $3 \% \mathrm{O}_{2}$. These results may have been affected by the sorption of flue gas mercury onto the ash as it passed through the sample filter assembly during inlet testing, resulting in a bias the particulate phase mercury results, with reported levels higher than actual. This leads to speculation that 
there was mercury adsorption during the winter series in the sample train, as indicated by the reported higher outlet than inlet vapor-phase mercury values.

\section{Arapahoe Unit 4 Coal and Ash Analysis}

Coal and ash samples sent for mercury concentration analysis were composites of the multiple samples taken during the triplicate flue gas sampling tests. Replicate composite samples were sent to the laboratory for analysis to determine the repeatability of the measurements. During the summer testing, a single coal sample was submitted for analysis. The coal sample analysis was duplicated, resulting in a coal mercury value ranging from $45-46 \mathrm{ng} / \mathrm{g}$ which converted to an average equivalent mercury concentration of $7.1 \mu \mathrm{g} / \mathrm{Nm}^{3} @ 3 \% \mathrm{O}_{2}$. A single ash sample was sent for analysis which calculated as an equivalent mercury concentration of $5.2 \mu \mathrm{g} / \mathrm{Nm}^{3} @ 3 \% \mathrm{O}_{2}$ for the ash. During the winter testing, triplicate coal samples sent for analysis yielded coal mercury values ranging from $52-57 \mathrm{ng} / \mathrm{g}$. This converted to an average equivalent mercury concentration of $8.4 \mu \mathrm{g} / \mathrm{Nm}^{3} @ 3 \% \mathrm{O}_{2}(11 \% \mathrm{RSD})$. Triplicate ash samples were sent for analysis resulting in an ash mercury value ranging from $730-1000 \mathrm{ng} / \mathrm{g}$ which converts to an average equivalent mercury concentration of $7.1 \mu \mathrm{g} / \mathrm{Nm}^{3} @ 3 \% \mathrm{O}_{2}$ (16\%RSD). The nominal carbon in the ash as measured by Loss on Ignition (LOI) was less than $14.4 \%$.

Coals from Arapahoe Unit 1 and Unit 4 were Powder River Basin sub-bituminous from the same mine, with the only difference being that the composite samples sent for analysis were collected at different times, within a few days to a week apart from each other. Therefore, a comparison of the mass balances was performed.

\section{Mass Balances for Arapahoe Units 1 and 4}

All Arapahoe units fire the same coal, and so mercury mass balances for Units 1 and 4 were compiled for comparison. Although the coal was sampled at different times, the coal supply was unchanged. Nonetheless, the mercury content measured in the coal varied, even within the same day. Therefore, comparison of the results between the two units is interesting.

A mass balance was performed based on the average mercury concentration measurements of the coal, ash and flue gas. The calculated and measured values are summarized in Table 4-3 and Figure 4-19. The "coal Hg" column presents the calculated mercury in the flue gas based on the measured mercury concentration and ultimate analysis of the coal. "Inlet $\mathrm{Hg}$ " refers to the total measured mercury (sum of sample filter ash mercury plus vapor-phase 
mercury) at the inlet to the particulate control device (ESP or baghouse). "Ash Hg" shows to the concentration of mercury detected in the collected fly ash converted to a flue-gas equivalent value. "Stack Hg" is the flue gas measurement result, presented above. "Ash + Stack" is provided for comparison of source (coal) and outlet. In a perfect mass balance, the mercury calculated from the coal would equal the ESP total inlet mercury measurement, which would equal the sum of the stack measurement plus the mercury found in the hopper ash.

Table 4-6. Mass Balances.

\begin{tabular}{|c|c|c|c|c|c|c|c|}
\hline \multirow{3}{*}{$\begin{array}{l}\text { Test Series } \\
\text { Arapahoe } \\
\text { Unit } 1\end{array}$} & \multicolumn{2}{|c|}{$\begin{array}{c}\text { Coal Hg } \\
\text { ng/g Total Hg }\end{array}$} & \multirow{3}{*}{$\begin{array}{c}\text { Total } \\
\text { Inlet } \mathrm{Hg} \\
6.9 \\
11.7\end{array}$} & \multicolumn{2}{|c|}{$\begin{array}{l}\text { Ash Hg } \\
\text { /g Total Hg }\end{array}$} & \multirow{3}{*}{$\begin{array}{c}\begin{array}{c}\text { Stack } \\
\mathrm{Hg}\end{array} \\
6.3 \\
8.3\end{array}$} & \multirow{3}{*}{$\begin{array}{c}\text { Ash }+ \\
\text { Stack } \\
8.1 \\
11.4\end{array}$} \\
\hline & \multirow{2}{*}{$\begin{array}{l}64 \\
58 \\
\end{array}$} & \multirow{2}{*}{$\begin{array}{r}10.8 \\
9.9 \\
\end{array}$} & & 197 & 1.8 & & \\
\hline & & & & 303 & 3.1 & & \\
\hline \multirow{2}{*}{$\begin{array}{l}\text { Arapahoe } \\
\text { Unit } 4\end{array}$} & 46 & 7.1 & 10.1 & 686 & 52 & 1.8 & 7.0 \\
\hline & 52 & 8.4 & 11.2 & 880 & 7.1 & 4.1 & 11.2 \\
\hline \multirow{2}{*}{$\begin{array}{l}\text { Cherokee } \\
\text { Unit } 3\end{array}$} & 18 & 2.5 & 2.2 & 171 & 4.1 & 0.04 & 4.1 \\
\hline & 28 & 3.5 & 3.9 & 777 & 8.7 & 0.04 & 8.7 \\
\hline $\begin{array}{l}\text { Comanche } \\
\text { Unit } 2\end{array}$ & 64.7 & 10.1 & 10.5 & 978 & 7.9 & 3.9 & 11.9 \\
\hline
\end{tabular}

Note: $\mathrm{Hg}$ units are $\mu \mathrm{g} / \mathrm{Nm}^{3} @ 3 \% \mathrm{O}_{2}$ unless otherwise noted.

Due to inconsistencies in the triplicate flue gas measurements, Arapahoe Unit 1 summer results were not reviewed. In winter tests, the total mercury calculated from the coal-Hg content is $9.9 \mu \mathrm{g} / \mathrm{Nm}^{3} @ 3 \% \mathrm{O}_{2}$, compared with $11.7 \mu \mathrm{g} / \mathrm{Nm}^{3} @ 3 \% \mathrm{O}_{2}$ measured at the ESP inlet. This translate to a $118 \%$ recovery of $\mathrm{Hg}$. Recovery for "ash+stack" is $11.4 \mu \mathrm{g} / \mathrm{Nm}^{3} @ 3 \% \mathrm{O}_{2}$, or $115 \%$ of the coal mercury.

In a recent publication by DeVito, mercury mass balances were reported for utility units ranging from $92 \%$ to $116 \%$ on three different units. ${ }^{4}$ The mass balance was calculated between the coal mercury and all outlet streams, in this case referred to as "ash+stack." These mass balances for comparison are $74 \%$ and $113 \%$. In a conversation with DeVito on this topic, a balance within $20 \%$ of a perfect balance (that is, ranging from $80 \%$ to $120 \%$ ) was proposed as good closure, and within 30\% still considered reasonable. Measurement of trace species in a power plant is very challenging, as indicated by the lack of repeatability seen in some of these 
data; the compounds of interest are often present in parts per million to parts per billion concentrations.

For Arapahoe Unit 4, Table 4-6 shows that the coal mercury content is 7.1 $\mu \mathrm{g} / \mathrm{Nm}^{3} @ 3 \%$ $\mathrm{O}_{2}$, compared with $10.1 \mu \mathrm{g} / \mathrm{Nm}^{3} @ 3 \% \mathrm{O}_{2}$ measured at the baghouse inlet during summer tests. This represents $142 \%$ recovery of coal $\mathrm{Hg}$ at the baghouse inlet during the summer testing. Mercury recovery at "ash+stack" is $7.0 \mu \mathrm{g} / \mathrm{Nm}^{3} @ 3 \% \mathrm{O}_{2}$, or $99 \%$ of the coal mercury. During winter testing, the coal mercury is $8.4 \mu \mathrm{g} / \mathrm{Nm}^{3} @ 3 \% \mathrm{O}_{2}$, in comparison with $11.2 \mu \mathrm{g} / \mathrm{Nm}^{3} @$ $3 \% \mathrm{O}_{2}$ measured at the inlet to the baghouse. This translates to $133 \%$ recovery of coal $\mathrm{Hg}$ at the baghouse inlet. Mercury recovery at the "ash+stack" is the same, also at $11.2 \mu \mathrm{g} / \mathrm{Nm}^{3} @ 3 \% \mathrm{O}_{2}$ or $133 \%$ recovery. These mass balance calculations for mercury reflect some variability in mercury measurements but are considered reasonable. They do not indicate a systematic bias, since closure varies with respect to the mass balance reference (coal compared to inlet, inlet compared to "ash+stack", or coal compared to "ash+stack") as well as with respect to the series.

As previously noted, the coal for Arapahoe Unit 1 and Arapahoe Unit 4 are subbituminous from the Antelope mine in the Powder River Basin (PRB). While the coal was the same at both units, process operations were different as shown in Table 4-3. These process operational differences could affect the inlet vapor-phase and particulate-phase mercury split as shown in Figures 4-17 and 4-18. In addition to the difference in firing mode and heat input, Arapahoe Unit 1 employed an ESP as the particulate control device while Arapahoe Unit 4 featured a reverse gas baghouse. Additionally, the flue gas stream for Arapahoe Unit 1 was treated with $\mathrm{SO}_{3}$ injection to improve the performance of the ESP. Arapahoe Unit 4 utilized sodium sesquicarbonate injection for $\mathrm{SO}_{2}$ control.

Figure 4-19 shows that Arapahoe Unit 4 coal analyses yielded lower mercury concentrations than Unit 1 . This is not unusual, as $\mathrm{Hg}$ concentrations can vary quite widely due to the inhomogeneous nature of coal. In a paper by Bloom and Prestbo ${ }^{11}$, the average variability for duplicates increased from $5 \%, 10 \%$ and $25 \%$ for replicate lab analysis, replicate lab digestion and replicate field samples, respectively. Treating the entire set of 11 mercury analyses as one data set, it has $20 \% \mathrm{RSD}$, with an average coal mercury of $56 \mathrm{ng} / \mathrm{g}$. The differences in reported coal mercury between the two units may easily have been due to natural variability in mercury concentration in the coal, or within the precision of the sampling and analysis methods. There did not appear to be a significant difference in coal mercury level. Upon examination, the inlet mercury measurements were also fairly uniform between the two units. However, significant differences in mercury level appeared in the stack data. Arapahoe 4 had consistently higher 
mercury removals across its reverse-gas baghouse than Arapahoe 1 had across its ESP. This may be attributable to multiple factors, including speciation of the mercury at the two units and the more efficient mercury-removal of a baghouse as compared to an ESP.

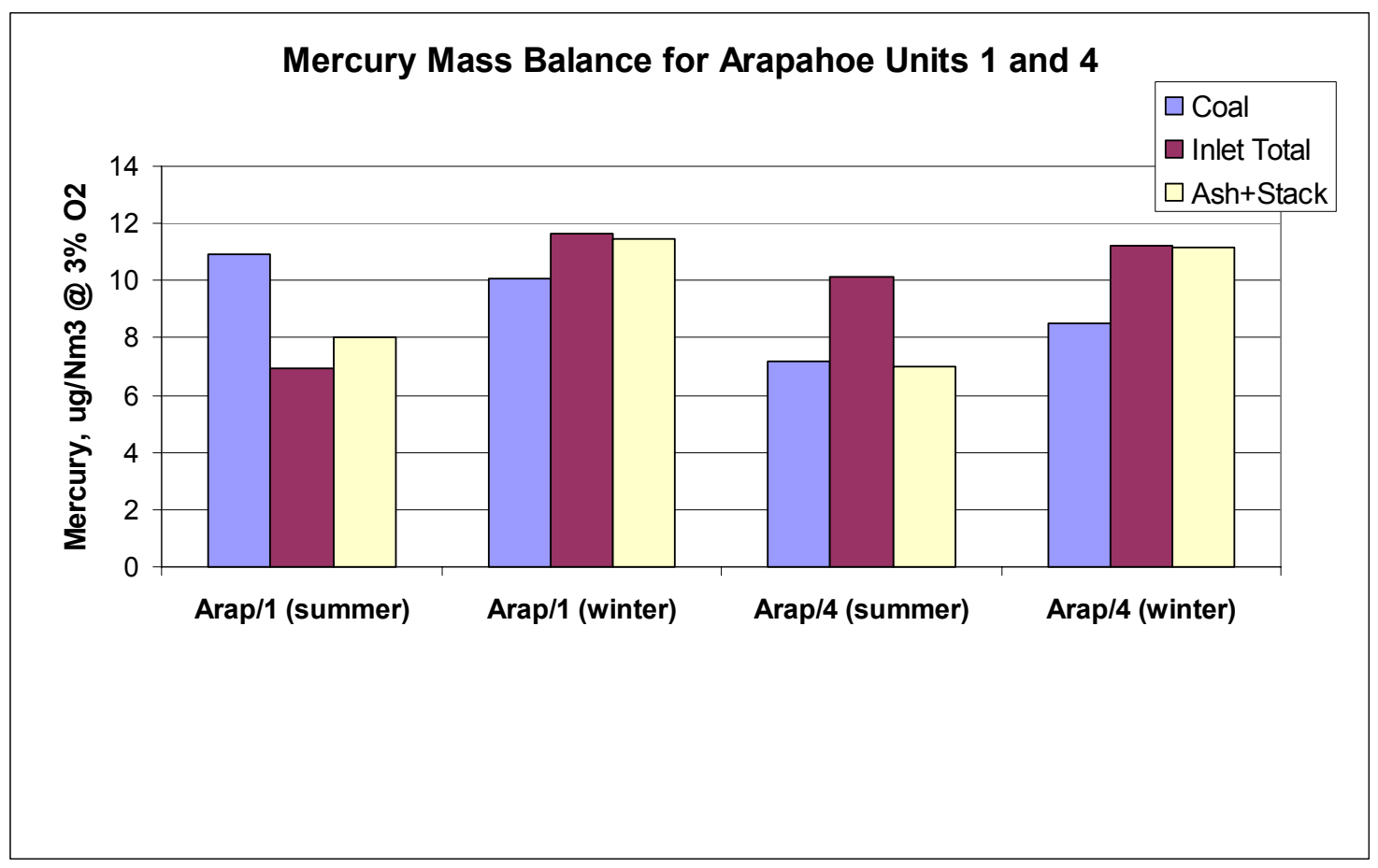

Figure 4-19. Mercury Mass Balance Comparison, Arapahoe Unit 1 and Unit 4.

\section{Cherokee Unit 3 Flue Gas Testing and Results}

Testing at Cherokee Unit 3 followed the procedure as described in the test methodology and shown in Table 4-4. The inlet and outlet flue gas mercury concentration test results for Cherokee Unit 3 are illustrated in Figure 4-20. Four replicate tests were run during the summer series; three in the winter series. Replicate tests consisted of simultaneous inlet and outlet flue gas mercury measurements. The data in Figure 4-20 best demonstrates the repeatability of all tests conducted. The summer and winter testing series resulted in a very uniform data set reflecting a very high mercury removal percentage, as shown in Table 4-5. The average summer mercury removal was $98 \%$ and the average winter mercury removal was $99 \%$. These are essentially the same (high) removal rate, even with a decrease in duct temperature from $300^{\circ} \mathrm{F}$ to $279^{\circ} \mathrm{F}$ during the winter testing. During both summer and winter testing, measured mercury removal efficiencies were very consistent, which resulted in an RSD of $0.8 \%$ for the summer data set and an RSD of $1.1 \%$ for the winter data set. 


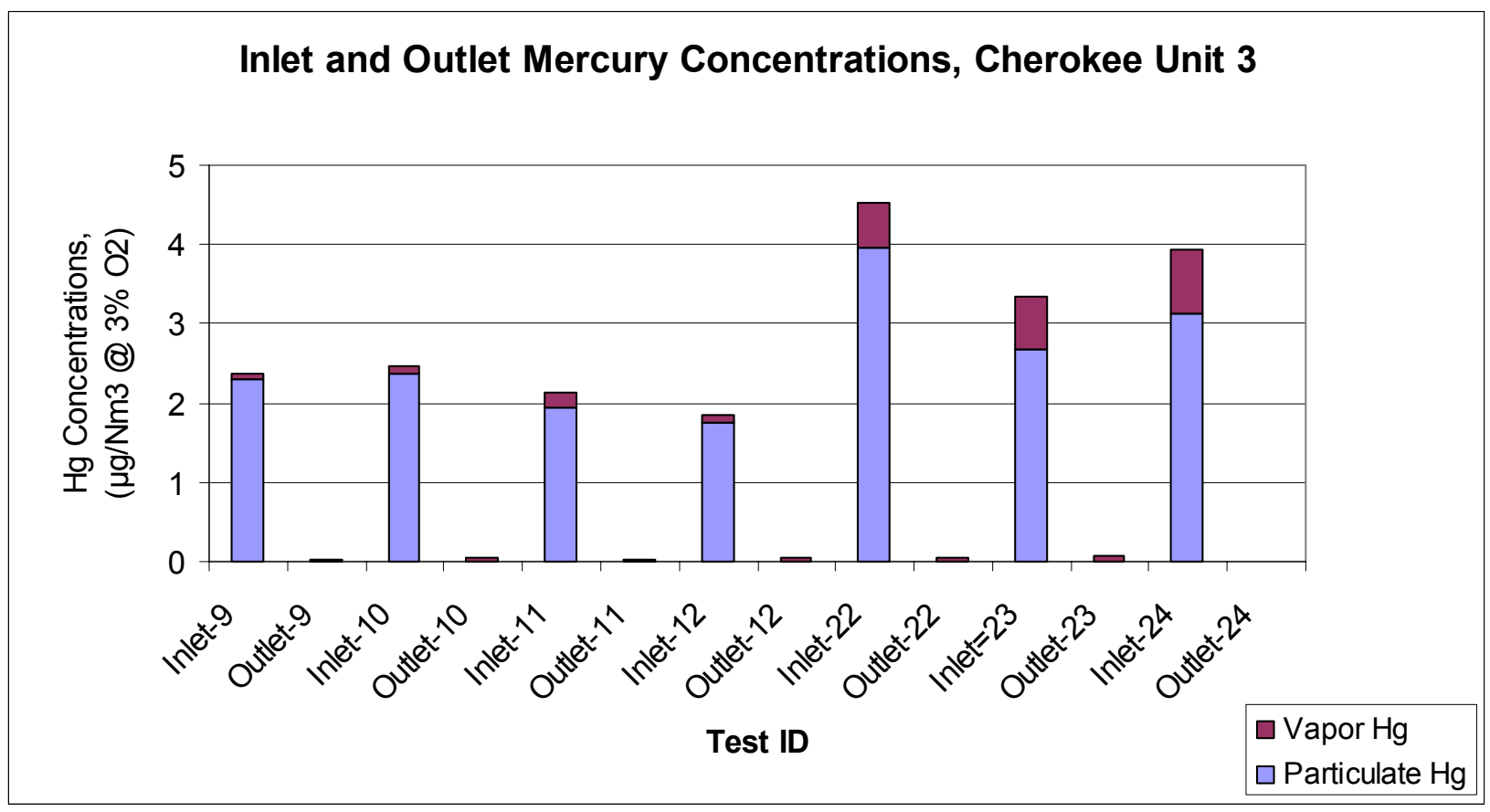

Figure 4-20. Inlet and Outlet Mercury Concentrations, Cherokee Unit 3.

The particulate fraction of total mercury, $95 \%$ during the summer and $83 \%$ during the winter, was not high enough to account for all of the mercury removed across the Cherokee Unit 3 baghouse. Therefore, some vapor-phase removal occurred between the inlet and outlet sample locations. This indicated that this ash was still reactive at temperatures between 280 and $300^{\circ} \mathrm{F}$, and so continued to adsorb mercury in the reverse-gas baghouse. Cherokee Unit 3 had significantly higher mercury removals than Comanche Unit 2 and Arapahoe Units 1 and 4, even though all the units operated at similar duct temperatures during the mercury sampling.

\section{Cherokee Unit 3 Coal and Ash Analysis}

Coal and fly ash samples submitted for mercury analysis were composites of the multiple samples taken during the replicate flue gas tests. During the summer testing, three replicate coal samples were analyzed, yielding mercury values in the range of $18-19 \mathrm{ng} / \mathrm{g}$, which converted to an average coal equivalent mercury value of $2.5 \mu \mathrm{g} / \mathrm{Nm}^{3} @ 3 \% \mathrm{O}_{2}$ (3\%RSD). A single fly ash sample was sent for analysis, which converted to an equivalent mercury value of $4.1 \mu \mathrm{g} / \mathrm{Nm}^{3} @$ $3 \% \mathrm{O}_{2}$. During the winter testing, triplicate coal samples yielded coal mercury values ranging from $25-31 \mathrm{ng} / \mathrm{g}$, which converted to an average equivalent mercury concentration of 3.6 $\mu \mathrm{g} / \mathrm{Nm}^{3} @ 3 \% \mathrm{O}_{2}$ (11\%RSD). Triplicate ash samples yielded mercury values ranging from 750 $-810 \mathrm{ng} / \mathrm{g}$, which converted to an average equivalent mercury concentration of $8.7 \mu \mathrm{g} / \mathrm{Nm}^{3} @$ $3 \% \mathrm{O}_{2}(4 \% \mathrm{RSD})$. The nominal carbon in the ash (LOI) was $7.6 \%$. Cherokee Unit 3 burns a 
Colorado bituminous coal that is much lower in mercury content than the PRB sub-bituminous coal burned in Arapahoe Units 1 and 4.

\section{Mass Balance at Cherokee Unit 3}

Table 4-6 shows the mass balance analysis. The equivalent coal mercury value was $2.5 \mu$ g/ $\mathrm{Nm}^{3} @ 3 \% \mathrm{O}_{2}$, compared with $2.2 \mu \mathrm{g} / \mathrm{Nm}^{3} @ 3 \% \mathrm{O}_{2}$ measured at the reverse-gas baghouse inlet during summer tests. This represented $88.0 \%$ recovery of coal mercury. Mercury recovery at "ash+stack" was $4.1 \mu \mathrm{g} / \mathrm{Nm}^{3} @ 3 \% \mathrm{O}_{2}$, or $164 \%$ of coal $\mathrm{Hg}$. This high result was due to the hopper ash analysis, which showed a high level of mercury in both test series on this unit. Some of this variance may be due to the low overall mercury content of the coal burned in Cherokee Unit 3. During winter testing, the coal-Hg content was $3.5 \mu \mathrm{g} / \mathrm{Nm}^{3} @ 3 \% \mathrm{O}_{2}$, compared with 3.9 $\mu \mathrm{g} / \mathrm{Nm}^{3} @ 3 \% \mathrm{O}_{2}$ measured at the baghouse inlet. This represented 111\% recovery of coal mercury. Mercury recovery at the "ash+stack" is $8.7 \mu \mathrm{g} / \mathrm{Nm}^{3} @ 3 \% \mathrm{O}_{2}$, or 249\% of coal mercury.

Although the coal mercury and inlet mercury measurements on this unit compare well, stack emissions are extremely low, and the hopper ash value is believed too high to be reasonable. This affected the mass balance adversely, as illustrated on Figure 4-21. Obtaining a representative ash sample from a full-scale baghouse (Cherokee's baghouse has 14 hoppers) can be very challenging. The high mercury in ash value likely reflected this sampling difficulty.

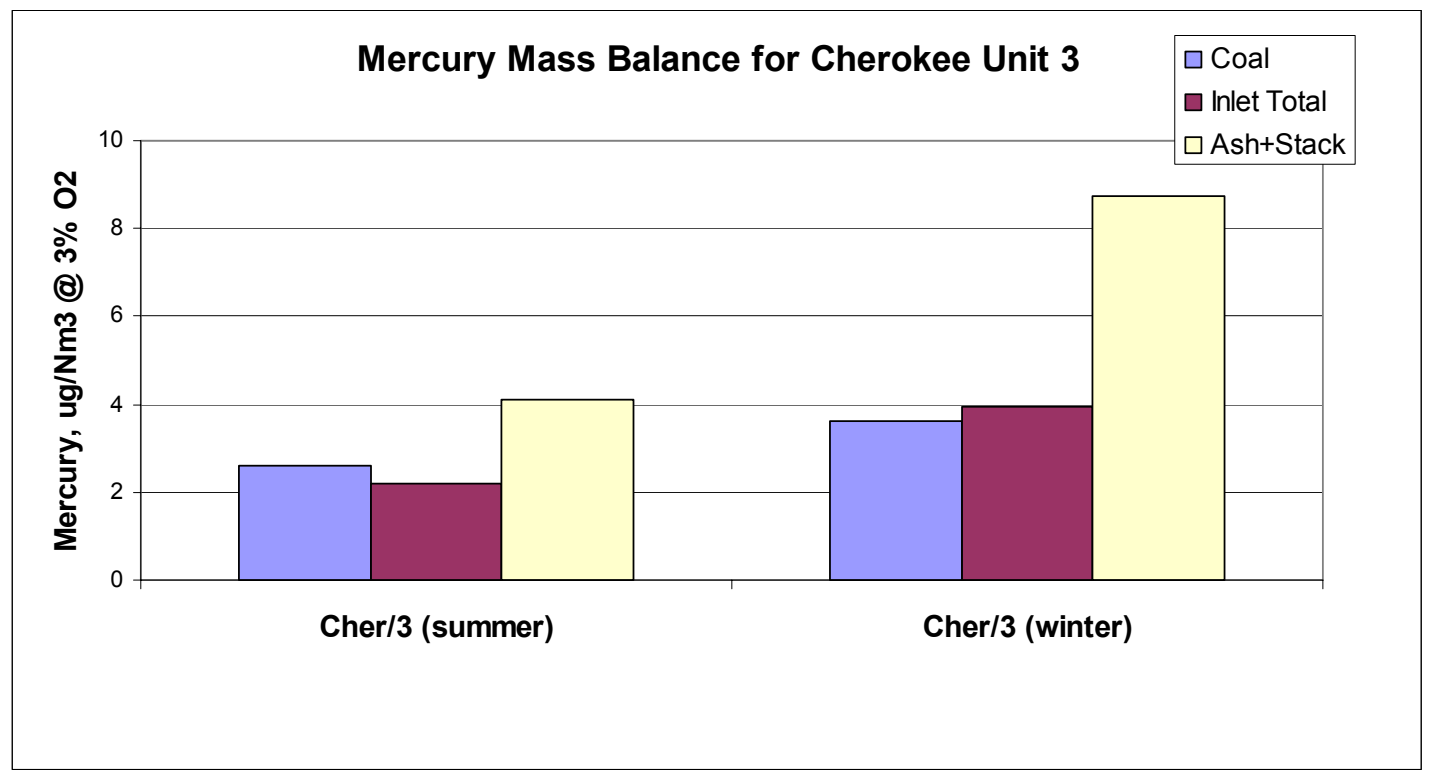

Figure 4-21. Mercury Mass Balance, Cherokee Unit 3. 


\section{Comanche Unit 2 Flue Gas Testing and Results}

Comanche Unit 2 was the only full-scale unit in which flue gas sampling for mercury content was performed per the EPA-approved protocol, the Ontario-Hydro Method. Three replicate test samples were obtained during a single test period on October, 1998. Testing followed the protocol described in the test methodology and shown in Table 4-4.

The inlet and outlet flue gas mercury concentration results are shown on Table 4-6 and Figure 4-22. The October test series yielded a very uniform data set that indicated an average mercury removal rate of $63 \%$ across the reverse-gas baghouse on the test unit. The mercury removal rates were consistent, with an $11.8 \%$ RSD for the data set. The particulate fraction of total inlet mercury at $31 \%$ was not high enough to account for all of the mercury removed across the baghouse. Therefore, some vapor-phase mercury was removed between the inlet and outlet sample locations. This indicated that this ash had additional sorbent capacity downstream of the inlet sampling location at a flue gas temperature of $299^{\circ} \mathrm{F}$. Since Ontario-Hydro testing was performed, values were obtained for both elemental and oxidized mercury. As shown in Figure 4-22, the partition of total inlet mercury was approximately $31 \%$ particulate, $21 \%$ oxidized vapor-phase, and $48 \%$ elemental vapor-phase. The stack outlet (vapor-phase) mercury partition was approximately $89 \%$ oxidized vapor-phase and $11 \%$ elemental vapor-phase. Thus as shown in Figure 4-22, elemental mercury was removed from the inlet flue gas stream. It seems likely that the elemental mercury continued to be adsorbed as the flue gas passed through the reversegas baghouse. It also appeared that elemental mercury was being converted to gaseous oxidized mercury. This conversion of elemental mercury to oxidized mercury has been observed in bench scale mercury sorbent testing in the presence of $\mathrm{SO}_{2}$ and $\mathrm{NO}_{2}$ by Miller et al (1998). 


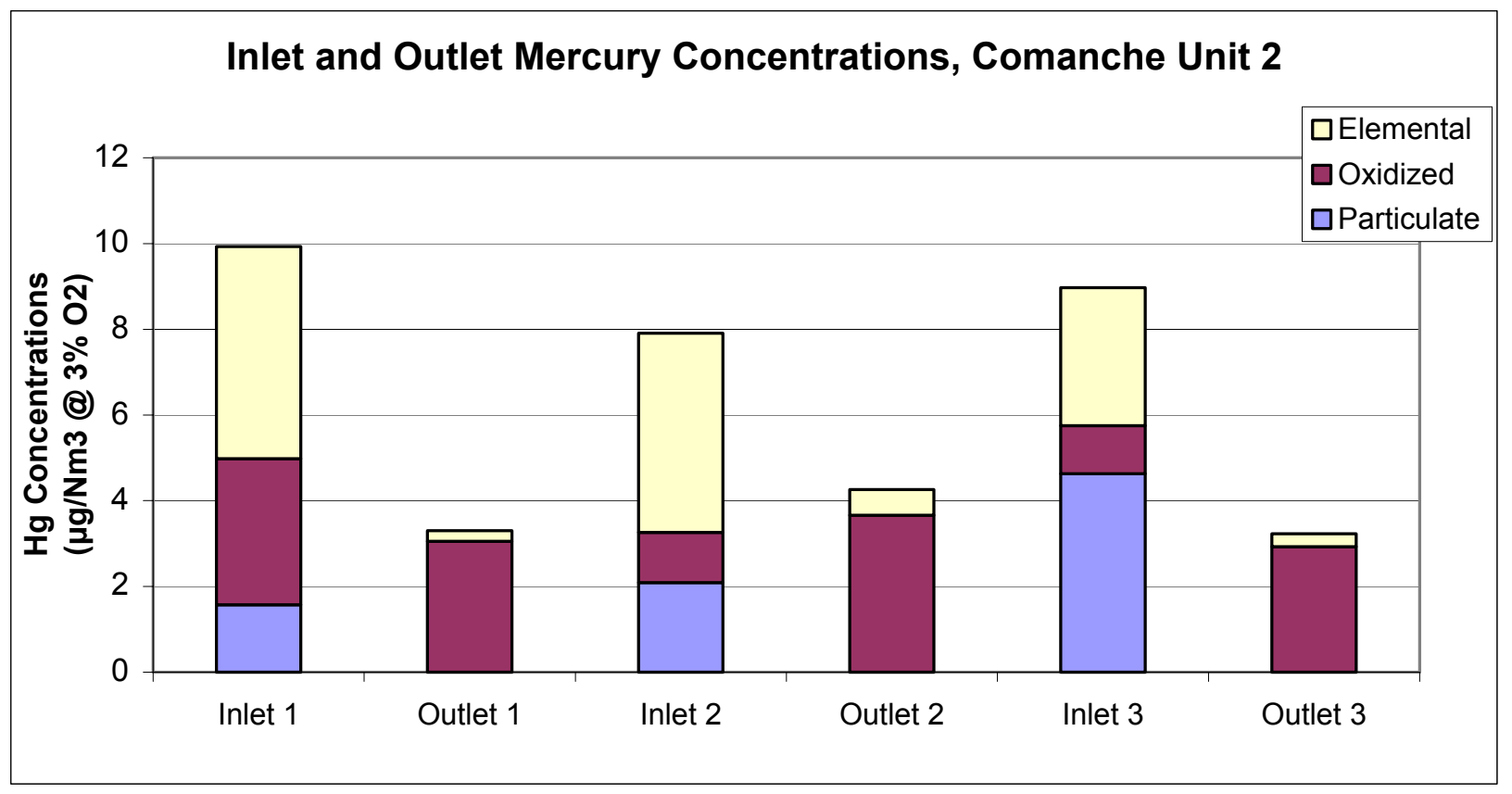

Figure 4-22. Inlet and Outlet Mercury Concentrations, Comanche Unit 2.

\section{Comanche Unit 2 Coal and Ash Analysis}

Coal and flyash samples submitted for mercury concentration analysis were composites of the multiple samples acquired during the triplicate flue gas tests. Three replicate coal samples were analyzed, yieldiing coal mercury values ranging from $57-70 \mathrm{ng} / \mathrm{g}$, which converted to an equivalent mercury concentration of $10.0 \mu \mathrm{g} / \mathrm{Nm}^{3} @ 3 \% \mathrm{O}_{2}$ (9\%RSD). Eight ash samples were analyzed, yielding ash mercury values ranging from $855-1160 \mathrm{ng} / \mathrm{g}$, which converted to an equivalent mercury concentration of $11.85 \mu \mathrm{g} / \mathrm{Nm}^{3} @ 3 \% \mathrm{O}_{2}(10.8 \% \mathrm{RSD})$. The nominal carbon in the ash (LOI) was $0.4 \%$.

\section{Mass Balance at Comanche Unit 2}

Table 4-6 shows the mass balance analysis for the sampling done at Comanche Unit 2, the host site for the ADA pilot where the activated carbon injection testing reported earlier was performed. Coal mercury was $10.1 \mu \mathrm{g} / \mathrm{Nm}^{3} @ 3 \% \mathrm{O}_{2}$, compared with $10.5 \mu \mathrm{g} / \mathrm{Nm}^{3} @ 3 \% \mathrm{O}_{2}$ measured at the reverse-gas baghouse inlet. This represented 104\% recovery of coal mercury. Mercury recovery at "ash + stack" was $11.9 \mu \mathrm{g} / \mathrm{Nm}^{3} @ 3 \% \mathrm{O}_{2}$, or $118 \%$ of coal $\mathrm{Hg}$. A graphic presentation of the Comanche 2 mercury mass balance is shown in Figure 4-23. 




Figure 4-23. Mercury Mass Balance, Comanche Unit 2.

\section{Hayden Unit 1 Flue Gas Testing and Results}

Unit 1 at Hayden station was selected for mercury testing for several reasons. First, earlier full-scale results had indicated that the Colorado bituminous coal burned in Cherokee Unit 3 created a fly ash that removed virtually all of the mercury from the flue gas for that unit; Hayden Unit 1 burned that same coal. Second, there was interest in determining if the spray dryer installed for $\mathrm{SO}_{2}$ control had any impact (positive or negative) on the removal of mercury in a full-scale unit. Third, if mercury removal rates were high for this unit, the fly ash would be considered a viable candidate for use as a mercury sorbent when reinjected at plants burning other coals. Laboratory and pilot-scale tests at the Comanche pilot plant have demonstrated the feasibility of using fly ash from selected PSCo plants as mercury sorbents.

ADA test crews conducted two unsuccessful attempts to obtain flue gas samples for mercury analysis at Hayden Unit 1. These attempts suffered from weather problems and a plant outage the first time, and from equipment failure the second time. On Oct. 16 and 17,1999 ADA personnel returned once again to the Hayden station to repeat full-scale mercury testing. On the $16^{\text {th }}$ ADA set-up test equipment, but was not able to perform a preliminary checkout test due to an outage on the generating unit. On the $17^{\text {th }}$ ADA collected three isokinetic mercury samples at 
the inlet, and four non-isokinetic samples at the outlet.

Table 4-7 shows the results of this testing. The inlet vapor values showed a wide variance in the triplicate measurements. Inlet particulate mercury concentrations were higher than expected with significant disparity in the measurements. Outlet mercury values were consistent, and well below one microgram per cubic meter, indicating a high level of removal across the particulate control equipment. Once the variance in the inlet sampling results was seen, an evaluation of the sampling technique was undertaken to attempt to determine an explanation.

One possibility was that the inlet sampling particulate filters contained trace concentrations of mercury either from their manufacture or from assembly and installation into the sampling train. It was discovered that vacuum grease had been used in the assemblies to assure that the fly ash collection filter housings did not leak. To assess the potential for filters and vacuum grease as alternate sources of mercury, samples were submitted to Frontier Geosciences for analysis. Results indicated that the vacuum grease contributed to an increased mercury level in the samples, but that the measured mercury on a filter contaminated with the vacuum grease was 87 nanograms, compared to a minimum of 250 nanograms of mercury measured for the filters from the isokinetic samples taken at Hayden. Thus the mercury contamination in the grease could not account for more than about $1 / 3$ of the mercury found in the particulate filter samples.

As an alternative method of determining the inlet mercury concentration at the Hayden generating unit, ADA used a model developed to predict flue gas mercury content from the measured mercury concentration in the feed coal. The model employed a set of combustion equations to predict the total gas volume, and then assumed that the mercury was present in gas stream as vapor and deposited on the fly ash. Measurements by ADA and other investigators of bottom ash at a wide variety of sites have indicated that there is no detectable mercury in bottom ash samples.

A representative coal mercury content for the Colorado coal burned at the Hayden station was obtained from EPA data collected in 1999 under its Information Collection Request (ICR). The ICR required coal-burning power plants to sample coal shipments on a routine basis, and to submit those samples for analysis of mercury content. The data was reported quarterly to EPA, and placed into an internet-accessible data base by the agency. ADA accessed the database, and performed some statistical analyses on the information for the Hayden coal. Two values for 
average coal mercury content were generated, one for the full year, and a second for the month preceding the October 17 test date. The full-year average mercury content of the coal burned at Hayden was 35 parts per billion, while for the month prior to testing the coal was found to have a somewhat higher mercury concentration of 54 parts per billion.

An ultimate analysis of the Twenty Mile mine coal was provided by Public Service Company, and used along with the mercury content for the month prior to testing to calculate using the combustion model a mercury concentration for the flue gas stream at the inlet to the particulate control equipment. This value was $7.2 \mu \mathrm{g} / \mathrm{Nm}^{3}$ mercury in the flue gas. With this as an inlet mercury concentration, and using the average outlet mercury concentration as measured during the testing, the mercury removal efficiency across the emissions control equipment at Hayden was $94.7 \%$. This value is similar to the very high mercury removal rate seen at the Cherokee Unit 3 site. Almost total mercury removal in this unit indicated that there was likely no detrimental effect due to the spray dryer scrubber. Since the only test case run was one where the spray dryer was in operation, any contribution of the spray dryer to improved mercury removal cannot be evaluated.

Table 4-7. Results of Hayden Full Scale Testing.

\begin{tabular}{|c|c|c|c|}
\hline $\begin{array}{c}\text { Measured Inlet } \\
\text { Vapor Phase } \\
\text { Mercury }\left(\boldsymbol{\mu g} / \mathbf{n m}^{\mathbf{3}}\right)\end{array}$ & $\begin{array}{c}\text { Measured Inlet } \\
\text { Particle Phase } \\
\text { Mercury }\left(\boldsymbol{\mu g} / \mathbf{n m}^{\mathbf{3}}\right)\end{array}$ & $\begin{array}{c}\text { Total Inlet Mercury } \\
\text { Concentration } \\
\left(\boldsymbol{\mu g} / \mathbf{n m}^{\mathbf{3}}\right)\end{array}$ & $\begin{array}{c}\text { Measured Outlet } \\
\text { Vapor Mercury } \\
\left(\boldsymbol{\mu g} / \mathbf{n m}^{\mathbf{3}}\right)\end{array}$ \\
\hline 6.43 & 4.66 & 11.10 & 0.36 \\
\hline 2.52 & 35.43 & 37.94 & 0.44 \\
\hline 24.07 & 9.56 & 33.63 & 0.34 \\
\hline & & & Avg. \\
\hline
\end{tabular}

\subsection{Waste Characterization}

The purpose of this task was to gather information on the material collected in the particulate control module of the Comanche pilot, which consisted of activated carbon mercury sorbent along with fly ash. Since disposal or sale of fly ash is a major issue for coal-burning power plants, there was considerable interest in quantifying the impact of the activated carbon sorbent on bulk properties of the fly ash that affect its disposition. One major concern with the use of activated carbon as a mercury sorbent was that the carbon content of the fly ash would be 
increased to the point where the ash could not be sold for use as a pozzolan material in concrete admixtures. Another was that the mercury collected on the activated carbon would be easily leached, potentially leading to the classification of the fly ash as a hazardous waste, if the carbon-containing fly ash failed the EPA Toxic Leaching Test Procedure (TCLP). Both these issues were addressed in activities carried out under this task.

An understanding of how re-injected flyash adsorbs mercury was also sought. An experiment was designed to provide some insight into relevant properties of Cherokee 3 fly ash, which had been shown to be an excellent sorbent of mercury in the full-scale generating unit survey. A Bahco centrifugal classifier was used to fractionate a sample of Cherokee 3 fly ash. The Bahco classifier divided the sample into fractions of similar-sized particles with known diameters. Each size fraction was then analyzed for both carbon and mercury content. These tests were run to determine if the mercury capacity of the fly ash used as sorbent was attributable only to the carbon content of the fly ash. The ultimate goal of these tests was to understand how some ashes sorb mercury, and to identify separation strategies that might enrich an ash product in mercury-attracting constituents.

One reason to examine the reinjection of fly ash as a mercury sorbent in flue gas is that the use of activated carbon for mercury removal may have a deleterious impact on the salability of the collected flyash/activated carbon mixture. Flyash sold by PSCo for use in concrete admixtures must have a carbon content below 1\% LOI (Loss On Ignition). This is a marketdriven limit, as ASTM standards for fly ash use in concrete allow LOI levels as high as 6\%. Activated carbon injection for mercury control at a rate of $1 \mathrm{lb} / \mathrm{MMacf}$ would increase LOI by $0.47 \%$ (based on an ash mass loading of 1.5 grains/acf at the Comanche 2 station). Injection at 4 lb/MMacf would increase LOI by $1.87 \%$. Comanche 2 fly ash LOI typically runs between 0.4 and $0.9 \%$. Based on increased LOI alone, carbon injection at a low rate could render Comanche 2 ash uncompetitive for sale on the open market. However, activated carbon has also been demonstrated to degrade ash properties for use in concrete to a greater degree than the simple increase in LOI carbon. The high surface area of activated carbon absorbs air-entraining agents added to the concrete mixture to improve the ability of the mixture to withstand freeze/thaw cycles. These air-entraining agents trap small air bubbles in the matrix of the concrete, which allow the concrete to expand and contract without damage during freeze/thaw cycles.

ADA supplied a sample of Comanche ash mixed with activated carbon collected from the hopper of the pilot plant during a typical injection test to Boral Material Technologies, a marketer of fly ash for use in concrete. Boral scientists performed tests to determine the amount of air-entraining agent required to obtain an acceptable concrete mixture with this activated 
carbon-contaminated fly ash. Results showed an increase by a factor of 15 in the amount of airentraining agent needed to match properties of concrete made with typical (uncontaminated) Comanche 2 ash (Majors, 1999).

Concrete manufacturers using fly ash collected with activated carbon as a pozzolan additive would be faced with the added expense of a significant increase in air-entraining agent consumption. This in itself would not be enough to forego the use of activated carbon as a mercury sorbent material in coal-fired flue gases, as the cost of air-entraining agent is a minor factor in concrete production. A greater concern is the inconsistency in activated carbon content of the fly ash that would be seen with intermittent injection of carbon. For example, in one operating scenario a station may only inject carbon for trimming $\mathrm{Hg}$ emissions during peak load. Users of fly ash in concrete admixture are most interested in a consistent fly ash product so that the recipe of additives used in preparation of the concrete can be held constant on a long-term basis.

\section{TCLP Testing}

Several ashes collected over the duration of the pilot plant testing and full-scale generating plant mercury surveys have been tested for mercury concentration and leachability by TCLP (Toxicity Characteristic Leaching Procedure). In discussions with ADA, Hazen Laboratories confirmed that TCLP testing is most commonly used to indicate a material's suitability and stability for landfilling, and is often sufficient to allow issuance of a landfill permit. It was also suggested that column leaching tests may be a useful technique in evaluating the stability of mercury bound to activated carbon and fly ash. This procedure involves trickling water though a vertical column of ash at a rate that would simulate groundwater flows due to rainfall. The effluent is then measured for pollutants ( $\mathrm{pH}$, conductivity, trace metals etc.). This procedure has also been used for permitting and is considered a valuable tool for predicting the fate of trace constituents of interest when deposited in a landfill.

TCLP analysis was performed by Hazen on ash that was collected during a carbon injection test at the Comanche pilot. The carbon was injected into the pilot unit at a rate of 5lbs/MMacf. The test did not detect any mercury in the leachate (less than $0.0002 \mathrm{mg} / \mathrm{L}$ detected, $0.2 \mathrm{mg} / \mathrm{L}$ is regulatory limit). This result is consistent with other TCLP analyses run throughout the pilot testing.

TCLP results from four fly ash samples are summarized in Table 4-8. The concentration of mercury in the leachate was below the limit of detection for all samples tested. The samples 
included two from the mercury control pilot that were mixtures of fly ash and activated carbon, and two fly ash samples from Public Service generating units. Fly ash in the flue gas of the Comanche host has been shown to remove about $60 \%$ of the resident mercury, and fly ash from the Cherokee 3 plant removes $98 \%$ of the mercury found at that site. These samples were analyzed to determine if mercury sorbed on the fly ash could be leached into groundwater per the TCLP protocol. A review of the TCLP test results for a sample extracted from the Comanche pilot and another taken during the Long-Term Carbon Injection test shows that mercury sorbed onto the activated carbon did not leach out to any measurable level. Thus per current regulation, the fly ash/activated carbon mixture collected in a mercury removal system would be suitable for disposal as a nonhazardous waste. This finding may be site specific, as the mechanism of mercury capture is highly dependent on the flue gas constituents present, i.e. variability in acid gases and chlorine concentration may favor the formation of mercury species which are more soluble than those captured at this site. Mercuric chloride, for example, is more soluble than elemental mercury.

Table 4-8. TCLP Results from Selected Fly Ash Samples.

\begin{tabular}{|c|c|c|c|c|c|}
\hline Metal & $\begin{array}{c}\text { Comanche } \\
\text { Host } \\
(\mathrm{mg} / \mathrm{L})\end{array}$ & $\begin{array}{c}\text { Comanche } \\
\text { Pilot } \\
\text { (mg/L) }\end{array}$ & $\begin{array}{c}\text { Long Term } \\
\text { Carbon Injection } \\
(\mathrm{mg} / \mathrm{L})\end{array}$ & $\begin{array}{c}\text { Cherokee } 3 \\
(\mathrm{mg} / \mathrm{L})\end{array}$ & $\begin{array}{l}\text { Regulatory } \\
\text { Limit } \\
(\mathrm{mg} / \mathrm{L})\end{array}$ \\
\hline As & $<0.24$ & $<0.24$ & $<0.24$ & $<<0.24$ & $\overline{55}$ \\
\hline $\mathrm{Ba}$ & 0.71 & 1.3 & 0.87 & 1.1 & 100 \\
\hline $\mathrm{Cd}$ & 0.026 & 0.023 & $<0.013$ & 0.042 & 1 \\
\hline $\mathrm{Cr}$ & 0.1 & 0.11 & 0.13 & 0.13 & 5 \\
\hline $\mathrm{Pb}$ & $<0.29$ & $<0.29$ & 0.44 & $<0.29$ & 5 \\
\hline $\mathrm{Se}$ & $<0.65$ & $<0.65$ & $<0.65$ & $<0.65$ & 1 \\
\hline $\mathrm{Ag}$ & $<0.013$ & $<0.013$ & $<0.013$ & $<0.013$ & 5 \\
\hline $\mathrm{Hg}$ & $<0.0002$ & $<0.0002$ & $<0.0002$ & $<0.0002$ & 0.2 \\
\hline
\end{tabular}

\section{Mercury and Ash Interactions}

Additional waste characterization activities included testing to quantify mercury associated with ash particle size fractions, and carbon separation fractions. Cherokee unit 3 ash has been found to remove most of the mercury in the flue gas as it passes through the Cherokee baghouse; this same ash performed quite well as an injected sorbent in the Comanche pilot baghouse. For this reason Cherokee 3 ash was chosen for further evaluation, and was separated into size fractions by the Bahco centrifugal classification method. The results of the Cherokee 3 ash particle size separation are shown in Figure 4-24. 
The Bahco classifier separates sample into nine size fractions, three more size fractions were obtained by sieve separation before use of the Bahco technique. Each fraction of Cherokee 3 ash was analyzed to determine its fractional concentration of total carbon in the ash sample, with results as presented in Table 4-9. Carbon concentration varied considerably among particle size fractions. The carbon was seen to be most concentrated in the smallest and largest particle size cuts. The coarsest fraction $(>149 \mu \mathrm{m})$ contained $51.85 \%$ carbon (by mass), while the finest fraction $(<2.5 \mu \mathrm{m})$ contained $13.09 \%$ carbon (by mass). This bimodal distribution has been seen in other ashes. The larger carbon particles are mostly unburned coal and incompletelycombusted spheres of porous char. During handling some of these char particles shatter into small carbon fragments which may increase the carbon content of the smallest size fraction. A physical characterization of these fractions via electron microscopy or other techniques has not been conducted.

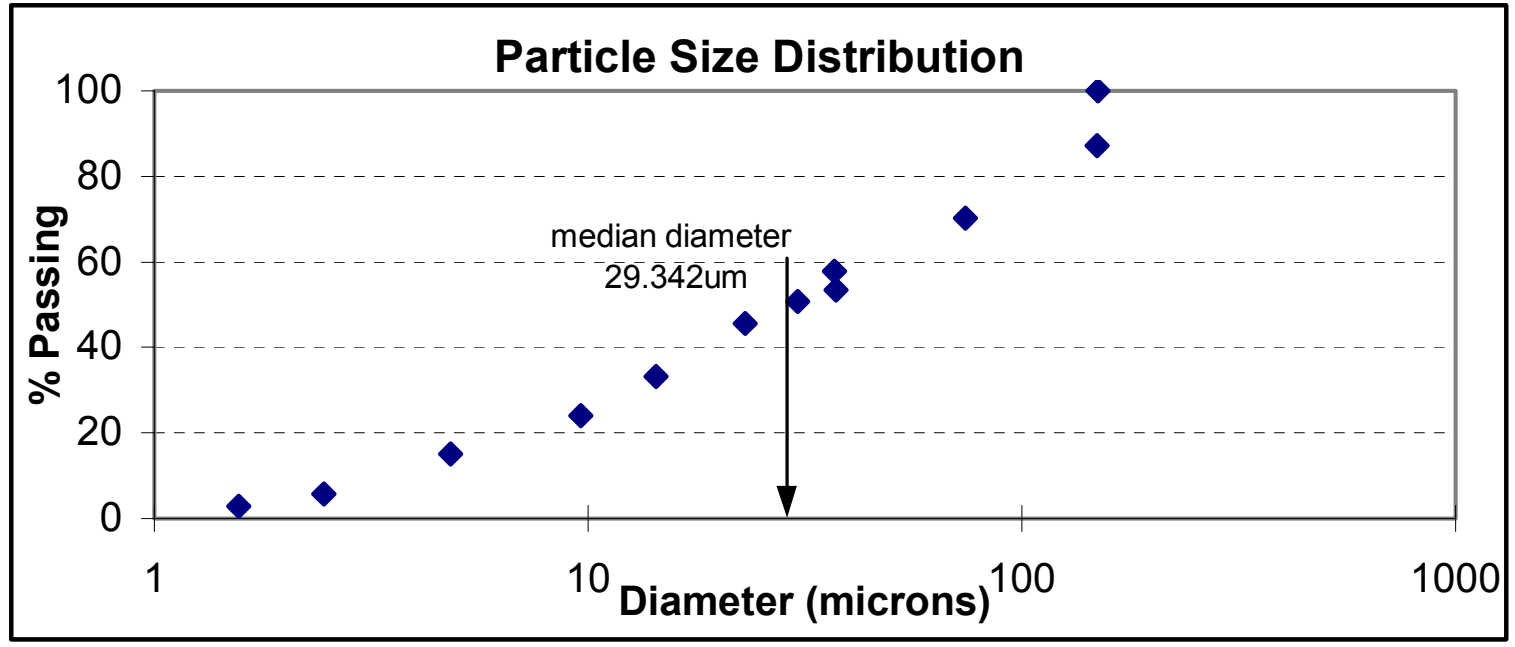

Figure 4-24. Particle Size Distribution of Cherokee 3 Ash.

For mercury analysis the Bahco-separated fractions were grouped into five categories according to size. The size ranges of these categories and the corresponding mercury distribution are shown in Table 4-10. The results indicate that most mercury is found in the fractions that contain significant carbon concentrations, and that the mercury is concentrated when surface area per unit volume is high (when particle size is small). Over one-quarter of the mercury is found on the $5.8 \%$ of the ash mass in the smallest size fraction, that contained only $6 \%$ of the total carbon the fly ash fraction. This means that the mercury in the smallest size fraction was concentrated by a factor of 4 in comparison to the carbon, implying that the mercury sorption is due to more than just the presence of carbon in the fly ash. This suggests that vapor phase mercury may bind to this high specific-surface area fraction of both carbon and fly ash 
particles. The small size/high surface area fraction appears to contribute strongly to the ash's affinity for mercury vapor, and would be the best candidate for isolation and further testing. This finding is corroborated by the University of Kentucky results which found that in a sample separated with a triboelectric technique the majority of the mercury was found in the fraction with the small carbon particles. However, it is also important to recall that one of the fly ash samples that was an effective mercury sorbent in a full-scale power plant showed significant sorption capacity after being heat-treated to remove virtually all the carbon present in the ash. One interpretation of this behavior is that carbon particles in the fly ash are not the sole contributor to mercury sorption capacity of fly ash from western coals.

Table 4-9. Carbon Mass Fractions for Separated Size Cuts.

\begin{tabular}{|r|c|c|}
\hline Cut \# & Size Range & Carbon \% \\
\hline \hline 1 & $<1.564$ & 14.23 \\
\hline 2 & $1.564-2.453$ & 12.04 \\
\hline 3 & $2.453-4.81$ & 9.06 \\
\hline 4 & $4.81-9.62$ & 8.98 \\
\hline 5 & $9.62-14.316$ & 7.66 \\
\hline 6 & $14.316-22.997$ & 7.28 \\
\hline 7 & $22.997-30.423$ & 8.54 \\
\hline 8 & $30.423-37.26$ & 8.95 \\
\hline 9 & $37.26-37$ & 0.49 \\
\hline 10 & $37-74$ & 0.72 \\
\hline 11 & $74-149$ & 7.24 \\
\hline 12 & $>149$ & 51.85 \\
\hline
\end{tabular}




\section{Table 4-10 Mercury and Carbon Distribution by Particle Size Fraction (Sizes mixed from Bahco separation fractions).}

\begin{tabular}{c|c|c|c|c}
$\begin{array}{c}\text { Size Cut } \\
(\boldsymbol{\mu m})\end{array}$ & $\begin{array}{c}\text { Mass } \\
\text { Fraction }\end{array}$ & $\begin{array}{c}\text { Carbon Dist. } \\
\%\end{array}$ & $\begin{array}{c}\text { Mercury } \\
\text { Dist., \% }\end{array}$ & Hg/C Ratio \\
\hline$>149$ & 12.7 & 52.2 & 13.4 & 0.26 \\
$74-149$ & 17.0 & 9.7 & 3.0 & 0.31 \\
$37.3-74$ & 16.7 & 0.9 & 0 & 0 \\
$2.45-37.3$ & 47.7 & 31.1 & 58.3 & 1.87 \\
$0-2.45$ & 5.8 & 6.0 & 25.3 & 4.21
\end{tabular}

Pittsburgh Mineral \& Environmental Technology (PMET) separated a sample of Cherokee 3 ash using a proprietary technology. This method involves a preliminary screening of ash (normally 200 mesh), followed by gravity separation of the minus 200 mesh fraction. The method is designed to produce a high-LOI carbon concentrate. In this case the procedure was not optimized in order to generate a significant amount of carbon-enriched material, as yield decreases with efficiency of separation. This process results in three fractions. The material which passes the sieve ( called "sieved ash") is (normally) discarded, while the +200 mesh material is gravity-separated into a "coarse carbon product", and a "coarse ash byproduct". As with the Bahco method, Cherokee 3 ash was used as the feedstock. Data from another separation technique produced results similar to those obtained using the Bahco classifier. These results are shown in Table 4-11.

The coarse carbon-concentrated materials from the two methods have similar LOIs. The Bahco $(>149 \mu \mathrm{m})$ is $51.85 \% \mathrm{LOI}$, and the PMET sample is $55.8 \% \mathrm{LOI}$. Both samples are also similar in mercury content, $0.6 \mathrm{ppm}$ from the Bahco method and $0.617 \mathrm{ppm}$ from the PMET method. These results corroborate the data from the Bahco separation, although the PMET technique does not capture the sub-5 $\mu \mathrm{m}$ carbon particles that are of greatest interest. 
Table 4-11. Fractions from PMET Separations.

\begin{tabular}{cccc}
\hline Sample & Weight \% & $\begin{array}{c}\text { Carbon Weight } \\
\text { \% }\end{array}$ & $\begin{array}{c}\text { Mercury } \\
\text { Concentration }\end{array}$ \\
\hline Bulk Cherokee 3 & 100 & 9.42 & $454.02 \mathrm{ng} / \mathrm{g}$ \\
Ash Concentrate & 6 & 15.8 & $192.79 \mathrm{ng} / \mathrm{g}$ \\
$\quad$ Sieved Ash & 91.1 & 6.78 & $116.91 \mathrm{ng} / \mathrm{g}$ \\
Carbon Concentrate & 2.9 & 55.8 & $617.12 \mathrm{ng} / \mathrm{g}$ \\
\hline
\end{tabular}

In this task, activities have addressed the potential use of fly ash as a mercury sorbent material. A literature review was undertaken to determine available technologies for the separation of carbon from fly ash or for the size separation of fly ash to produce a fly ash size fraction suitable for use as a mercury sorbent. Several technologies were identified as available in either commercial or developmental stages. Prater Industries of Chicago attempted to perform a size separation by air classification of a small sample of Cherokee 3 fly ash which was not successful. The University of Kentucky Center for Applied Energy Research has a triboelectric separation technology that has been demonstrated on a laboratory scale. This method employs triboelectric forces to isolate the smallest carbon particles that are believed to have strong affinity for mercury. A small sample of Cherokee 3 fly ash was successfully treated in the UK lab-scale apparatus; recall that Cherokee 3 fly ash has a nominal LOI of 7.6\%. PMET also has a proprietary technology for the separation of carbon from fly ash that was noted in an earlier discussion. Testing of a carbon-enriched fly ash material has been proposed for the pilot with funding from other programmatic sources at DOE.

In order to demonstrate the long term stability of mercury bound to ash and/or activated carbon, mercury concentration tests were performed at scheduled intervals on samples stored at the pilot plant site. Ash samples from Comanche 2 (the host unit) and a sample of Comanche pilot ash collected during carbon injection (Long-Term C.Inj.) were tested for baseline mercury concentration. After 8 months in a sealed container, ash from Comanche 2 was tested for mercury concentration; results showed that the mercury concentration in the fly ash sample was within $5 \%$ of the initial value. Samples from the long-term carbon injection hopper collection and from the Comanche 2 host baghouse were also analyzed after eight months, with mercury levels of the samples found to remain very close to the initial values. The data shown in Table 4- 
12 indicates that once captured by either activated carbon or fly ash, the mercury tends to remain on the particles of the sorbent.

Table 4-12. Stability of Mercury on Fly Ash

\begin{tabular}{||l|c|c|c|}
\hline Sample & $\begin{array}{c}\text { Baseline Hg } \\
\text { (ng/gram) }\end{array}$ & $\begin{array}{c}\text { Hg at 8 Months } \\
\text { (ng/gram) }\end{array}$ & $\begin{array}{c}\text { Loss of Hg } \\
\text { at 8 months }\end{array}$ \\
\hline \hline Cherokee 3 (closed jar) & 171 & 199 & $+16 \%$ \\
\hline Comanche 2 & 1128 & 1081 & $4 \%$ \\
\hline Long-Term Carb. Inj. & 2159 & 1951 & $10 \%$ \\
\hline Comanche 2 Host & 1128 & 1153 & $+2 \%$ \\
\hline
\end{tabular}

\subsection{Cost Modeling}

In order to facilitate use of the results of this project in the estimation of full-scale costs for mercury removal with activated carbon injection, an economic model was formulated and applied to two different generating plant configurations to predict costs of mercury removal. The approach taken to the modeling effort was to utilize a cost prediction model first proposed by EPA in the Mercury Study Report to Congress (1997), and to modify that model to account for size changes in the equipment cited in the configurations of interest. One variable required for use of the modified EPA model was the injection rate for activated carbon required to meet target mercury removal rates. To finalize injection rates of activated carbon for the several plant configurations included in the study, results from the pilot plant were fitted to multiple linear regression models for each particulate control configuration. These performance regression equations were then used to predict carbon injection rates for the full-scale plant configurations defined in the study.

\section{Model of Mercury Removal}

The mercury removal capacity of Norit carbon was evaluated at the Comanche power station in Pueblo, CO in a 600-acfm pilot plant under a range of operating conditions, reported earlier in this document. The test plan investigated the effects of flue gas temperature, inlet mercury concentration, and carbon injection rate for mercury removal from flue gas taken upstream of the facility's baghouse. Mercury removal tests were conducted with the pilot plant particulate control module (PCM) configured as an ESP, a reverse-gas baghouse, or as a pulse-jet bag house to evaluate the mercury capture efficiency of each PCM device. 
In order to estimate the cost to remove mercury from a full-scale coal-fired generating facility, two elements were required. The first was an estimate of the capital costs for the equipment needed to inject the activated carbon, and the second was an estimate of the required carbon sorbent injection rate to meet target mercury removal levels from the flue gas. These elements were then input to the EPA cost prediction model to develop a specific cost for the removal of mercury from the flue gas that included operating costs and amortization of capital costs. A multiple linear regression model was developed for each PCM to predict mercury removal efficiency as a function of process variables, including the injection rate of activated carbon. The models are of the form:

$$
\mathbf{Y}=\mathbf{a}\left(\mathbf{T}_{\text {Fluegas }}\right)+\mathbf{b}\left(\mathbf{C}_{\text {Mercury }}\right)+\mathbf{c}\left(\mathbf{M}_{\text {Carbon }}\right)^{\mathbf{n}}+\mathbf{d}
$$

where $\mathrm{Y}$ is the percent mercury removed from the flue gas during a test, $\mathrm{T}_{\text {fluegas }}$ is the flue gas temperature, $\mathrm{C}_{\text {mercury }}$ is the inlet mercury concentration, and $\mathrm{M}_{\text {carbon }}$ is the carbon injection rate, $\mathrm{n}$ is an experimentally determine exponent for each PCM device, and a, b, c, and d are regression coefficients. An exponential approach was assumed for the carbon injection ratio, since the data graphs appeared to show a nonlinear dependence of mercury removal fraction on the carbon injection ratio. Data from the pilot testing were input to the models to calculate the coefficients. The results of these calculations are summarized in Table 4-13 As presented in the final column, the regressions were of reasonable quality, with two of the three showing a coefficient of determination greater than 0.9 .

Table 4-13. Multiple Linear Regression Analyses for Mercury Removal Tests

\begin{tabular}{|c|c|c|c|c|c|c|}
\hline $\begin{array}{c}\text { PCM } \\
\text { Device }\end{array}$ & Coeff. a & Coeff. b & Coeff. c & $\begin{array}{c}\text { Constant } \\
\mathbf{d}\end{array}$ & $\begin{array}{c}\text { Exponent } \\
\mathbf{n}\end{array}$ & $\begin{array}{c}\text { Regress. } \\
\text { Coeff. of } \\
\text { Determin. }\end{array}$ \\
\hline ESP & -0.1220 & -1.455 & 30.75 & 79.93 & 0.56 & 0.74 \\
\hline $\begin{array}{c}\text { Reverse- } \\
\text { Gas }\end{array}$ & -0.5630 & -1.535 & 61.50 & 213.7 & 1.27 & 0.96 \\
\hline Pulse-Jet & -0.2964 & 1.279 & 29.31 & 144.4 & 0.34 & 0.92 \\
\hline
\end{tabular}

These regression models were used to predict baseline mercury removal (no carbon injection), and the carbon injection rates needed for $70 \%$ and $90 \%$ mercury control levels for two sizes of generating units, $100 \mathrm{MW}$ and $975 \mathrm{MW}$ electric output. Baseline and carbon injection rates were determined for two flue gas temperatures, 1) nominal flue gas temperature of $300^{\circ} \mathrm{F}$ and 2) gas cooled to a temperature of $200^{\circ} \mathrm{F}$ using spray cooling. The mercury concentration in 
the flue gas from the coal burned in the units was the same for all calculations at $10 \mu \mathrm{g} / \mathrm{dscm}$.

Pilot test data from the Comanche facility showed that the best baseline mercury removal occurred with the PCM in the pulse-jet baghouse configuration, and the lowest removal rate was with the ESP configuration. These results were reflected in the predictions generated with the multiple linear regression models. Because of the high baseline removal with the pulse-jet baghouse, the model predicts that no carbon injection is needed for the $70 \%$ and $90 \%$ mercury control levels at the $200^{\circ} \mathrm{F}$ flue gas temperature, as well as for the $70 \%$ control level at the $300^{\circ} \mathrm{F}$ temperature. Table 4-14 summarizes the results for baseline mercury removal and carbon injection ratios needed for $70 \%$ and $90 \%$ mercury control for those conditions where carbon injection is needed to meet target mercury removal levels. Carbon injection ratios range from as low as $0.45 \mathrm{lb}$ per million actual cubic feet of flue gas to as high as $12.57 \mathrm{lb}$ per MMacf. There is a dramatic reduction in the required ratios at the lower flue gas temperature. As noted earlier, the ESP configuration is the most difficult from which to remove mercury with the injection of activated carbon; it requires as much as 3.5 times the carbon of the reverse-gas baghouse configuration to reach the $90 \%$ control level at the high flue gas temperature.

The amounts of carbon required for mercury control at target removal levels on an annual basis were predicted using these regression model results for a set of plant configurations. The annual carbon usage levels were then incorporated into an economic model to estimate the specific costs for mercury control for various particluate control devices, flue gas temperatures, and mercury control levels included in the study. 
Table 4-14. Summary of Predicted Carbon Injection Rates for a PRB-fired Plant

\begin{tabular}{|c|c|c|c|}
\hline \multicolumn{4}{|c|}{ Data at $300^{\circ} \mathrm{F}$ Flue Gas Temperature } \\
\hline \multirow[b]{2}{*}{ Configuration } & \multirow{2}{*}{$\begin{array}{l}\text { Baseline Mercury } \\
\text { Removal Rate }\end{array}$} & \multicolumn{2}{|c|}{ Carbon Injection Ratio, lb/MMacf } \\
\hline & & $70 \%$ Control & $90 \%$ Control \\
\hline ESP & $29 \%$ & 6.21 & 12.57 \\
\hline Reverse-gas baghouse & $47 \%$ & 2.64 & 3.62 \\
\hline Pulse-jet baghouse & $68 \%$ & None & 1.53 \\
\hline \multicolumn{4}{|c|}{ Data at $200^{\circ} \mathrm{F}$ Flue Gas Temperature } \\
\hline & \multirow{2}{*}{$\begin{array}{l}\text { Baseline Mercury } \\
\text { Removal Rate }\end{array}$} & \multicolumn{2}{|c|}{ Carbon Injection Ratio, lb/MMacf } \\
\hline Configuration & & $70 \%$ Control & $90 \%$ Control \\
\hline ESP & $41 \%$ & 3.33 & 8.46 \\
\hline Reverse-gas baghouse & $72 \%$ & None & 0.45 \\
\hline Pulse-jet baghouse & $98 \%$ & None & None \\
\hline
\end{tabular}

Economic Model

The cost of installing and operating a carbon injection system to remove mercury from coal-fired flue gas has been estimated and presented in EPA's Mercury Study Report to Congress (1997). The EPA report developed costs for 90\% mercury control at a 975-MW(e) and a 100MW(e) power plant. Annual costs were based on total capital costs, operating labor and materials, maintenance labor and materials, power consumption, carbon cost, disposal costs, overhead, taxes and insurance. Capital costs were amortized over a 20 -year period at an interest rate of $7 \%$.

For this report, the EPA cost model was adjusted to estimate the annual total capital and operating costs for power plants burning Powder River Basin (PRB) coal. The approach was to use a logarithmic relationship to scale costs similar to the "sixth-tenths factor" from the Chemical Engineer's Handbook (Perry, 1973). The basic form of the sixth-tenths factor is:

\section{New Cost $=$ Old Cost $(\text { New Capacity/Old Capacity })^{0.6}$}

The Perry scaling equation was adapted for use in this study by replacing the 0.6 exponent with exponents suitable for the dry carbon injection and spray cooling systems. This was done by 
substituting listed cost and capacity values from the EPA analysis, and determining exponents needed to satisfy the equation of the form shown above. These values for exponents are then substituted for the 0.6 value in the Perry equation, and used to scale cost estimates for capital, operations and maintenance, and for power and carbon disposal. The "capacity" variable in the Perry equation was the amount of activated carbon injected into the flue gas stream. It was found that the exponent for capital costs adjustments had a value of 0.68 . The same approach was used to estimate operating and maintenance cost adjustments as well as power and disposal cost adjustments. The exponents for operating and maintenance costs was 0.33 and nearly 1.0 for power and carbon disposal costs.

Annual carbon consumption values for target mercury control levels in power plants burning PRB coal were determined from the mercury removal models discussed in the previous section. The same plant availability factor of $65 \%$ used in the EPA cost estimate was used in calculating the annual carbon consumption for this economic analysis.

Cost estimates for these coal- and configuration-specific cases were then made using adjustments to the capital, operating and maintenance, and power and disposal costs computed with the Perry equation modified with the previously-noted exponents. The old cost and old capacity values were those from the EPA study, and the new capacity was that predicted by the ADA mercury removal model. The new cost was then calculated from the modified Perry scaling equation.

Cost estimates for mercury removal via carbon injection coupled with spray cooling were also made. Again, the EPA model was used as the base case, which was presented for both the 975-MW and 100-MW plants. Gas cooling and carbon injection costs were listed separately, which facilitated the scaling of these processes individually. All carbon injection system capital costs for plants burning PBR coal were estimated using the modified sixth-tenths factor based on the ratio of the predicted carbon injection rate to the EPA carbon injection rate for the same plant configuration and the exponent of 0.68 derived from the EPA model data. The same exponents used to determine the total annual costs for a carbon injection system were used to estimate costs for a plant operating with spray cooling, based on the ratio of gas flow rate through the plant to the EPA plant configuration.

\section{Basic Assumptions for the Cost Estimate}

This section outlines the basic assumptions used in the cost estimate model. Table 4-15 
below presents the factors included in the cost estimate model and the basis used in the estimating process.

Table 4-15. Factors Considered in the Cost Model and Their Basis

\begin{tabular}{|c|c|}
\hline Model Factor & Basis \\
\hline Plant generating capacity & 975-MW and 100-MW \\
\hline Plant annual availability & $65 \%$ \\
\hline Mercury concentration in flue gas & $10 \mu \mathrm{g} / \mathrm{dscm}$ \\
\hline Desired mercury removal efficiency & $70 \%$ and $90 \%$ \\
\hline Duct residence time of carbon sorbent & 1 second \\
\hline Gas flow rate & $4,050,000 \mathrm{dscm} / \mathrm{hr}$ and $411,000 \mathrm{dscm} / \mathrm{hr}$ \\
\hline Gas temperature without gas cooling & $300^{\circ} \mathrm{F}$ \\
\hline Gas temperature with gas cooling & $200^{\circ} \mathrm{F}$ \\
\hline Coal type & Low-sulfur PRB \\
\hline Operating labor hourly rate & $\$ 12 / \mathrm{hr}$ \\
\hline Supervision labor & $15 \%$ of operating labor costs \\
\hline Maintenance labor hourly rate & $\$ 13.20 / \mathrm{hr}$ \\
\hline Maintenance materials & Equal to maintenance labor \\
\hline Carbon cost & $\$ 0.55 /$ pound \\
\hline Nonhazardous waste disposal cost & $\$ 36 /$ ton \\
\hline Power cost & $\$ 0.046 / \mathrm{kW}-\mathrm{hr}$ \\
\hline Overhead rate & $60 \%$ of labor and maintenance costs \\
\hline Taxes, Insurance and Administration & $4 \%$ of the total capital cost \\
\hline Capital recovery factor & $7 \%$ interest rate for 20 years \\
\hline
\end{tabular}

Case Definitions for the Cost Modeling

A total of six cases were defined for input to the cost model. Each case addressed a specific type of particle control equipment and a fixed flue gas temperature. Variables for each 
case included the plant size (975 or $100 \mathrm{MW}(\mathrm{e})$ ) and the level of mercury control, $70 \% \mathrm{v}$ or $90 \%$. Cost were computed in two categories, total capital costs and annual operating costs. The capital costs were amortized over a 20 year period at $7 \%$ interest to compute an annual capital recovery cost. The operating costs and capital recovery costs were summed to arrive at total annual costs for mercury removal. To provide a basis of comparison, the total annual costs were divided by the amount of mercury removed from the flue gas stream to calculate a specific cost per pound of mercury.

\section{Case I - Carbon Injection Upstream of Existing ESP}

In this case, mercury control is achieved with the pneumatic injection of activated carbon into the flue gas duct upstream of an existing ESP. The mercury species are adsorbed onto the activated carbon while it is in contact with the flue gas. The sorbent is then removed from the gas stream along with fly ash in the ESP. The required sorbent injection levels were predicted by the mercury removal model to be 6.2 and $12.8 \mathrm{lb} /$ MMacf for $70 \%$ and $90 \%$ mercury control, respectively, high compared to the other cases. As expected the cost of carbon was a major portion of the operating cost in this case, accounting over $85 \%$ of the total annual cost in most of the configurations. Relative to the other cases at $90 \%$ mercury control, this control scheme was the most costly per pound of mercury removed.

\section{Case II - Carbon Injection with Spray Cooling Upstream of Existing ESP}

Spray cooling to drop the flue gas temperature by $100^{\circ} \mathrm{F}$ was included in this case to reduce the amount of activated carbon needed to reach target mercury removal levels. The amount of carbon required for $70 \%$ and $90 \%$ mercury control was cut in half compared to carbon usage in Case I. However, total capital costs were much higher than Case I due to the cost of the gas cooling equipment and higher energy consumption to generate the small droplet sizes needed to facilitate evaporation in the flue gas stream. Overall, the specific costs for $90 \%$ mercury control in the $975-\mathrm{MW}$ plant with spray cooling was cut by $20 \%$ per pound of mercury compared with carbon injection alone. However, in the $100 \mathrm{MW}$ plant, the spray cooling option resulted in higher mercury removal costs as compared to the baseline flue gas temperature case, due to the significant capital cost of the spray cooling equipment a this smaller plant size.

\section{Case III - Carbon Injection Upstream of Existing Reverse-Gas Baghouse}

This case featured a reverse-gas baghouse as the particulate control equipment, with injection of activated carbon into the flue gas at $300^{\circ} \mathrm{F}$. Model estimates for this case assumed 
that the reverse-gas baghouse already existed, and the there were no changes to the baghouse required to accommodate the injection of activated carbon for mercury removal. Specific costs to remove mercury from flue gas at a plant equipped with a reverse-gas baghouse were found to be significantly lower than those determined for power plants with an ESP. This mirrored pilot test results that showed much more efficient mercury removal in configurations with the reversegas baghouse. The lower costs were primarily due to reduced carbon usage and the lower total capital costs associated with a smaller carbon delivery system. The specific costs to remove mercury from the flue gas in a plant equipped with a reverse-gas baghouse were roughly the same for the two mercury control levels at around $\$ 6,000$ per pound of mercury for the large plant, and about $\$ 8,000$ per pound for the small plant.

\section{Case IV - Carbon Injection with Spray Cooling Upstream of Existing Reverse-Gas Baghouse}

In this case, spray cooling was added to an existing reverse-gas baghouse facility, and mercury removal costs were calculated for a flue gas stream where the temperature has been reduced to $200^{\circ} \mathrm{F}$. The spray cooling reduced the annual carbon usage, but at the same time increased the total capital costs due to the added hardware for the injection of water spray to the flue gas. Specific costs for Case IV were comparable to Case III, showing that there is little economic benefit to spray cooling when a plant burning western coal was equipped with a reverse-gas baghouse.

\section{Case V - Carbon Injection Upstream of Existing Pulse-Jet Baghouse}

Pulse-jet baghouses are relatively new to the utility marketplace, and have been installed at only a few locations. For this case, a pulse-jet baghouse was assumed to exist, with room upstream to install an activated carbon injection system for mercury control. Because of the fact that the pilot-scale testing showed very high removal rates of mercury from the native fly ash present in the flue gas, the predictive model indicated very low injection rates required for the $70 \%$ mercury control level. The net effect was that the specific cost for mercury control are very low for the $70 \%$ control level. The cost to achieve a $90 \%$ mercury control level was the lowest among the particulate control technologies included in the study, ranging from $\$ 3,000$ per pound of mercury removed in the large capacity plant, to $\$ 4,500$ per pound of mercury in the small plant. 


\section{Case VI - Carbon Injection with Spray Cooling Upstream of Existing Pulse-Jet Baghouse}

The addition of spray cooling to a power plant with an existing pulse-jet baghouse was considered in the final case. The modeling results for this case were different from the other particulate control options, in that the spray cooling did not offer any cost reduction for mercury removal. That is, the model predicted that it would actually cost more to install and operate a spray cooling system than to simply employ carbon injection at the higher flue gas temperature. Under spray cooling conditions, the mercury removal model predicted that carbon injection is not needed to meet the $70 \%$ or the $90 \%$ mercury control levels. In fact, cooling the flue gas to a temperature of $230^{\circ} \mathrm{F}$ is sufficient to achieve $90 \%$ mercury control level due to removal by the native fly ash without any carbon injection whatsoever.

\section{Comparison of Specific Costs for Mercury Removal for the Configurations of Interest}

The cost estimate models were run for the six cases defined above, with input data sets for two plant sizes, $975 \mathrm{MW}(\mathrm{e})$ and $100 \mathrm{MW}(\mathrm{e})$, and for two mercury control levels, 70\% removal and $90 \%$ removal. Thus a total of 24 cost estimates were prepared, including the elements noted above, capital costs and operating and maintenance costs. Tables 4-16 and 4-17 below compile the specific cost for removal of mercury for the several configurations in each case; Table 4-16 presents the results for a mercury control level of 70\%, and Table 4-17 summarizes the data for a control level of $90 \%$ mercury removal.

At $70 \%$ mercury removal, the most expensive specific costs for mercury removal are associated with the ESP as the particulate control device. This reflects the results from the pilot testing at Comanche station where $90 \%$ mercury control was not reached, and the fact that the mercury removal model predicted injection ratios for activated carbon that were higher for the ESP than for any other particulate control technology. The pulse-jet baghouse presented the low-cost option for both plant sizes, due to the high predicted mercury removal rates by the native (resident) fly ash.

The spray cooling results require some explanation. For both sizes of plants, there is no carbon injection required to achieve $70 \%$ mercury control when operating a reverse-gas or pulsejet baghouse for particulate control. The cooling of the flue gas stream increases the native fly ash capacity for mercury sufficiently to reach the target control level. For the 975-MW plant size, spray cooling reduces the requirement for carbon injection significantly, but the cost of the spray cooling system raises the specific cost for mercury removal to the point where the savings 
with spray cooling is less than $10 \%$. For the $100-\mathrm{MW}$ plant, the cost of the spray cooling hardware has a major effect on the specific costs for the ESP configuration. Less cooling is in fact required to achieve a mercury removal level of $70 \%$ for the reverse-gas baghouse and pulsejet baghouse configurations, as for these two designs, the mercury removal model predicted that cooling to an intermediate temperature above $200^{\circ} \mathrm{F}$ was all that was needed. No supplemental carbon injection was required for this lower level of mercury control with the use of baghouses. Thus the specific costs for mercury removal for the two baghouse configurations at a $70 \%$ control level reflect only the cost of spray cooling, with no supplemental carbon injection.

Table 4-16. Comparative Specific Costs for Mercury Removal at 70\% Control Level

\begin{tabular}{|c|l|c|c|}
\cline { 3 - 4 } \multicolumn{2}{c}{} & \multicolumn{2}{c|}{ Specific Mercury Removal Cost (\$/lb Hg) } \\
\hline $\begin{array}{c}\text { Plant Size } \\
(\mathbf{M W})\end{array}$ & \multicolumn{1}{c|}{$\begin{array}{c}\text { Particulate Control } \\
\text { Equipment }\end{array}$} & $\begin{array}{c}\text { No Gas Cooling } \\
\left(\mathbf{3 0 0} \mathbf{}^{\circ} \mathbf{)}\right.\end{array}$ & $\begin{array}{c}\text { Spray Cooling to } \\
\mathbf{2 0 0} \mathbf{F}^{\circ}\end{array}$ \\
\hline 975 & ESP & $\$ 13,651$ & $\$ 12,496$ \\
975 & Reverse-gas baghouse & $\$ 6,181$ & $\$ 5,801$ \\
975 & Pulse-jet baghouse & $\$ 188$ & $\$ 4,162$ \\
\hline 100 & ESP & $\$ 16,270$ & $\$ 23,124$ \\
100 & Reverse-gas baghouse & $\$ 8,234$ & $\$ 6,676$ \\
100 & Pulse-jet baghouse & $\$ 380$ & $\$ 3,698$ \\
\hline
\end{tabular}

Economic calculations for the 90\% mercury control level are presented in Table 4-17. Once again, for the configurations with no gas cooling, the ESP is the high-cost particulate control option. For both size plants, the specific cost for mercury removal across an ESP is over $\$ 20,000$ per pound, while the baghouse configurations are all well under $\$ 10,000$. Once again, the pulse-jet baghouse configurations shows a considerable advantage in comparison to the reverse-gas baghouse; for $90 \%$ control, the pulse-jet system is typically less than half the specific cost of the reverse-gas system.

For the $90 \%$ control level, spray cooling improves the collection efficiency of the native fly ash, but injection of activated carbon is required for all configurations except the pulse-jet baghouse at both plant sizes. In the ESP-equipped large plant, the carbon consumption drops by over $40 \%$ with spray cooling, but the incremental cost of the spray cooling equipment raises the specific cost back to where the spray cooling offers only a $20 \%$ specific cost advantage over the 
normal flue gas temperature condition. The fact that the spray cooling system installation represents a considerable capital investment is reflected in the capital recovery portion of the annual costs, such that for the large-plant reverse-gas baghouse configuration, the spray cooling contribution to the specific cost of mercury removal is over $80 \%$. For the pulse-jet baghouse configurations, spray cooling is seen to be more expensive than the normal flue gas temperature configurations, since a relatively small injection ratio of activated carbon is required to meet the $90 \%$ control level, and the specific cost of spray cooling is higher than the savings in activated carbon. For the reverse-gas configurations, there is a definite effect of size; for the 975-MW plant, spray cooling offers a specific cost advantage, while for the 100-MW plant, the spray cooling capital and operating costs push the specific cost above the natural temperature configuration value.

Table 4-17. Comparative Specific Costs for Mercury Removal at 90\% Control Level

\begin{tabular}{|c|c|c|c|}
\hline \multirow[b]{2}{*}{$\begin{array}{l}\text { Plant Size } \\
\text { (MW) }\end{array}$} & \multirow[b]{2}{*}{$\begin{array}{c}\text { Particulate Control } \\
\text { Equipment }\end{array}$} & \multicolumn{2}{|c|}{ Specific Mercury Removal Cost (\$/lb Hg) } \\
\hline & & $\begin{array}{c}\text { No Gas Cooling } \\
\left(300^{\circ} \mathbf{F}\right)\end{array}$ & $\begin{array}{l}\text { Spray Cooling to } \\
200^{\circ} \mathrm{F}\end{array}$ \\
\hline 975 & ESP & $\$ 20,816$ & $\$ 16,897$ \\
\hline 975 & Reverse-gas baghouse & $\$ 6,415$ & $\$ 5,520$ \\
\hline 975 & Pulse-jet baghouse & $\$ 2,964$ & $\$ 4,370$ \\
\hline 100 & ESP & $\$ 23,242$ & $\$ 27,241$ \\
\hline 100 & Reverse-gas baghouse & $\$ 8,167$ & $\$ 9,065$ \\
\hline 100 & Pulse-jet baghouse & $\$ 4,318$ & $\$ 4,930$ \\
\hline
\end{tabular}

In comparing the three types of particulate control equipment included in the economic analysis, mercury control was lowest cost in conjunction with a pulse-jet baghouse. Mercury removal in conjunction with a reverse gas baghouse option was more expensive than the pulsejet, but about half the cost of an ESP-equipped plant. There is no doubt that the ESP represents the most inefficient and therefore the most expensive approach to removal of mercury-sorbing activated carbon from coal-fired combustion streams.

Finally, Table 4-18 was generated to show the incremental costs for removing the additional mercury to increase from $70 \%$ to $90 \%$ removal from the flue gas stream. The data shows that for 10 of the 12 configurations presented in the table, the specific cost to remove an 
additional $20 \%$ of the mercury is significantly more expensive than the cost to remove the first $70 \%$ of the mercury present in the flue gas stream. In particular, the specific costs for the increased efficiency of mercury removal for the ESP configurations are all above $\$ 30,000$ per pound, due to the relatively poor efficiency at which carbon sorbs mercury at the low concentrations in the gas stream when used in combination with an ESP. The pulse-jet incremental specific costs are the next highest, because with the pulse-jet configuration it is fairly simple to reach a $70 \%$ mercury removal level. In fact, the pulse-jet is the only system configuration where $90 \%$ mercury removal can be achieved simply by cooling the flue gas with no supplemental injection of activated carbon.

Table 4-18. Incremental Specific Costs for Mercury Removal for Additional Mercury Removed by Improving Removal from $70 \%$ to $90 \%$.

\begin{tabular}{|c|l|c|c|}
\cline { 3 - 4 } \multicolumn{2}{c|}{} & \multicolumn{2}{|c|}{$\begin{array}{c}\text { Incremental Specific Mercury Removal Cost } \\
\text { (\$/lb Hg) }\end{array}$} \\
\hline $\begin{array}{c}\text { Plant Size } \\
(\mathbf{M W})\end{array}$ & \multicolumn{1}{|c|}{$\begin{array}{c}\text { Particulate Control } \\
\text { Equipment }\end{array}$} & $\begin{array}{c}\text { No Gas Cooling } \\
\mathbf{( 3 0 0} \text { F) }\end{array}$ & $\begin{array}{c}\text { Spray Cooling to } \\
\mathbf{2 0 0} \text { F }\end{array}$ \\
\hline 975 & ESP & $\$ 45,893$ & $\$ 31,472$ \\
975 & Reverse-gas baghouse & $\$ 7,235$ & $\$ 4,538$ \\
975 & Pulse-jet baghouse & $\$ 12,677$ & $\$ 5,099$ \\
\hline 100 & ESP & $\$ 47,642$ & $\$ 41,650$ \\
100 & Reverse-gas baghouse & $\$ 7,933$ & $\$ 17,430$ \\
100 & Pulse-jet baghouse & $\$ 18,101$ & $\$ 9,242$ \\
\hline
\end{tabular}

Details of the cost estimates for 975-MW and 100-MW power plants operating with carbon injection and gas cooling are summarized in the following Tables 4-19 and 4-20 respectively. 
Table 4-19. Details of Cost Model Results for Mercury Removal at 975 MW(e) Plant




Table 4-20. Details of Cost Model Results for Mercury Removal at 100 MW(e) Plant

\begin{tabular}{|c|c|c|c|c|c|c|}
\hline & \multicolumn{6}{|c|}{ Without Gas Cooling } \\
\hline & $\begin{array}{r}\text { ESP } \\
70 \% \text { Control }\end{array}$ & $90 \%$ Control & \begin{tabular}{|r|} 
Revers \\
$70 \%$ Control \\
\end{tabular} & $\begin{array}{l}\text { e Gas } \\
90 \% \text { Control }\end{array}$ & \begin{tabular}{|l|} 
Pulse J \\
$70 \%$ Control \\
\end{tabular} & $\begin{array}{l}\text { Jet } \\
\mid 90 \% \text { Control }\end{array}$ \\
\hline Annual Carbon Usage (lb/yr) & 772,750 & $1,562,429$ & 328,767 & 450,744 & 116 & 190,603 \\
\hline Total Capital Costs (TCC) & $\$ 151,913$ & $\$ 245,130$ & $\$ 84,987$ & $\$ 105,315$ & $\$ 382$ & $\$ 58,674$ \\
\hline Operating Costs & $\$ 572,742$ & $\$ 1,055,101$ & $\$ 289,073$ & $\$ 368,935$ & $\$ 13,663$ & $\$ 194,767$ \\
\hline Capital Recovery Costs & $\$ 14,340$ & $\$ 23,139$ & $\$ 8,022$ & $\$ 9,941$ & $\$ 36$ & $\$ 5,538$ \\
\hline Total Annual Costs & $\$ 587,082$ & $\$ 1,078,240$ & $\$ 297,095$ & $\$ 378,876$ & $\$ 13,700$ & $\$ 200,305$ \\
\hline \multirow[t]{3}{*}{ Specific Costs (\$/lb Hg) } & $\$ 16,270$ & $\$ 23,242$ & $\$ 8,234$ & $\$ 8,167$ & $\$ 380$ & $\$ 4,318$ \\
\hline & \multicolumn{6}{|c|}{ With Gas Cooling } \\
\hline & $\begin{array}{r}\text { ESP } \\
70 \% \text { Control }\end{array}$ & $90 \%$ Control & \begin{tabular}{|r|} 
Revers \\
$70 \%$ Control
\end{tabular} & $\begin{array}{l}\text { Gas G } \\
90 \% \text { Control }\end{array}$ & \begin{tabular}{|c|}
\multicolumn{2}{|c}{ Pulse J } \\
$70 \%$ Control
\end{tabular} & \begin{tabular}{|l|} 
Jet \\
$90 \%$ Control
\end{tabular} \\
\hline Annual Carbon Usage (lb/yr) & 361,769 & 919,737 & 0 & 48,484 & 0 & 0 \\
\hline Total Capital Costs (TCC) & $\$ 1,344,375$ & $\$ 1,532,527$ & $\$ 1,021,005$ & $\$ 1,186,092$ & $\$ 160,317$ & $\$ 914,873$ \\
\hline Operating Costs & $\$ 707,466$ & $\$ 1,119,097$ & $\$ 144,499$ & $\$ 308,610$ & $\$ 118,292$ & $\$ 142,342$ \\
\hline Capital Recovery Costs & $\$ 126,899$ & $\$ 144,660$ & $\$ 96,376$ & $\$ 111,959$ & $\$ 15,133$ & $\$ 86,357$ \\
\hline Total Annual Costs & $\$ 834,365$ & $\$ 1,263,757$ & $\$ 240,875$ & $\$ 420,569$ & $\$ 133,425$ & $\$ 228,700$ \\
\hline Specific Costs (\$/lb Hg) & $\$ 23,124$ & $\$ 27,241$ & $\$ 6,676$ & $\$ 9,065$ & $\$ 3,698$ & $\$ 4,930$ \\
\hline
\end{tabular}




\section{Conclusions}

Over 150 test cases were run in the test pilot plant under the four configurations for the particulate control module. Activated carbon and fly ash gathered from other PSCo plants were used as mercury sorbents in these tests. Tests were also run over a range of flue gas temperatures to evaluate the impact of this parameter on mercury removal. To better understand the natural removal of mercury by the native fly ash present in the flue gas of full-scale plants, measurements were made at five PSCo generating units. In addition, tests were run on the fly ash plus carbon collected from the pilot to determine the effect of the activated carbon on the disposal of the fly ash. Conclusions from the tests noted above are presented in this section.

\section{Pilot Plant Testing}

The following observations apply to the injection of activated carbon injection for mercury control in the pilot when fitted with an ESP:

- Mercury removal at fixed injection rates of activated carbon was lowest for the ESP configuration when compared to the several baghouse configurations of the pilot plant.

- At all temperatures tested $\left(228^{\circ}-349^{\circ} \mathrm{F}\right)$, mercury control of greater than $50 \%$ was attainable with carbon injected at greater than $3.5 \mathrm{lb} / \mathrm{MMacf}$. This was a relatively low removal rate for a significant carbon concentration in the flue gas stream when compared to the results from the baghouse configurations of the pilot.

- Mercury removal rates seemed to rise slowly when the carbon concentration was increased, resulting in diminishing returns from incremental boosts in carbon injection. Removal cost therefore would increase nonlinearly for higher mercury removal rates. Based on the pilot test data, significantly higher carbon injection rates would be required to achieve consistent control levels as high as $80 \%$ in the ESP configuration. In fact, this level was not achieved in the pilot testing; the test matrix limited injection rates for activated carbon to less than 5 $\mathrm{lb} / \mathrm{MMACF}$, resulting on a maximum mercury removal rate of about $70 \%$.

- Cooling the flue gas to $230^{\circ} \mathrm{F}$ by injection of a fine water mist had about the same mercury removal effect as injecting about $1 \mathrm{lb} / \mathrm{MMacf}$ carbon into $300^{\circ} \mathrm{F}$ flue gas. The native fly ash resident in the flue gas appeared to collect additional mercury from the cooled flue gas stream. That is, baseline mercury removal rates increased when the flue gas was spray- 
cooled.

- Increasing the activated carbon contact time in the test facility before the flue gas entered the ESP from 0.5 to 1.0 seconds did not measurably impact the mercury removal efficiency in these few tests.

In the reverse-gas and pulse-jet baghouse configuration of the pilot facility the following conclusions were noted:

- Very high removal rates were sometimes obtained during these tests due to the high proportion of mercury present in the flue gas in the particulate phase. This is not an effect attributable to adsorption by carbon, but rather to collection of mercury-containing particulate matter in the baghouse.

- The native fly ash present in the Comanche flue gas continued to sorb mercury in the baghouse, as evidenced by the higher mercury removal efficiency in the baghouse tests when compared with the ESP configuration. Both activated carbon and native fly ash appeared to sorb mercury in the dustcake formed on the bags of both reverse-gas and pulse-jet baghouse modules. A similar phenomenon was observed in full-scale mercury removal measurements made at Arapahoe station; the ESP-equipped unit showed much lower mercury removal than an adjacent baghouse-equipped unit.

- In a baghouse configuration, similar mercury control levels were achieved by either injecting carbon or by cooling the flue gas. It was also shown that flue gas cooling could be combined with carbon injection to achieve target mercury control levels at reduced sorbent injection rates.

- Mercury removal levels greater than $70 \%$ were measured consistently with carbon concentrations as low as $0.5 \mathrm{lb} /$ MMacf. A significant fraction of this removal was attributed to the fly ash in the extracted flue gas stream.

- In the baghouse configurations, the pilot was able to demonstrate mercury removal rates greater than $90 \%$, much greater than the maximum $70 \%$ achieved with the ESP configuration.

Selected fly ash materials were evaluated in the pilot facility for use as mercury sorbents, 
after characterization of full-scale generating units showed significant mercury removal by these fly ashes. Specific conclusions of the fly ash sorbent testing are:

- Candidate fly ash materials were reinjected in the pilot plant into a fly ash-free flue gas stream doped with elemental mercury vapor, and demonstrated high mercury removal rates. The best-performing ashes were those with the highest LOI values, Arapahoe 4 and Cherokee 3.

- The best-performing fly ash materials demonstrated mercury removal rates in the pilot greater than $80 \%$ at a flue gas temperature of $320^{\circ} \mathrm{F}$.

- Mercury removal rates greater than $80 \%$ were maintained at fly ash injection ratios of 0.13 grains per actual cubic foot of gas treated. This is less than $10 \%$ of the typical grain loading in flue gas from western coals for the plants sampled.

- Pilot test data supported the concept that fly ashes from some western coals could serve as sorbent materials to remove mercury from coal-fired flue gas streams.

- The presence of unburned carbon plays a strong role in the mercury removal capacity of some fly ashes, but one low-carbon ash has shown significant ability to remove mercury, especially at low temperatures.

- LOI carbon in fly ash and activated carbon injected for mercury control each impact the salability of fly ash for use in concrete. Activated carbon appears to have a greater effect on the quantity of air-entraining agents needed for concrete mixtures incorporating fly ash.

- The real-time mercury measurement technology used in these tests showed the value of rapid availability of results in the planning and optimization of a limited test matrix.

\section{Full-Scale Plant Survey}

Five PSCo units were sampled to measure mercury in the coal, in the flue gas at the inlet to the particulate collector, in the hopper ash, and in the stack flue gas. The following conclusions are drawn from the data obtained in these tests. 


\section{1) Sampling and Test Methodology}

- The in-situ test method developed by FGS and ADA utilizing isokinetic sampling and IC trap mercury collection appeared to provide reasonable and repeatable total mercury measurements for Arapahoe Units 1 and 4 and Cherokee Unit 3.

- It was difficult to obtain a representative hopper sample of collected flyash from the fullscale baghouses or ESPs. The sample method likely contributed to the high hopper ash mercury levels measured at Cherokee 3 .

- Analytical variability for replicate coal and ash analyses ranged from 3\% to $29 \%$. This variability was quite typical and has been observed in other studies (e.g., Bloom and Prestbo, 1994). This variability was due to the combination of the inhomogeneity of the samples and the precision of analytical procedures.

\section{2) Mercury Results}

- Arapahoe Unit 1's ESP removed approximately $28 \%$ of the mercury in the system in one set of triplicate tests. The fraction of mercury in the particulate phase at the inlet was not high enough to account for all of the mercury removed across Arapahoe Unit 1's ESP. Therefore, some vapor-phase removal was thought to occur in the duct between the inlet and outlet sample locations. This value was not confirmed by repeat testing, since one data set exhibited variance too large to be considered useful.

- Arapahoe Unit 4's reverse-gas baghouse removed 63 and $82 \%$ of the mercury in two sets of triplicate tests conducted. In the summer test series, $55 \%$ of the total mercury was in the particulate phase, and in the winter test series $94 \%$ of the total mercury was in the particulate phase. One possible explanation for the winter results was that adsorption of vapor-phase mercury onto sampled fly ash took place in the sample train, since stack vapor-phase mercury emissions were greater than the vapor-phase mercury level measured at the inlet. However, this did not occur in the summer tests, or at other sites, so the proposed mechanism cannot be confirmed. This result pointed to the need for a better sampling method in which particulates are separated from the flue gas as rapidly as possible for accurate fractionation of the particulate-bound and vapor-phase mercury. 
- Cherokee Unit 3's reverse-gas baghouse removed 98 and $99 \%$ of the mercury in two sets of triplicate tests conducted. A significant fraction of the mercury (83 and 95\%) was in the particulate phase at the inlet to the baghouse. The high removal rate of mercury indicates that that ash remained reactive in the baghouse, and continued to adsorb mercury (temperature 280 to $300^{\circ} \mathrm{F}$ ).

- Comanche Unit 2's reverse-gas baghouse removed $63 \%$ of the mercury with approximately $30 \%$ of the inlet total mercury associated with the particulate phase. The high removal rate of mercury indicated that the ash was still reactive in the dustcake and continued to adsorb elemental mercury at $299^{\circ} \mathrm{F}$.

- There appeared to be a speciation change from elemental to oxidized mercury across the Comanche Unit 2 reverse-gas baghouse, possibly due to the interaction of flyash, $\mathrm{NO}_{2}$ and $\mathrm{SO}_{2}$ as observed by Miller et al (1998).

- Mass balance closures were mostly reasonable. Comparing the coal mercury to the outlet streams ("ash+stack"), recoveries of $115 \%$ on Arapahoe 1, 117\% on Comanche Unit 2, and $99 \%$ and $133 \%$ on Arapahoe 4 were calculated. On Cherokee 3 the mercury concentration measurements for the fly ash were high in comparison to the coal and inlet values. For this unit, comparing the coal to the inlet mercury measurement resulted in the most repeatable data, with recoveries of $111 \%$ during both of the two test series.

- A series of measurements at Hayden Unit 1 yielded a significant variance in the inlet mercury concentrations. However, when the outlet gas phase measurements were compared to the calculated value for the coal used at the plant, removal rates of about $95 \%$ were computed. The plant employed a spray dryer scrubber for removal of $\mathrm{SO}_{2}$ upstream of a reverse-gas baghouse, so there was interest in the effect of the added pollution control equipment on mercury removal.

\section{Characterization of Collected Sorbent and Fly Ash}

Tests were conducted to gather information on the chemical and physical properties of the activated carbon collected along with the fly ash in the particulate control device of the pilot. In many plants, fly ash is sold as an additive in the manufacture of concrete, and there are known limits on the amount of unburned carbon that can be present in this material. Fly ash that is not 
sold is often landfilled, and there was a concern that the activated carbon sorbent added to the fly ash would render it a hazardous waste, subject to more rigorous disposal regulations. A series of samples of the collected fly ash and activated carbon were removed from the hopper of the pilot during testing of activated carbon sorbents. These samples were subjected to a test protocol known as the Toxic Characteristic Leaching Procedure (TCLP). If the TCLP leachate was found to contain soluble mercury above the EPA-mandated limit, the fly ash could be classified as a hazardous waste. Samples were collected from the pilot as well as from the baghouse hoppers of the host unit. A sample of fly ash from Cherokee Unit 3 was also submitted for TCLP analysis, since this fly ash was shown to remove virtually all the mercury from the flue gas in Unit 3 . The mercury level in the leachates from all these samples were found to be less than the detectable limit, or $0.0002 \mathrm{mg} /$ liter. The EPA regulatory limit for mercury in the TCLP is $0.2 \mathrm{mg} / \mathrm{liter}$; thus the samples were all seen to be orders of magnitude below the limit.

To determine if mercury captured by the fly ash was stable, several samples from the pilot and full-scale plants were analyzed to quantify their mercury content. The samples were stored for eight months, then tested again. The samples showed a maximum loss of $10 \%$, and several samples showed slight gains, which was believed to be an indication of the variability of the measurement. The interpretation of this test was that the mercury captured by fly ash tends to remain present on the fly ash particles over time.

Other tests were run to determine the distribution of mercury and carbon in fly ash samples collected from PSCo's Cherokee station. This fly ash was found to remove over $98 \%$ of the mercury present in the coal burned in Cherokee Unit 3. This fly ash contained $7.6 \%$ unburned carbon (LOI) due to the low-NOx burners installed on Unit 3. The Cherokee 3 fly ash was separated into five different size fractions, and the fractions were analyzed to determine their mercury and carbon content. The tests were conducted to evaluate a hypothesis that the reason for an affinity for mercury seen in the fly ash was due to the presence of unburned carbon particles. If the mercury and carbon distributions in the fractions were similar, it would provide strong evidence that the fly ash capture of mercury was due to the presence of carbon.

The fly ash fractions ranged from very fine (less than $2.5 \mu \mathrm{m}$ diameter) to very coarse (greater than $150 \mu \mathrm{m}$ diameter). The mercury distribution in the fractions did not follow the carbon. In fact, the largest size fraction contained over half the carbon, but less than $14 \%$ of the mercury, while the finest fraction contained only $6 \%$ of the carbon and over $25 \%$ of the mercury. Thus the mercury was concentrated by over a factor of four in the finest fraction as compared to the carbon. This is a strong indication that particle size has an effect on the ability of the fly ash 
to sorb mercury, over and above the carbon content of the fly ash.

\section{Economic Modeling of Sorbent Removal}

An economic model was developed to predict costs of mercury removal for plants burning western coals where there is significant removal of mercury on the native fly ash present in the flue gas. The ADA model was an extension of the EPA cost prediction model presented in the Mercury Study Report to Congress (1997). Results from the pilot plant testing were used to predict activated carbon injection rates for two sizes of commercial power plants in six different configurations of particulate control equipment. Cost estimates were prepared for mercury removal rates of $70 \%$ and $90 \%$. Results were expressed in terms of dollars per pound of mercury removed from the flue gas. The following conclusions were drawn from the model predictions.

- Plant configurations using an ESP for particulate control showed the highest cost for mercury removal at both the $70 \%$ and $90 \%$ levels.

- For both plant sizes, the reverse-gas baghouse configuration resulted in mercury removal costs that were less than one-half the mercury removal costs for plants equipped with ESPs.

- Because the native fly ash was most effective as a mercury sorbent in the pulse-jet baghouse configuration, the lowest mercury removal costs were predicted for this particulate control option.

- Estimated costs ranged from as high as $\$ 23,000$ to as little as $\$ 200$ per pound of mercury removed.

- The use of spray cooling to improve the sorption efficiency of activated carbon and native fly ash was cost-effective for some cases, and more expensive for others.

- The incremental costs to increase the mercury removal rate from $70 \%$ to $90 \%$ was calculated, and ranged from over $\$ 47,000$ per pound down to $\$ 4,500$ per pound of mercury removed. For only two of the twelve plant configurations included in the study was the per-pound mercury removal cost reduced at the higher removal rate. 


\section{References}

\subsection{Report references}

Bloom N.S and Prestbo E.M. 1994. A New Survey of Mercury in U.S. Coals, Proceedings of Coal-Energy and the Environment, 11th Annual Pittsburgh Coal Conference, Vol. 1, pp. 563-568, U. of Pittsburgh, PA, September 12-16.

Bullock O.R. Jr., Benjey W.G. and Keating M.H. (1997) "Modeling of Regional-Scale Atmospheric Mercury Transport and Deposition Using RELMAP," Atmospheric Deposition of Contaminants t the Great Lakes and Coastal Waters, J.E. Baker, Ed., pp. 323-347, SEATAC Press, Pensacola, Florida

DeVito, M., Rosenhoover, W. "Flue Gas Hg Measurements from Coal-Fired Boilers Equipped with West Scrubbers," Presented at Air \& Waste Management Conference, St. Louis, MO, 1999.

Hwang, J.Y., X. Huang, J. M. Gillis, A. M. Hein, D. C. Popko, R. E. Tieder, M. G. McKimpson, "Utilization of Low NOx Coal Combustion By-Products," Proceedings of the Advanced Coal-Based Power and Environmental Systems '98 Conference, July 21-23, 1998

Laudal D.L., Heidt M.K., Brown T.D., Nott B.R. and Prestbo E.M. 1996. Mercury Speciation: A Comparison Between EPA Method 29 and Other Sampling Methods, proceedings of the Air \& Waste Mngmt Assoc. Annual Meeting, \#96-WA64A.04.

Laudel et al, (1996). "Bench and Pilot-Scale Evaluation of Mercury Speciation Measurement Methods", Presented at the First Joint Power \& Fuel Systems Contractors Conference, Pittsburgh, PA, July 9-11.

Majors, R., “Activated Carbon Study”, personal communication (e-mail), July, 1999

Mercury Study Report to Congress, U.S. EPA, EPA-452/R-97-010, December 1997.

Miller, S.J., Dunham, G.E., Olson, E.S., Brown, T.D., "Mercury Sorbent Development in CoalFired Boilers," In proceedings of the Conference on Air Quality: Mercury, Trace Elements, and Particulate Matter, McLean, VA, December 1998.

Nott, B.R., "Intercomparison of Stack Gas Mercury Measurment Methods", Water, Air, and Soil Pollution, 1995, Volume 80: 1311-1314

Perry, R.H. (1973): Chemical Engineers' Handbook, McGraw-Hill, New York.

Prestbo and Bloom. "Mercury Speciation Adsorption (MESA) Method for Combustion Flue Gas: Methodology, Artifacts, Intercomparison, and Atmospheric Implications", Water, Air, and Soil Pollution, 1995, Volume 80: 145-158. 
Prestbo E.M and Tokos J.S., Mercury Speciation in Coal Combustion Flue Gas: MESA Method, AWMA Conference paper 97-WP72B.02, Nashville TN, June 1997.

Roberts, D.L., J. Albiston, T. Broderick, C. Greenwell, and R. Stewart, "Novel Process for Removal and Recovery of Vapor Phase Mercury," Phase I Final Report under Contract DE-AC22-95PC95257 to DOE Federal Energy Technology Center, March 9, 1998.

\subsection{List of Project Publications}

Butz, J. and J Albiston (2000). "Use of Fly Ash Fractions from Western Coals for Mercury Removal from Flue Gas Streams," presented at Air Quality II conference, September 1719.

Butz, J., J. Smith, C. Grover, S. Haythornthwaite, M. Fox, T. Hunt, R. Chang, T.D. Brown (1999): "Coal Fly Ash as a Sorbent for Mercury". A\&WMA Mercury in the Environment Specialty Conference, Minneapolis, MN, September 19-21.

Butz, J.R., C. Turchi, T.E. Broderick, and J. Albiston (2000): “Options for Mercury Removal from Coal-Fired Flue Gas Streams: Pilot-Scale Research on Activated Carbon, Alternative and Regenerable Sorbents," presented at Pittsburgh Coal Conference, September 12-15.

Grover, C, J. Butz, S. Haythornthwaite, J. Smith, M. Fox, T. Hunt, R. Chang, T. Brown, E. Prestbo,(1999): "Mercury Measurements Across Particulate Collectors of PSCo CoalFired Utility Boilers," EPRI-DOE-EPA Mega-Symposium, August 1999.

Haythornthwaite, S., S. Sjostrom, T. Ebner, J. Ruhl, R. Slye, J. Smith, T. Hunt, R. Chang, T. Brown, (1997): "Demonstration of Dry Carbon-Based Sorbent Injection for Mercury Control in Utility ESPs and Baghouses," EPRI-DOE-EPA Mega-Symposium, August 1997.

Haythornthwaite, S.M., J. Smith, G. Anderson, T. Hunt, M. Fox, R. Chang, T. Brown (1999): "Pilot-Scale Carbon Injection for Mercury Control at Comanche Station," Paper \#99-524, $92^{\text {nd }}$ Annual Meeting of the Air \& Waste Management Association, St. Louis, MO, June 21-24, 1999.

Hunt, T., R. Chang, S. Sjostrom, S, Haythornthwaite, T. Ebner, J. Ruhl, R. Slye, J. Smith, "Investigation and Demonstration of Dry Carbon-Based Sorbent Injection for Mercury Control, Final Report, DOE Contract DE-AC22-95PC95256, Pittsburgh Energy Technology Center, April, 1998. 


\section{Acknowledgments}

A project of this magnitude is completed only with the consistent effort of a dedicated team. In Phase I, Ms. Jean Bustard and Ms. Sharon Sjostrom of ADA provided technical direction; in Phase II technical direction was transferred to Ms. Sheila Haythornthwaite and Mr. James Butz. Throughout the project, Dr. Ramsay Chang of EPRI served as a technical resource. The DOE Contracting Officer's Technical Representative was Mr. Thomas Brown, succeeded late in the project by Mr. Anthony Mayne. Technical oversight on behalf of Public Service Company was provided by Mr. Terry Hunt and Mr. Mark Fox.

The ADA engineers and technicians assigned to this project each contributed to the overall success of the design and construction of the pilot plant, testing of the many configurations, and analysis of the data obtained from the extensive test matrix. Contributing engineers included Jason Ruhl, Justin Smith, Cathy Grover, and Jason Albiston. Technicians Norm Haberkorn, Gary Anderson, Rick Slye, and Ken Cramsey all performed admirably both in the lab and in the field. This final report was compiled and edited by Mr. James Butz, drawing heavily from quarterly technical reports, numerous technical papers, and data analysis files prepared throughout the Phase II project by all members of the team.

The efforts of Consol personnel Matt DeVito, Ron Oda, Leonard Anthony and Orville Bedillion Jr. must be recognized for their excellence in conducting the Ontario Hydro mercury measurements and reporting of results. The assistance of the staffs at Public Service Company of Colorado's Arapahoe, Comanche, Hayden, and Cherokee Generating Stations in the measurement of mercury concentrations in their plants is also gratefully acknowledged. 


\section{Appendix: Results Database}




\begin{tabular}{|c|c|c|c|c|c|c|c|c|c|c|c|}
\hline Test ID & $\begin{array}{c}\text { PCM } \\
\text { Configuration }\end{array}$ & $\begin{array}{l}\text { Test } \\
\text { date }\end{array}$ & $\begin{array}{c}\text { Test } \\
\text { time }\end{array}$ & $\begin{array}{c}\text { Test } \\
\text { Conditions }\end{array}$ & $\begin{array}{c}\text { Carbon } \\
\text { Concent. } \\
\text { (sorb.rate) }\end{array}$ & $\begin{array}{l}\text { Gas Temp. } \\
@ \text { inj. point }\end{array}$ & $\begin{array}{c}\text { Inlet } \\
\text { Mercury } \\
\text { Concent. } \\
\end{array}$ & $\begin{array}{c}\text { Outlet } \\
\text { Mercury } \\
\text { Concent. } \\
\end{array}$ & $\begin{array}{c}\text { Outlet Hg } \\
\text { Temp. } \\
\left({ }^{\circ} \mathrm{F}\right)\end{array}$ & $\begin{array}{l}\text { Residence } \\
\text { Time }\end{array}$ & $\begin{array}{c}\text { Total } \\
\text { Mercury } \\
\text { Removal } \\
\end{array}$ \\
\hline 1 & ESP & $5 / 15 / 1998$ & $15: 30$ & ESP Off, Duct Heater Off, "Natural Temp" & 0.0 & 253 & 6.33 & 6.20 & 255 & NA & 2.0 \\
\hline 4 & ESP & $5 / 19 / 1998$ & $15: 35$ & ESP Off, Duct Heater Off, "Natural Temp" & 0.0 & 271 & 7.49 & 6.92 & 281 & NA & 7.7 \\
\hline 5 & ESP & $5 / 20 / 1998$ & $10: 10$ & ESP Off, Duct Heater Off, "Natural Temp" & 0.0 & 260 & 7.29 & 10.58 & 255 & NA & -45.1 \\
\hline 6 & ESP & 5/20/1998 & 11:55 & ESP Off, Duct Heater Off, "Natural Temp" & 0.0 & 264 & 7.27 & 4.98 & 258 & NA & 31.5 \\
\hline 7 & ESP & $5 / 20 / 1998$ & 13:50 & ESP Off, Duct Heater Off, "Natural Temp" & 0.0 & 273 & 8.47 & 10.92 & 268 & NA & -28.9 \\
\hline 8 & ESP & $5 / 21 / 1998$ & $12: 43$ & ESP Off, Duct heater on, heat to $300 \mathrm{~F}$ & 0.0 & 293 & 7.29 & 7.15 & 301 & NA & 1.9 \\
\hline 9 & ESP & $5 / 21 / 1998$ & $15: 38$ & ESP Off, Duct heater on, heat to $300 \mathrm{~F}$ & 0.0 & 294 & 7.82 & 7.13 & 303 & NA & 8.8 \\
\hline 10 & ESP & $5 / 21 / 1998$ & 17:58 & ESP Off, Duct heater on, heat to $300 \mathrm{~F}$ & 0.0 & 295 & 8.29 & 7.50 & 304 & NA & 9.5 \\
\hline 11 & ESP & 5/28/1998 & $15: 28$ & ESP ON, Duct Heater Off ,"natural Temp" & 0.0 & 292 & 7.73 & 4.95 & 293 & NA & 35.9 \\
\hline 12 & ESP & $5 / 28 / 1998$ & $17: 30$ & ESP ON, Duct Heater Off, ,"natural Temp" & 0.0 & 292 & 7.68 & 4.96 & 292 & NA & 35.3 \\
\hline 13 & ESP & $5 / 28 / 1998$ & 19:15 & ESP ON, Duct Heater Off, "natural Temp" & 0.0 & 286 & 7.92 & 5.99 & 287 & NA & 24.4 \\
\hline 14 & ESP & $6 / 1 / 1998$ & $10: 35$ & ESP ON, Duct Heater On , Heat to 300 deg. F & 0.0 & 298 & 14.18 & 9.41 & 299 & NA & 33.7 \\
\hline 15 & ESP & $6 / 1 / 1998$ & $12: 08$ & ESP ON, Duct Heater On , Heat to 300 deg. F & 0.0 & 298 & 13.51 & 8.39 & 303 & NA & 37.9 \\
\hline 16 & ESP & 6/1/1998 & 13:38 & ESP ON, Duct Heater On , Heat to 300 deg. F & 0.0 & 300 & 8.35 & 7.50 & 303 & NA & 10.2 \\
\hline 17 & ESP & 6/15/1998 & $14: 45$ & ESP off, Duct heater on, heat to 300 deg F & 0.0 & 301 & 18.04 & 18.92 & 299 & NA & -4.8 \\
\hline 18 & ESP & 6/15/1998 & $15: 20$ & ESP off, Duct heater on, heat to $300 \mathrm{deg} F$ & 0.0 & 301 & 14.19 & 15.94 & 299 & NA & -12.3 \\
\hline 19 & ESP & 6/15/1998 & $15: 55$ & ESP off, Duct heater on, heat to $300 \mathrm{deg} F$ & 0.0 & 301 & 14.98 & 17.00 & 300 & NA & -13.5 \\
\hline 20 & ESP & 6/16/1998 & 10:50 & ESP off, Duct heater on, heat to $300 \mathrm{deg} F$ & 0.0 & 302 & 72.74 & 77.76 & 299 & NA & -6.9 \\
\hline 21 & ESP & 6/16/1998 & $11: 30$ & ESP off, Duct heater on, heat to 300 deg F & 0.0 & 302 & 77.95 & 80.97 & 299 & NA & -3.9 \\
\hline 22 & ESP & 6/16/1998 & $12: 03$ & ESP off, Duct heater on, heat to 300 deg F & 0.0 & 302 & 79.82 & 81.41 & 300 & NA & -2.0 \\
\hline 23 & ESP & 6/18/1998 & $15: 10$ & ESP off, Duct heater on, heat to $300 \mathrm{deg} F$ & 0.0 & 303 & 162.69 & 193.51 & 300 & NA & -18.9 \\
\hline 24 & ESP & 6/18/1998 & $15: 45$ & ESP off, Duct heater on, heat to $300 \mathrm{deg} F$ & 0.0 & 302 & 183.87 & 201.93 & 300 & NA & -9.8 \\
\hline 25 & ESP & $6 / 18 / 1998$ & 16:05 & $\begin{array}{l}\text { ESP off, Duct heater on, heat to } 300 \mathrm{deg} F \\
\text { ESP ON, Duct Heater Off, "natural Temp", No }\end{array}$ & 0.0 & 302 & 191.50 & 199.30 & 300 & NA & -4.1 \\
\hline 26 & ESP & $6 / 24 / 1998$ & $12: 50$ & $\begin{array}{l}\text { Carbon Inj } \\
\text { ESP ON, Duct Heater Off ,"natural Temp", No }\end{array}$ & 0.0 & 275 & 8.25 & 6.47 & 277 & NA & 21.5 \\
\hline 27 & ESP & $6 / 24 / 1998$ & $14: 05$ & $\begin{array}{l}\text { Carbon Inj } \\
\text { ESP ON, Duct Heater Off, "natural Temp", No }\end{array}$ & 0.0 & 277 & 8.69 & 6.69 & 273 & NA & 23.0 \\
\hline 28 & ESP & $6 / 24 / 1998$ & $15: 00$ & $\mid \begin{array}{l}\text { Carbon Inj } \\
\text { ESP ON, Duct Heater Off, "natural Temp", Carbon Inj }\end{array}$ & 0.0 & 278 & 8.57 & 7.48 & 280 & NA & 12.7 \\
\hline 29 & ESP & $6 / 25 / 1998$ & 13:35 & $\begin{array}{l}\text { @ } 1 \mathrm{lbs} / \mathrm{MMACF} \\
\text { ESP ON, Duct Heater Off, ,"natural Temp", Carbon Inj }\end{array}$ & 0.3 & 277 & 10.40 & 5.95 & 284 & 1 & 42.8 \\
\hline 30 & ESP & $6 / 25 / 1998$ & $14: 30$ & \begin{tabular}{|l|} 
@ 1 lbs/MMACF \\
ESP ON, Duct Heater Off ,"natural Temp", Carbon Inj
\end{tabular} & 0.3 & 282 & 10.44 & 5.72 & 291 & 1 & 45.2 \\
\hline 31 & ESP & 6/25/1998 & $15: 25$ & $\begin{array}{l}\text { @ } 1 \text { lbs/MMACF } \\
\text { ESP ON, Duct Heater Off ,"natural Temp", Carbon Inj }\end{array}$ & 0.3 & 287 & 10.50 & 5.35 & 289 & 1 & 49.0 \\
\hline 32 & ESP & $6 / 26 / 1998$ & 11:15 & \begin{tabular}{|l|} 
@ 4 lbs/MMACF \\
ESP ON, Duct Heater Off ,"natural Temp", Carbon Inj
\end{tabular} & 1.2 & 283 & 13.08 & 4.36 & 283 & 1 & 66.7 \\
\hline 33 & ESP & 6/26/1998 & $12: 00$ & $\begin{array}{l}\text { @ } 4 \text { lbs/MMACF } \\
\text { ESP ON, Duct Heater Off ,"natural Temp", Carbon Inj }\end{array}$ & 1.2 & 285 & 10.80 & 4.29 & 284 & 1 & 60.2 \\
\hline 34 & ESP & $6 / 26 / 1998$ & $12: 55$ & $\left|\begin{array}{l}@ 4 \mathrm{lbs} / \mathrm{MMACF} \\
\text { ESP ON, Duct Heater Off ,"natural Temp", Carbon Inj }\end{array}\right|$ & 1.2 & 288 & 10.66 & 3.94 & 285 & 1 & 63.0 \\
\hline 35 & ESP & 6/29/1998 & $11: 30$ & $\begin{array}{l}\text { @ } 0.5 \mathrm{lbs} / \mathrm{MMACF} \\
\text { ESP ON, Duct Heater Off ,"natural Temp", Carbon Inj }\end{array}$ & 0.2 & 309 & 11.07 & 8.09 & 313 & 1 & 26.9 \\
\hline 36 & ESP & $6 / 29 / 1998$ & $12: 40$ & \begin{tabular}{|l}
$@ 0.5 \mathrm{lbs} / \mathrm{MMACF}$ \\
ESP ON, Duct Heater Off ,"natural Temp", Carbon Inj
\end{tabular} & 0.2 & 315 & 11.28 & 8.09 & 321 & 1 & 28.3 \\
\hline 37 & ESP & 6/29/1998 & 13:35 & $@ 0.5 \mathrm{lbs} / \mathrm{MMACF}$ & 0.2 & 318 & 12.81 & 8.85 & 324 & 1 & 30.9 \\
\hline 38 & ESP & 6/30/1998 & $10: 40$ & ESP ON, Duct Heater to $350 \mathrm{~F}$, NO Carbon Inj & 0.0 & 351 & 11.93 & 11.82 & 348 & NA & 0.8 \\
\hline 40 & ESP & 6/30/1998 & 13:05 & ESP ON, Duct Heater to $350 \mathrm{~F}$, NO Carbon Inj & 0.0 & 352 & 11.26 & 11.53 & 350 & NA & -2.4 \\
\hline 41 & ESP & |6/30/1998| & 14:00 & ESP ON, Duct Heater to $350 \mathrm{~F}$, NO Carbon Inj & 0.0 & 353 & 11.30 & 11.27 & 350 & NA & 0.3 \\
\hline
\end{tabular}




\begin{tabular}{|c|c|c|c|c|c|c|c|c|c|c|c|}
\hline Test ID & $\begin{array}{c}\text { PCM } \\
\text { Configuration }\end{array}$ & $\begin{array}{l}\text { Test } \\
\text { date }\end{array}$ & $\begin{array}{c}\text { Test } \\
\text { time }\end{array}$ & $\begin{array}{c}\text { Test } \\
\text { Conditions }\end{array}$ & $\begin{array}{l}\text { Carbon } \\
\text { Concent. } \\
\text { (sorb.rate) }\end{array}$ & \begin{tabular}{|c|} 
Gas Temp. \\
$@$ inj. point
\end{tabular} \mid & $\begin{array}{l}\text { Inlet } \\
\text { Mercury } \\
\text { Concent. }\end{array}$ & $\begin{array}{l}\text { Outlet } \\
\text { Mercury } \\
\text { Concent. }\end{array}$ & $\begin{array}{l}\text { Outlet } \mathrm{Hg} \\
\text { Temp. } \\
\left({ }^{\circ} \mathrm{F}\right)\end{array}$ & $\begin{array}{l}\text { Residence } \\
\text { Time }\end{array}$ & $\begin{array}{c}\text { Total } \\
\text { Mercury } \\
\text { Removal }\end{array}$ \\
\hline 42 & ESP & 7/1/1998 & 11:15 & $\begin{array}{l}\text { ESP ON, Duct Heater to } 350 \mathrm{~F} \text {, Carbon Inj @ } 4 \\
\text { Ibs/MMACF } \\
\text { ESP ON, Duct Heater to } 350 \mathrm{~F} \text {, Carbon Inj @ } 4\end{array}$ & 1.0 & 349 & 10.58 & 5.31 & 345 & 1 & 49.8 \\
\hline 43 & ESP & 7/1/1998 & $12: 20$ & $\begin{array}{l}\text { Ibs/MMACF } \\
\text { ESP ON, Duct Heater to } 350 \mathrm{~F} \text {, Carbon Inj @ } 4\end{array}$ & 1.0 & 354 & 12.05 & 5.80 & 349 & 1 & 51.9 \\
\hline 44 & ESP & 7/1/1998 & $13: 30$ & $\begin{array}{l}\text { Ibs/MMACF } \\
\text { ESP ON, Duct Heater Off ,"natural Temp", Carbon Inj }\end{array}$ & 1.0 & 353 & 12.07 & 5.60 & 351 & 1 & 53.6 \\
\hline 45 & ESP & $7 / 13 / 1998$ & $14: 40$ & $\begin{array}{l}@ 1 \mathrm{lbs} / \text { MMACF, short res. Time } \\
\text { ESP ON, Duct Heater Off ,"natural Temp", Carbon Inj }\end{array}$ & 0.3 & 292 & 8.40 & 4.01 & 287 & 0.5 & 52.3 \\
\hline 46 & ESP & $7 / 13 / 1998$ & $15: 40$ & $\begin{array}{l}\text { @ } 1 \text { lbs/MMACF, short res. Time } \\
\text { ESP ON, Duct Heater Off ,Spray cool to 230F, NO }\end{array}$ & 0.3 & 295 & 7.83 & 4.07 & 293 & 0.5 & 48.1 \\
\hline 48 & ESP & 7/14/1998 & $15: 40$ & $\begin{array}{l}\text { Carbon Inj. } \\
\text { ESP ON, Duct Heater Off, Spray cool to } 230 \mathrm{~F}, \mathrm{NO}\end{array}$ & 0.0 & 228 & 4.86 & 2.28 & 236 & 1 & 53.1 \\
\hline 49 & ESP & $7 / 14 / 1998$ & $16: 30$ & $\begin{array}{l}\text { Carbon Inj. } \\
\text { ESP ON, Duct Heater Off ,Spray cool to } 230 \mathrm{~F}, \mathrm{NO}\end{array}$ & 0.0 & 225 & 4.79 & 2.03 & 232 & 1 & 57.7 \\
\hline 50 & ESP & 7/14/1998 & $17: 30$ & $\begin{array}{l}\text { Carbon Inj. } \\
\text { ESP ON, Duct Heater Off ,Spray cool to 230F, }\end{array}$ & 0.0 & 230 & 4.76 & 1.86 & 229 & 1 & 60.9 \\
\hline 51 & ESP & 7/14/1998 & $19: 10$ & $\begin{array}{l}\text { Carbon Inj. @ } 1 \mathrm{lbs} / \mathrm{MMACF} \\
\text { ESP ON, Duct Heater Off ,Spray cool to 230F, }\end{array}$ & 0.3 & 229 & 4.22 & 1.81 & 228 & 1 & 57.1 \\
\hline 52 & ESP & 7/14/1998 & $20: 00$ & $\begin{array}{l}\text { Carbon Inj. @ } 1 \text { lbs/MMACF } \\
\text { ESP ON, Duct Heater Off,Spray cool to 230F, }\end{array}$ & 0.3 & 229 & 4.66 & 1.80 & 228 & 1 & 61.4 \\
\hline 53 & ESP & |7/14/1998 & $20: 50$ & $\begin{array}{l}\text { Carbon Inj. @ } 1 \mathrm{lbs} / \mathrm{MMACF} \\
\text { ESP ON, Duct Heater to } 310 \text { F, Carbon Inj @ } 1\end{array}$ & 0.3 & 228 & 4.38 & 1.93 & 228 & 1 & 55.8 \\
\hline 54 & ESP & |7/15/1998 & 13:15 & $\begin{array}{l}\text { Ibs/MMACF } \\
\text { ESP ON, Duct Heater to } 310 \text { F, Carbon Inj @ } 1\end{array}$ & 0.3 & 310 & 5.57 & 2.75 & 305 & 1 & 50.6 \\
\hline 55 & ESP & 7/15/1998 & $14: 10$ & $\begin{array}{l}\text { Ibs/MMACF } \\
\text { ESP ON, Duct Heater to } 310 \text { F, Carbon Inj @ } 1\end{array}$ & 0.3 & 309 & 6.53 & 3.08 & 306 & 1 & 52.9 \\
\hline 56 & ESP & |7/15/1998 & $15: 05$ & Ibs/MMACF & 0.3 & 308 & 6.65 & 2.76 & 308 & 1 & 58.5 \\
\hline 57 & ESP & |7/16/1997 & 8:30 & ESP ON, Duct Heater to $310 \mathrm{~F}$, NO Carbon Inj & 0.0 & 304 & 5.91 & 3.86 & 310 & 1 & 34.6 \\
\hline 58 & ESP & |7/16/1997 & 11:00 & ESP ON, Duct Heater to $310 \mathrm{~F}$, NO Carbon Inj & 0.0 & 307 & 6.28 & 3.96 & 313 & 1 & 36.9 \\
\hline 59 & ESP & |7/16/1997 & $11: 50$ & $\begin{array}{l}\text { ESP ON, Duct Heater to } 310 \mathrm{~F} \text {, NO Carbon Inj } \\
\text { ESP ON, Duct Heater to } 310 \mathrm{~F} \text {, Carbon Inj @ } 4\end{array}$ & 0.0 & 309 & 6.89 & 4.19 & 314 & 1 & 39.2 \\
\hline 60 & ESP & 7/16/1997 & $13: 25$ & $\begin{array}{l}\text { Ibs/MMACF } \\
\text { ESP ON, Duct Heater to } 310 \text { F, Carbon Inj @ } 4\end{array}$ & 1.2 & 309 & 7.58 & 2.73 & 311 & 1 & 64.0 \\
\hline 61 & ESP & $7 / 16 / 1997$ & $14: 30$ & $\begin{array}{l}\text { Ibs/MMACF } \\
\text { ESP ON, Duct Heater to } 310 \text { F, Carbon Inj @ } 4\end{array}$ & 1.2 & 310 & 7.50 & 3.02 & 310 & 1 & 59.7 \\
\hline 62 & ESP & |7/16/1997 & $15: 25$ & $\begin{array}{l}\text { Ibs/MMACF } \\
\text { ESP ON, Duct Heater to } 310 \text { F, Carbon Inj @ } 4\end{array}$ & 1.2 & 310 & 7.12 & 2.56 & 310 & 1 & 64.1 \\
\hline 63 & ESP & 7/17/1997 & $11: 15$ & $\begin{array}{l}\text { Ibs/MMACF, short residence time } \\
\text { ESP ON, Duct Heater to } 310 \mathrm{~F} \text {, Carbon Inj @ } 4\end{array}$ & 1.2 & 312 & 7.60 & 3.08 & 314 & 0.5 & 59.5 \\
\hline 64 & ESP & |7/17/1997 & 12:10 & $\begin{array}{l}\text { Ibs/MMACF, short residence time } \\
\text { ESP ON, Duct Heater to } 310 \mathrm{~F} \text {, Carbon Inj @ } 4\end{array}$ & 1.2 & 313 & 8.31 & 2.80 & 314 & 0.5 & 66.3 \\
\hline 65 & ESP & 7/17/1997 & $13: 00$ & Ibs/MMACF, short residence time & 1.2 & 311 & 7.94 & 2.60 & 313 & 0.5 & 67.3 \\
\hline 66 & ESP & |7/31/1998 & $12: 00$ & ESP ON, Duct Heater to $350 \mathrm{~F}$, No Carbon Inj & 0.0 & 353 & 10.18 & 7.57 & 349 & 1 & 25.6 \\
\hline 67 & ESP & |7/31/1998 & 13:00 & ESP ON, Duct Heater to 350F, No Carbon Inj & 0.0 & 354 & 10.39 & 7.81 & 350 & 1 & 24.8 \\
\hline 68 & ESP & |7/31/1998 & 13:55 & $\begin{array}{l}\text { ESP ON, Duct Heater to 350F, No Carbon Inj } \\
\text { ESP ON, Duct Heater to } 350 \text { F, Canbon Inj @ }\end{array}$ & 0.0 & 354 & 10.85 & 9.28 & 350 & 1 & 14.5 \\
\hline 69 & ESP & 7/31/1998 & $15: 48$ & $\begin{array}{l}1 \mathrm{lbs} / \mathrm{MMACF} \\
\text { ESP ON, Duct Heater to } 350 \text { F, Canbon Inj @ }\end{array}$ & 0.3 & 350 & 11.15 & 6.33 & 350 & 1 & 43.2 \\
\hline 70 & ESP & $|7 / 31 / 1998|$ & $16: 38$ & |11bs/MMACF & 0.3 & 349 & 10.07 & 6.03 & 349 & 1 & 40.1 \\
\hline
\end{tabular}




\begin{tabular}{|c|c|c|c|c|c|c|c|c|c|c|c|}
\hline Test ID & $\begin{array}{c}\text { PCM } \\
\text { Configuration }\end{array}$ & $\begin{array}{l}\text { Test } \\
\text { date }\end{array}$ & $\begin{array}{c}\text { Test } \\
\text { time }\end{array}$ & $\begin{array}{c}\text { Test } \\
\text { Conditions }\end{array}$ & $\begin{array}{l}\text { Carbon } \\
\text { Concent. } \\
\text { (sorb.rate) }\end{array}$ & $\mid \begin{array}{c}\text { Gas Temp. } \\
@ \text { inj. point }\end{array}$ & $\begin{array}{l}\text { Inlet } \\
\text { Mercury } \\
\text { Concent. }\end{array}$ & $\begin{array}{l}\text { Outlet } \\
\text { Mercury } \\
\text { Concent. }\end{array}$ & $\begin{array}{l}\text { Outlet } \mathrm{Hg} \\
\text { Temp. } \\
\left({ }^{\circ} \mathrm{F}\right)\end{array}$ & $\begin{array}{l}\text { Residence } \\
\text { Time }\end{array}$ & $\begin{array}{c}\text { Total } \\
\text { Mercury } \\
\text { Removal }\end{array}$ \\
\hline 71 & ESP & 7/31/1998 & $17: 45$ & $\begin{array}{l}\text { ESP ON, Duct Heater to } 350 \text { F, Canbon Inj @ } \\
1 \text { llbs/MMACF } \\
\text { ESP ON, Duct Heater to } 350 \text { F, Canbon Inj @ }\end{array}$ & 0.3 & 348 & 10.05 & 5.65 & 348 & 1 & 43.8 \\
\hline 72 & ESP & 8/3/1998 & 13:01 & $\begin{array}{l}\text { 4lbs/MMACF } \\
\text { ESP ON, Duct Heater to } 350 \text { F, Canbon Inj @ }\end{array}$ & 1.1 & 349 & 10.47 & 5.05 & 350 & 1 & 51.7 \\
\hline 73 & ESP & $8 / 3 / 1998$ & 14:00 & $\begin{array}{l}\text { 4lbs/MMACF } \\
\text { ESP ON, Duct Heater to } 350 \text { F, Canbon Inj @ }\end{array}$ & 1.1 & 349 & 11.42 & 5.47 & 350 & 1 & 52.1 \\
\hline 74 & ESP & $8 / 3 / 1998$ & 15:00 & 4lbs/MMACF & 1.1 & 349 & 10.95 & 4.80 & 350 & 1 & 56.1 \\
\hline 75 & Pulse Jet & $8 / 10 / 1998$ & $11: 27$ & Duct Heater Off, "Natural Temp", Baseline & 0.0 & 271 & 7.61 & 1.85 & 280 & NA & 75.7 \\
\hline 76 & Pulse Jet & $8 / 10 / 1998$ & $12: 20$ & Duct Heater Off, "Natural Temp", Baseline & 0.0 & 272 & 7.92 & 1.90 & 282 & NA & 76.1 \\
\hline 77 & Pulse Jet & $8 / 10 / 1998$ & $13: 10$ & $\begin{array}{l}\text { Duct Heater Off, "Natural Temp", Baseline } \\
\text { Duct Heater Off, "Natural Temp", Carbon Inj @ } 1\end{array}$ & 0.0 & 285 & 7.87 & 2.64 & 290 & NA & 66.5 \\
\hline 78 & Pulse Jet & $8 / 11 / 1998$ & $11: 58$ & $\begin{array}{l}\text { Ibs/MMACF } \\
\text { Duct Heater Off, "Natural Temp", Carbon Ini @ } 1\end{array}$ & 0.3 & 282 & 7.32 & 1.28 & 285 & 1 & 82.5 \\
\hline 79 & Pulse Jet & $8 / 11 / 1998$ & $12: 50$ & $\begin{array}{l}\text { Ibs/MMACF } \\
\text { Duct Heater Off, "Natural Temp", Carbon Inj @ } 1\end{array}$ & 0.3 & 282 & 7.82 & 1.18 & 288 & 1 & 84.9 \\
\hline 80 & Pulse Jet & $8 / 11 / 1998$ & 13:41 & $\begin{array}{l}\text { Ibs/MMACF } \\
\text { Duct Heater Off, "Natural Temp", Carbon Inj @ } 4\end{array}$ & 0.3 & 283 & 7.43 & 1.10 & 288 & 1 & 85.3 \\
\hline 81 & Pulse Jet & $8 / 14 / 1998$ & $12: 52$ & $\begin{array}{l}\text { Ibs/MMACF } \\
\text { Duct Heater Off, "Natural Temp", Carbon Inj @ } 4\end{array}$ & 0.1 & 279 & 7.18 & 0.59 & 286 & 1 & 91.7 \\
\hline 82 & Pulse Jet & $8 / 14 / 1998$ & 13:57 & Ibs/MMACF & 0.1 & 279 & 7.60 & 0.55 & 286 & 1 & 92.7 \\
\hline 83 & Pulse Jet & $8 / 17 / 1998$ & 14:00 & Duct Heater On, heat to 350 deg F, Baseline & 0.0 & 352 & 7.22 & 7.35 & 350 & NA & -1.8 \\
\hline 84 & Pulse Jet & $8 / 17 / 1998$ & 15:02 & $\begin{array}{l}\text { Duct Heater On, heat to } 350 \text { deg F, Baseline } \\
\text { Duct Heater On, heat to } 350 \text { deg F, Carbon Inj. @ } 1\end{array}$ & 0.0 & 352 & 9.60 & 4.50 & 351 & NA & 53.2 \\
\hline 85 & Pulse Jet & 8/18/1998 & 12:10 & $\begin{array}{l}\text { Ibs./MMACF } \\
\text { Duct Heater On, heat to } 350 \text { deg F, Carbon Inj. @ } 1\end{array}$ & 0.3 & 350 & 10.86 & 2.87 & 348 & 1 & 73.6 \\
\hline 86 & Pulse Jet & $8 / 18 / 1998$ & 13:13 & $\begin{array}{l}\text { Ibs./MMACF } \\
\text { Duct Heater On, heat to } 350 \text { deg F, Carbon Inj. @ } 4\end{array}$ & 0.3 & 352 & 7.97 & 2.79 & 349 & 1 & 65.0 \\
\hline 87 & Pulse Jet & 8/19/1998 & $11: 55$ & $\begin{array}{l}\text { Ibs./MMACF } \\
\text { Duct Heater On, heat to } 350 \text { deg F, Carbon Inj. @ } 4\end{array}$ & 1.2 & 350 & 7.75 & 1.53 & 347 & 1 & 80.3 \\
\hline 88 & Pulse Jet & $8 / 19 / 1998$ & 13:05 & Ibs./MMACF & 1.2 & 351 & 7.78 & 0.90 & 348 & 1 & 88.5 \\
\hline 89 & Pulse Jet & $8 / 21 / 1998$ & $12: 33$ & Duct Heater On, heat to 310 deg F, Baseline & 0.0 & 312 & 7.40 & 5.70 & 316 & NA & 22.9 \\
\hline 90 & Pulse Jet & $8 / 21 / 1998$ & 13:35 & $\begin{array}{l}\text { Duct Heater On, heat to } 310 \text { deg F, Baseline } \\
\text { Duct Heater On, heat to } 310 \text { deg F, Carbon Inj. @ } 1\end{array}$ & 0.0 & 313 & 8.49 & 5.43 & 318 & NA & 36.0 \\
\hline 91 & Pulse Jet & $8 / 27 / 1998$ & $15: 40$ & $\begin{array}{l}\text { Ibs./MMACF } \\
\text { Duct Heater On, heat to } 310 \text { deg F, Carbon Inj. @ } 1\end{array}$ & 0.3 & 310 & 7.15 & 1.34 & 313 & 1 & 81.3 \\
\hline 92 & Pulse Jet & $8 / 27 / 1998$ & $16: 37$ & $\begin{array}{l}\text { Ibs./MMACF } \\
\text { Duct Heater On, heat to } 310 \text { deg F, Carbon Inj. @ } 4\end{array}$ & 0.3 & 311 & 7.20 & 1.00 & 314 & 1 & 86.1 \\
\hline 93 & Pulse Jet & 8/28/1998 & $9: 42$ & $\begin{array}{l}\text { Ibs./MMACF } \\
\text { Duct Heater On, heat to } 310 \text { deg F, Carbon Inj. @ } 4\end{array}$ & 1.1 & 310 & 7.88 & 0.71 & 313 & 1 & 91.0 \\
\hline 94 & Pulse Jet & $8 / 28 / 1998$ & 10:37 & Ibs./MMACF & 1.1 & 311 & 8.50 & 0.52 & 313 & 1 & 93.8 \\
\hline 95 & Pulse Jet & 9/10/1998 & $15: 25$ & Duct Heater On, heat to 350 deg F, Baseline & 0.0 & 349 & 6.62 & 3.32 & 348 & NA & 49.8 \\
\hline 96 & Pulse Jet & 9/10/1998 & $16: 30$ & Duct Heater On, heat to 350 deg F, Baseline & 0.0 & 348 & 6.50 & 3.62 & 348 & NA & 44.2 \\
\hline 97 & Pulse Jet & 9/10/1998 & $17: 27$ & Duct Heater On, heat to 350 deg F, Baseline & 0.0 & 343 & 6.62 & 3.03 & 345 & NA & 54.1 \\
\hline 98 & Reverse-gas & $10 / 05 / 98$ & 13:00 & Baseline, No Carbon Injection, "Natural" Temperature & 0.0 & 0 & 8.85 & 3.71 & 0 & NA & \\
\hline 99 & Reverse-gas & $10 / 05 / 98$ & 14:00 & Baseline, No Carbon Injection, "Natural" Temperature & 0.0 & 0 & 7.09 & 4.71 & 0 & NA & \\
\hline 100 & Reverse-gas & $10 / 09 / 98$ & 10:15 & Carbon Inj @ 1 lb./MMacf, "Natural" Temperature & 1.0 & 273 & 4.57 & 0.92 & 282 & 1 & $79.9 \%$ \\
\hline 101 & Reverse-gas & |10/09/98 & 11:20 & Carbon Inj @ 1 lb./MMacf, "Natural" Temperature & 1.0 & 276 & 7.61 & 0.84 & 287 & 1 & $88.9 \%$ \\
\hline
\end{tabular}




\begin{tabular}{|c|c|c|c|c|c|c|c|c|c|c|c|}
\hline Test ID & $\begin{array}{c}\text { PCM } \\
\text { Configuration }\end{array}$ & $\begin{array}{l}\text { Test } \\
\text { date }\end{array}$ & $\begin{array}{c}\text { Test } \\
\text { time }\end{array}$ & $\begin{array}{l}\text { Test } \\
\text { Conditions }\end{array}$ & $\begin{array}{c}\text { Carbon } \\
\text { Concent. } \\
\text { (sorb.rate) }\end{array}$ & \begin{tabular}{|l|} 
Gas Temp. \\
$@$ inj. point
\end{tabular} & $\begin{array}{c}\text { Inlet } \\
\text { Mercury } \\
\text { Concent. }\end{array}$ & $\begin{array}{l}\text { Outlet } \\
\text { Mercury } \\
\text { Concent. }\end{array}$ & $\begin{array}{c}\text { Outlet } \mathrm{Hg} \\
\text { Temp. } \\
\left({ }^{\circ} \mathrm{F}\right)\end{array}$ & $\begin{array}{l}\text { Residence } \\
\text { Time }\end{array}$ & $\begin{array}{c}\text { Total } \\
\text { Mercury } \\
\text { Removal }\end{array}$ \\
\hline 102 & Reverse-gas & $10 / 09 / 98$ & $15: 45$ & Carbon Inj @ 4 lbs./MMacf, "Natural" Temperature & 3.9 & 277 & 9.07 & 0.57 & 285 & 1 & $93.7 \%$ \\
\hline 103 & Reverse-gas & 10/09/98 & $16: 58$ & $\begin{array}{l}\text { Carbon Inj @ } 4 \text { Ibs./MMacf, "Natural" Temperature } \\
\text { Consol Test--No Carbon Injection, Heated to } 330 \text { F }\end{array}$ & 4.1 & 278 & 6.06 & 0.49 & 289 & 1 & $91.8 \%$ \\
\hline Con1 & Reverse-gas & 10/13/98 & 10:09 & $\begin{array}{l}\text { (to Match Host) } \\
\text { Consol Test--No Carbon Injection, Heated to } 330 \mathrm{~F}\end{array}$ & 0.0 & 327 & 9.09 & 8.15 & 320 & NA & \\
\hline Con2 & Reverse-gas & 10/13/98 & 11:00 & $\begin{array}{l}\text { (to Match Host) } \\
\text { Consol Test--No Carbon Injection, Heated to } 330 \mathrm{~F}\end{array}$ & 0.0 & 328 & 8.26 & 8.14 & 322 & NA & \\
\hline Con3 & Reverse-gas & 10/13/98 & 11:55 & $\begin{array}{l}\text { (to Match Host) } \\
\text { Consol Test--No Carbon Injection, Heated to } 330 \mathrm{~F}\end{array}$ & 0.0 & 333 & 8.30 & 8.96 & 327 & NA & \\
\hline Con4 & Reverse-gas & 10/13/98 & $14: 36$ & $\begin{array}{l}\text { (to Match Host) } \\
\text { Consol Test--No Carbon Injection, Heated to } 330 \mathrm{~F}\end{array}$ & 0.0 & 336 & 9.12 & 8.40 & 336 & NA & \\
\hline Con5 & Reverse-gas & 10/13/98 & $15: 35$ & $\begin{array}{l}\text { (to Match Host) } \\
\text { Consol Test--No Carbon Injection, Heated to } 330 \mathrm{~F}\end{array}$ & 0.0 & 338 & 9.71 & 8.84 & 337 & NA & \\
\hline Con6 & Reverse-gas & $10 / 13 / 98$ & $16: 37$ & $\begin{array}{l}\text { (to Match Host) } \\
\text { Consol Test--No Carbon Injection, Heated to } 330 \mathrm{~F}\end{array}$ & 0.0 & 337 & 8.92 & 8.25 & 337 & NA & \\
\hline Con7 & Reverse-gas & $10 / 14 / 98$ & $9: 00$ & $\begin{array}{l}\text { (to Match Host) } \\
\text { Consol Test--No Carbon Injection, Heated to } 330 \mathrm{~F}\end{array}$ & 0.0 & 333 & 8.68 & 7.58 & 327 & NA & \\
\hline Con8 & Reverse-gas & $10 / 14 / 98$ & $10: 38$ & $\begin{array}{l}\text { (to Match Host) } \\
\text { Consol Test--No Carbon Injection, Heated to } 330 \mathrm{~F}\end{array}$ & 0.0 & 335 & 7.77 & 7.09 & 329 & NA & \\
\hline Con9 & Reverse-gas & $10 / 14 / 98$ & $11: 32$ & (to Match Host) & 0.0 & 335 & 9.09 & 7.94 & 331 & NA & \\
\hline 104 & Reverse-gas & 10/23/98 & 10:07 & Baseline, No Carbon Injection, Heated to $330 \mathrm{~F}$ & 0.0 & 332 & 7.36 & 7.09 & 323 & NA & \\
\hline 105 & Reverse-gas & $10 / 23 / 98$ & $11: 15$ & Baseline, No Carbon Injection, Heated to $330 \mathrm{~F}$ & 0.0 & 333 & 9.05 & 7.30 & 326 & NA & \\
\hline 106 & Reverse-gas & $10 / 23 / 98$ & $15: 36$ & Carbon Inj @ $1 \mathrm{lb} . / \mathrm{MMacf}$, Heated to $330 \mathrm{~F}$ & 1.0 & 337 & 4.37 & 6.73 & 333 & 1 & $-54.2 \%$ \\
\hline 107 & Reverse-gas & 10/23/98 & $16: 45$ & Carbon Inj @ 1 lb./MMacf, Heated to $330 \mathrm{~F}$ & 1.1 & 337 & 5.96 & 5.16 & 332 & 1 & $13.5 \%$ \\
\hline 108 & Reverse-gas & 10/28/98 & $14: 43$ & Carbon Inj @ 4 lbs./MMacf, Heated to 330 F & 3.9 & 331 & 9.77 & 2.48 & 316 & 1 & $74.7 \%$ \\
\hline 109 & Reverse-gas & 10/28/98 & $16: 00$ & Carbon Inj @ 4 lbs./MMacf, Heated to 330 F & 4.3 & 330 & 10.60 & 2.05 & 314 & 1 & $80.7 \%$ \\
\hline 110 & Reverse-gas & $11 / 16 / 98$ & $12: 45$ & Baseline, No Carbon Injection, Spray Cooling & 0.0 & 231 & 7.30 & 1.53 & 244 & NA & $57.8 \%$ \\
\hline 111 & Reverse-gas & $11 / 16 / 98$ & 13:52 & Baseline, No Carbon Injection, Spray Cooling & 0.0 & 232 & 7.26 & 2.06 & 241 & NA & $53.4 \%$ \\
\hline 112 & Reverse-gas & $11 / 16 / 98$ & $15: 30$ & Carbon Inj @ $0.5 \mathrm{lb}$./MMacf, Spray Cooling & 0.6 & 233 & 8.39 & 1.73 & 239 & 1 & $59.7 \%$ \\
\hline 113 & Reverse-gas & $11 / 16 / 98$ & $16: 37$ & Carbon Inj @ 0.5 lb./MMacf, Spray Cooling & 0.7 & 230 & 7.00 & 1.27 & 238 & 1 & $65.5 \%$ \\
\hline 114 & Reverse-gas & $11 / 17 / 98$ & $10: 12$ & Carbon Inj @ 1 lb./MMacf, Spray Cooling & 0.9 & 229 & 7.33 & 2.16 & 231 & 1 & $53.4 \%$ \\
\hline 115 & Reverse-gas & $11 / 17 / 98$ & $11: 22$ & $\begin{array}{l}\text { Carbon Inj @ } 1 \mathrm{lb} . / \mathrm{MMacf} \text {, Spray Cooling } \\
\text { Baseline w/ Hg Doping and Clean Gas, Heated to }\end{array}$ & 1.0 & 230 & 7.92 & 1.59 & 237 & 1 & $63.2 \%$ \\
\hline 116 & Reverse-gas & $11 / 21 / 98$ & $15: 22$ & $\begin{array}{l}330 \mathrm{~F} \\
\text { Baseline w/ Hg Doping and Clean Gas, Heated to }\end{array}$ & 0.0 & 334 & 13.40 & 16.25 & 332 & NA & $0.0 \%$ \\
\hline 117 & Reverse-gas & $11 / 21 / 98$ & $15: 55$ & $\begin{array}{l}330 \mathrm{~F} \\
\text { Ash (Desorbed) Re-injection @ } 1 \text { grain/acf, Heated to }\end{array}$ & 0.0 & 337 & 15.93 & 18.05 & 335 & NA & $-7.5 \%$ \\
\hline 118 & Reverse-gas & $11 / 21 / 98$ & $16: 47$ & $\begin{array}{l}330 \mathrm{~F} \\
\text { Ash (Desorbed) Re-injection @ } 1 \text { grain/acf, Heated to }\end{array}$ & 154.3 & 336 & 15.62 & 14.99 & 337 & 1 & $12.3 \%$ \\
\hline 119 & Reverse-gas & $11 / 21 / 98$ & $17: 17$ & $\begin{array}{l}330 \text { F } \\
\text { Ash (Desorbed) Re-injection @ } 1 \text { grain/acf, Heated to }\end{array}$ & 155.1 & 336 & 12.74 & 13.30 & 337 & 1 & $6.2 \%$ \\
\hline 120 & Reverse-gas & $11 / 21 / 98$ & $17: 56$ & $\begin{array}{l}330 \mathrm{~F} \\
\text { Baseline w/ Hg Doping and Clean Gas, Heated to }\end{array}$ & 154.7 & 335 & 10.89 & 10.58 & 336 & 1 & $7.5 \%$ \\
\hline 121 & Reverse-gas & $11 / 22 / 98$ & $10: 59$ & $\begin{array}{l}280 \mathrm{~F} \\
\text { Baseline w/ Hg Doping and Clean Gas, Heated to }\end{array}$ & 0.0 & 282 & 15.48 & 14.14 & 289 & NA & $-4.5 \%$ \\
\hline 122 & Reverse-gas & $11 / 22 / 98$ & $11: 36$ & $\begin{array}{l}280 \mathrm{~F} \\
\text { Ash (Desorbed) Re-injection @ } 1 \text { grain/acf, Heated to }\end{array}$ & 0.0 & 285 & 15.83 & 16.26 & 292 & NA & $-7.5 \%$ \\
\hline 123 & Reverse-gas & $11 / 22 / 98$ & $12: 30$ & $\begin{array}{l}280 \mathrm{~F} \\
\text { Ash (Desorbed) Re-injection @ } 1 \text { grain/acf, Heated to }\end{array}$ & 167.5 & 294 & 15.43 & 11.09 & 301 & 1 & $17.0 \%$ \\
\hline 124 & Reverse-gas & $11 / 22 / 98$ & 13:03 & $280 \mathrm{~F}$ & 167.8 & 297 & 15.33 & 11.60 & 303 & 1 & $26.3 \%$ \\
\hline
\end{tabular}




\begin{tabular}{|c|c|c|c|c|c|c|c|c|c|c|c|}
\hline Test ID & $\begin{array}{c}\text { PCM } \\
\text { Configuration }\end{array}$ & $\begin{array}{l}\text { Test } \\
\text { date }\end{array}$ & $\begin{array}{c}\text { Test } \\
\text { time }\end{array}$ & $\begin{array}{c}\text { Test } \\
\text { Conditions }\end{array}$ & $\begin{array}{c}\text { Carbon } \\
\text { Concent. } \\
\text { (sorb.rate) }\end{array}$ & \begin{tabular}{|c|} 
Gas Temp. \\
$@$ inj. point
\end{tabular} \mid & $\begin{array}{l}\text { Inlet } \\
\text { Mercury } \\
\text { Concent. }\end{array}$ & $\begin{array}{l}\text { Outlet } \\
\text { Mercury } \\
\text { Concent. }\end{array}$ & $\begin{array}{l}\text { Outlet } \mathrm{Hg} \\
\text { Temp. } \\
\left({ }^{\circ} \mathrm{F}\right)\end{array}$ & $\begin{array}{l}\text { Residence } \\
\text { Time }\end{array}$ & $\begin{array}{c}\text { Total } \\
\text { Mercury } \\
\text { Removal }\end{array}$ \\
\hline 125 & Reverse-gas & 11/22/98 & $13: 33$ & $\begin{array}{l}\text { Ash (Desorbed) Re-injection @ } 1 \text { grain/acf, Heated to } \\
280 \text { F } \\
\text { Ash (Native) Re-injection @ } 1 \text { grain/acf, Heated to }\end{array}$ & 169.1 & 301 & 15.95 & 12.42 & 305 & 1 & $21.5 \%$ \\
\hline 126 & Reverse-gas & $11 / 24 / 98$ & $10: 45$ & $\begin{array}{l}\text { 280-300 F } \\
\text { Ash (Native) Re-injection @ } 1 \text { grain/acf, Heated to }\end{array}$ & 159.3 & 279 & 28.82 & 24.36 & 290 & 1 & $1.4 \%$ \\
\hline 127 & Reverse-gas & $11 / 24 / 98$ & $11: 16$ & $\begin{array}{l}\text { 280-300 F } \\
\text { Ash (Native) Re-injection @ } 1 \text { grain/acf, Heated to }\end{array}$ & 160.4 & 279 & 30.88 & 25.00 & 282 & 1 & $17.0 \%$ \\
\hline 128 & Reverse-gas & $11 / 24 / 98$ & $11: 50$ & $280-300 \mathrm{~F}$ & 160.6 & 280 & 31.29 & 30.26 & 285 & 1 & $8.5 \%$ \\
\hline 129 & Reverse-gas & $12 / 02 / 98$ & $11: 32$ & $\sim 280 \mathrm{~F}$ w/o inj (SO2 for CEM) aka Na-2 & 0.0 & 278 & 5.36 & 1.39 & 288 & & $58.9 \%$ \\
\hline 130 & Reverse-gas & $12 / 02 / 98$ & $12: 32$ & $\sim 280 \mathrm{~F}$ w/o inj (SO2 for CEM) aka Na-2 & 0.0 & 275 & 6.06 & 1.35 & 289 & & $59.0 \%$ \\
\hline 131 & Reverse-gas & $12 / 03 / 98$ & $10: 58$ & 280F w/ Na inj. @ NSR=1.6 aka Na-4 & 0.0 & 273 & 5.35 & 7.21 & 285 & & $-83.2 \%$ \\
\hline 132 & Reverse-gas & $12 / 03 / 98$ & $11: 59$ & $\begin{array}{l}\sim 280 \mathrm{~F} \text { w/ Na inj. @ NSR=1.6 aka Na-4 } \\
\sim 280 \mathrm{~F} \text { w/ Na inj. @ NSR=1.6 and } \mathrm{C} \text { inj. @ 0.5lbs }\end{array}$ & 0.0 & 273 & 6.33 & 7.47 & 288 & & $-104.8 \%$ \\
\hline 133 & Reverse-gas & $12 / 03 / 98$ & $15: 30$ & $\begin{array}{l}\text { aka Na-5 } \\
\sim 280 \mathrm{~F} \text { w/ Na inj. @ NSR=1.6 and C inj. @ 0.5lbs }\end{array}$ & 0.5 & 276 & 1.81 & 1.41 & 291 & & $-161.5 \%$ \\
\hline 134 & Reverse-gas & $12 / 03 / 98$ & $16: 34$ & aka $\mathrm{Na}-5$ & 0.5 & 275 & 3.49 & 7.15 & 290 & & $-168.8 \%$ \\
\hline 135 & Reverse-gas & $12 / 10 / 98$ & 9:50 & $\sim 320 \mathrm{~F}$ w/o inj aka Na-9 & 0.0 & 324 & 6.09 & 3.63 & 320 & & $-45.1 \%$ \\
\hline 136 & Reverse-gas & $12 / 10 / 98$ & 11:09 & $\begin{array}{l}\sim 320 \mathrm{~F} \text { w/o inj aka Na-9 } \\
\sim 320 \mathrm{~F} \text { w/ Na @NSR=1.6 Test not developed due to }\end{array}$ & 0.0 & 325 & 6.55 & 3.81 & 322 & & $14.6 \%$ \\
\hline 137 & Reverse-gas & 12/09/98 & $12: 22$ & $\begin{array}{l}\text { plumbing problem,rpt as } 143,144 \\
\sim 320 \mathrm{~F} \text { w/ Na @NSR=1.6 Test not developed due to }\end{array}$ & 0.0 & 314 & \#VALUE! & \#VALUE! & 308 & & \#VALUE! \\
\hline 138 & Reverse-gas & $12 / 09 / 98$ & $13: 28$ & $\begin{array}{l}\text { plumbing problem,rpt as } 143,144 \\
\sim 320 \mathrm{~F} \text { w/ } \mathrm{Na} @ \mathrm{NSR}=1.6 \text { and } \mathrm{C} \text { inj. @ 0.5lbs. Aka }\end{array}$ & 0.0 & 314 & \#VALUE! & \#VALUE! & 307 & & \#VALUE! \\
\hline 139 & Reverse-gas & $12 / 09 / 98$ & $15: 20$ & $\begin{array}{l}\mathrm{Na}-12 \\
\sim 320 \mathrm{~F} w / \mathrm{Na} @ \mathrm{NSR}=1.6 \text { and } \mathrm{C} \text { inj. @ 0.5lbs. Aka }\end{array}$ & 0.6 & 316 & 6.66 & 6.67 & 310 & & $-36.3 \%$ \\
\hline 140 & Reverse-gas & $12 / 09 / 98$ & 16:17 & $\begin{array}{l}\mathrm{Na}-12 \\
\sim 320 \mathrm{~F} \text { w/ C inj. @ } 0.5 \mathrm{lbs} \text { Test not developed due to } \\
\text { residual effects of previous test. Aka Na-14, rpt as }\end{array}$ & 0.6 & 317 & 7.91 & 7.60 & 311 & & $-3.0 \%$ \\
\hline 141 & Reverse-gas & 12/10/98 & $16: 18$ & $\begin{array}{l}145,146 \\
\sim 320 \mathrm{~F} \text { w/ C inj. @ } 0.5 \mathrm{lbs} \text { Test not developed due to } \\
\text { residual effects of previous test. Aka Na-14, rpt as }\end{array}$ & 0.6 & 325 & \#VALUE! & \#VALUE! & 322 & & \#VALUE! \\
\hline 142 & Reverse-gas & $12 / 10 / 98$ & $17: 20$ & 145,146 & 0.6 & 326 & \#VALUE! & \#VALUE! & 323 & & \#VALUE! \\
\hline 143 & Reverse-gas & $12 / 14 / 98$ & $11: 52$ & 320F w/ Na @NSR=1.6 aka Na-11 & 0.0 & 328 & 6.00 & 8.08 & 329 & & $-263.7 \%$ \\
\hline 144 & Reverse-gas & $12 / 14 / 98$ & $12: 53$ & $\sim 320 \mathrm{~F}$ w/ Na @NSR=1.6 aka Na-11 & 0.0 & 330 & 6.37 & 7.54 & 332 & & $-162.5 \%$ \\
\hline 145 & Reverse-gas & 12/15/98 & $13: 23$ & 320F w/ C inj. @ 0.5lbs aka Na-14 & 0.5 & 325 & 6.33 & 1.73 & 326 & & $38.0 \%$ \\
\hline 146 & Reverse-gas & $12 / 15 / 98$ & $14: 32$ & $\begin{array}{l}\sim 320 \mathrm{~F} \mathrm{w} / \mathrm{C} \text { inj. @ } 0.5 \mathrm{lbs} \text { aka Na-14 } \\
147 \text { and } 148 \text { are repeats of tests } 106 \& 107.330 \mathrm{~F}\end{array}$ & 0.5 & 324 & 6.51 & 1.63 & 326 & & $49.7 \%$ \\
\hline 147 & Reverse-gas & $12 / 29 / 98$ & & $\begin{array}{l}\text { w/C@ } 1 \text { lbs. } \\
148 \text { and } 148 \text { are repeats of tests } 106 \& 107.330 \mathrm{~F}\end{array}$ & 0.9 & 331 & 7.58 & 2.36 & & & $-5.9 \%$ \\
\hline 148 & Reverse-gas & $12 / 29 / 98$ & & w/C@1lbs. & 0.9 & 333 & 7.87 & 1.92 & & & $27.5 \%$ \\
\hline 149 & Reverse-gas & $12 / 30 / 98$ & & 300F Baseline at $~ 3 " \mathrm{DP}$ for Long Term Carbon Inj. & 0.0 & 296 & 7.75 & 5.96 & & & $17.7 \%$ \\
\hline 150 & Reverse-gas & $12 / 30 / 98$ & & 300F Baseline at $\sim 3 " \mathrm{DP}$ for Long Term Carbon Inj. & 0.0 & 296 & 5.59 & 2.77 & & & $28.6 \%$ \\
\hline 151 & Reverse-gas & $12 / 30 / 98$ & & 300F Baseline at $\sim 3 " \mathrm{DP}$ for Long Term Carbon Inj. & 0.0 & 296 & 4.97 & 5.91 & & & $24.7 \%$ \\
\hline 152 & Reverse-gas & $12 / 30 / 98$ & & 300F Baseline at $\sim 5$ "DP for Long Term Carbon Inj. & 0.0 & 297 & 9.02 & 6.82 & & & $26.9 \%$ \\
\hline 153 & Reverse-gas & $12 / 30 / 98$ & & 300F Baseline at $\sim 5$ "DP for Long Term Carbon Inj. & 0.0 & 297 & 9.37 & 8.45 & & & $30.9 \%$ \\
\hline 154 & Reverse-gas & 12/30/98 & & $\begin{array}{l}300 \mathrm{~F} \text { Baseline at } \sim 5 " \mathrm{DP} \text { for Long Term Carbon Inj. } \\
300 \mathrm{~F} \text { w/ Carbon at 5lbs and } \sim 3 " \mathrm{DP} \text {, after one day of }\end{array}$ & 0.0 & 298 & 7.74 & 6.49 & & & $-14.7 \%$ \\
\hline 155 & Reverse-gas & $12 / 31 / 98$ & & $\begin{array}{l}\text { carbon inj. } \\
300 \mathrm{~F} \text { w/ Carbon at } 5 \mathrm{lbs} \text { and } \sim 3 " \mathrm{DP} \text {, after one day of }\end{array}$ & 4.9 & 303 & 7.92 & 0.15 & & & $46.6 \%$ \\
\hline 156 & Reverse-gas & $12 / 31 / 98$ & & carbon inj. & 4.9 & 303 & 7.80 & 0.12 & & & $48.8 \%$ \\
\hline
\end{tabular}




\begin{tabular}{|c|c|c|c|c|c|c|c|c|c|c|c|}
\hline Test ID & $\begin{array}{c}\mathrm{PCM} \\
\text { Configuration }\end{array}$ & $\begin{array}{l}\text { Test } \\
\text { date }\end{array}$ & $\begin{array}{c}\text { Test } \\
\text { time }\end{array}$ & $\begin{array}{c}\text { Test } \\
\text { Conditions }\end{array}$ & $\begin{array}{l}\text { Carbon } \\
\text { Concent. } \\
\text { (sorb.rate) }\end{array}$ & $\left|\begin{array}{l}\text { Gas Temp. } \\
@ \text { inj. point }\end{array}\right|$ & $\begin{array}{l}\text { Inlet } \\
\text { Mercury } \\
\text { Concent. }\end{array}$ & $\begin{array}{l}\text { Outlet } \\
\text { Mercury } \\
\text { Concent. }\end{array}$ & $\begin{array}{l}\text { Outlet } \mathrm{Hg} \\
\text { Temp. } \\
\left.\text { ( }{ }^{\circ} \mathrm{F}\right)\end{array}$ & $\begin{array}{l}\text { Residence } \\
\text { Time }\end{array}$ & $\begin{array}{c}\text { Total } \\
\text { Mercury } \\
\text { Removal }\end{array}$ \\
\hline 157 & Reverse-gas & 12/31/98 & & $\begin{array}{l}300 \mathrm{~F} w / \text { Carbon at } 5 \mathrm{lbs} \text { and } \sim 3 " \mathrm{DP} \text {, after one day of } \\
\text { carbon inj. } \\
300 \mathrm{~F} \text { w/ Carbon at } 5 \mathrm{lbs} \text { and } \sim 5 " \mathrm{DP} \text {, after one day of }\end{array}$ & 4.9 & 305 & 7.41 & 0.09 & & & $62.3 \%$ \\
\hline 158 & Reverse-gas & $12 / 31 / 98$ & & $\begin{array}{l}\text { carbon inj. } \\
300 \mathrm{~F} w / \text { Carbon at } 5 \mathrm{lbs} \text { and } \sim 5 \mathrm{DP} \text {, after one day of }\end{array}$ & 4.6 & 306 & 7.24 & 0.10 & & & $58.4 \%$ \\
\hline 159 & Reverse-gas & $12 / 31 / 98$ & & $\begin{array}{l}\text { carbon inj. } \\
300 \mathrm{~F} w / \text { Carbon at } 5 \mathrm{lbs} \text { and } \sim 5 \mathrm{DP} \text {, after one day of }\end{array}$ & 4.6 & 303 & 7.12 & 0.12 & & & $20.3 \%$ \\
\hline 160 & Reverse-gas & $12 / 31 / 98$ & & $\begin{array}{l}\text { carbon inj. } \\
300 \mathrm{~F} \text { w/ Carbon at } 5 \mathrm{lbs} \text { and } \sim 3 " \mathrm{DP} \text {, after five days of }\end{array}$ & 4.6 & 303 & 7.00 & 0.11 & & & $48.4 \%$ \\
\hline 161 & Reverse-gas & 01/04/99 & & $\begin{array}{l}\text { carbon inj. } \\
300 \mathrm{~F} / \text { Carbon at } 5 \mathrm{lbs} \text { and } \sim 3 " \mathrm{DP} \text {, after five days of }\end{array}$ & 4.5 & 306 & 8.94 & 1.24 & & & $41.7 \%$ \\
\hline 162 & Reverse-gas & 01/04/99 & & $\begin{array}{l}\text { carbon inj. } \\
300 \mathrm{~F} \text { w/ Carbon at } 5 \mathrm{lbs} \text { and } \sim 3 " \mathrm{DP} \text {, after five days of }\end{array}$ & 4.6 & 305 & 9.06 & 1.50 & & & $36.0 \%$ \\
\hline 163 & Reverse-gas & $01 / 04 / 99$ & & $\begin{array}{l}\text { carbon inj. } \\
300 \mathrm{~F} \text { w/ Carbon at } 5 \mathrm{lbs} \text { and } \sim 5 \mathrm{DPP} \text {, after five days of }\end{array}$ & 4.5 & 306 & 8.34 & 0.79 & & & $47.8 \%$ \\
\hline 164 & Reverse-gas & $01 / 05 / 99$ & & $\begin{array}{l}\text { carbon inj. } \\
300 \mathrm{~F} / \text { Carbon at } 5 \mathrm{lbs} \text { and } \sim 5 \mathrm{DP} \text {, after five days of }\end{array}$ & 4.8 & 304 & 7.35 & 0.08 & & & $57.3 \%$ \\
\hline 165 & Reverse-gas & 01/05/99 & & $\begin{array}{l}\text { carbon inj. } \\
300 \mathrm{~F} \text { w/ Carbon at } 5 \mathrm{lbs} \text { and } \sim 5 " \mathrm{DP} \text {, after five days of }\end{array}$ & 4.8 & 305 & 7.74 & 0.00 & & & $3.1 \%$ \\
\hline 166 & Reverse-gas & 01/05/99 & & $\begin{array}{l}\text { carbon inj. } \\
300 \mathrm{~F} \mathrm{w} / \text { Carbon at } 0.5 \mathrm{lbs} \text { and } 3 " \mathrm{DP} \text {, after one half }\end{array}$ & 4.8 & 305 & 6.92 & 0.12 & & & $29.5 \%$ \\
\hline 167 & Reverse-gas & 01/07/99 & & $\begin{array}{l}\text { day of } C \text { inj. } \\
300 \mathrm{~F} \text { w/ Carbon at } 0.5 \mathrm{lbs} \text { and } 3 " \mathrm{DP} \text {, after one half }\end{array}$ & 0.5 & 302 & 9.05 & 1.20 & & & $53.9 \%$ \\
\hline 168 & Reverse-gas & 01/07/99 & & $\begin{array}{l}\text { day of } C \text { inj. } \\
300 \mathrm{~F} / \text { Carbon at } 0.5 \mathrm{lbs} \text { and } 5 " \mathrm{DP} \text {, after one half }\end{array}$ & 0.5 & 303 & 8.66 & 1.72 & & & $54.5 \%$ \\
\hline 169 & Reverse-gas & $01 / 08 / 99$ & & $\begin{array}{l}\text { day of } C \text { inj. } \\
300 \mathrm{~F} \text { w/ Carbon at } 0.5 \mathrm{lbs} \text { and } 5 " \mathrm{DP} \text {, after one half }\end{array}$ & 0.4 & 303 & 8.30 & 0.99 & & & $50.6 \%$ \\
\hline 170 & Reverse-gas & $01 / 08 / 99$ & & day of $C$ inj. & 0.4 & 299 & 7.99 & 0.96 & & & $53.3 \%$ \\
\hline 171 & Reverse-gas & 03/25/99 & & 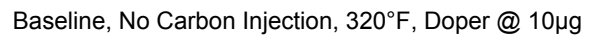 & 0.0 & 319 & 15.43 & 23.37 & & & $-4.6 \%$ \\
\hline 172 & Reverse-gas & $03 / 25 / 99$ & & $\begin{array}{l}\text { Baseline, No Carbon Injection, } 320^{\circ} \mathrm{F} \text {, Doper @ } 10 \mu \mathrm{g} \\
320 \mathrm{~F} \text { w/ Cherokee } 3 \text { Ash Inj @ } 0.25 \text { gr/acf, Doper @ }\end{array}$ & 0.0 & 320 & 19.93 & 22.47 & & & $2.6 \%$ \\
\hline 173 & Reverse-gas & $03 / 25 / 99$ & & $\begin{array}{l}10 \mu \mathrm{g} \\
320 \mathrm{~F} \text { w/ Cherokee } 3 \text { Ash Inj @0.25 gr/acf, Doper @ }\end{array}$ & 47.6 & 320 & 19.53 & 4.83 & & & $74.8 \%$ \\
\hline 174 & Reverse-gas & 03/25/99 & & 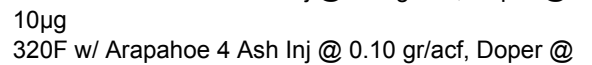 & 47.8 & 320 & 19.86 & 3.52 & & & $77.7 \%$ \\
\hline 175 & Reverse-gas & 03/26/99 & & $\begin{array}{l}10 \mu \mathrm{g} \\
320 \mathrm{~F} \text { w/ Arapahoe } 4 \text { Ash Inj @ } 0.10 \text { gr/acf, Doper @ }\end{array}$ & 18.5 & 321 & 17.73 & 3.15 & & & $77.1 \%$ \\
\hline 176 & Reverse-gas & | 03/26/99 & & $10 \mu \mathrm{g}$ & 18.6 & 321 & 18.0701 & 2.72 & & & $82.4 \%$ \\
\hline
\end{tabular}

